\title{
How pre-publication journal peer review (re)produces ignorance at scientific and medical journals: a case study
}

Joanne Gaudet ${ }^{1}$

${ }^{1}$ Department of Sociology, University of Ottawa, Ottawa ON K1N 6N5

AUTHOR'S NOTE: This sociological preprint is one of a series in which I explore ignorance (re)production in journal peer review and journal peer review dynamics more generally. The main target audience is natural science and medical researchers, publishers, and policymakers and a secondary audience is social scientists with an interest in peer review at natural scientific and medical journals.

(C) 2014 The author (Joanne Gaudet). For any use, the original work must be properly cited: Gaudet, J. 2014. How prepublication journal peer review (re)produces ignorance at scientific and medical journals: a case study. uO Research. Pp. 1-67. http://hdl.handle.net/10393/31198

\begin{abstract}
The main goal of this paper is to explore how journal peer review produces and reproduces ignorance at scientific and medical journals. I focus on the case of prepublication journal peer review (traditional peer review). Scientific ignorance is nonpejorative as the limits and borders of knowledge where new scientific ideas can contain new ignorance that pushes the boundaries of knowledge. Traditional peer review is an example of a 'boundary judgement' social form where content refers to decisions from the judgement of scientific written texts held to account to an overarching knowledge system - creating boundaries between what is and what is not considered science. Moreover, boundary judgement forms interact with the social form of scientific exchange where scientists communicate knowledge and ignorance. I investigate traditional peer review's structural properties - elements that contribute to shaping relations in a form to understand ignorance (re)production. Analysis of twenty-five cases with empirical and self- and third party accounts data, and data from eleven semi-structured interviews helps construct theoretical insights into how traditional peer review mostly contributes to ignorance reproduction. Reproduction owes to four structural properties: (1) contingency traditional peer review places on scientific exchange; (2) secrecy for original manuscripts and editorial judgements and decisions; (3) a relation of accountability to empiricism for editorial readers that helps construct a boundary for manuscripts, deemed as scientific or not; and (4) a relation of accountability to readers enhanced by a criterion of originality that appears to construct another boundary for manuscripts, deemed as newsworthy or not. I conclude with implications from this work set against Kuhn's theory of paradigms. I also look to implications for authors, policymakers, editors, and journal publishers.
\end{abstract}

\section{A - Introduction}

The main goal of this paper is to explore how journal peer review (re)produces ignorance at scientific and medical ${ }^{1}$ journals. I adopt a case study approach using the paradigmatic case of pre-publication journal peer review (traditional peer review). Scientific ignorance here is non-pejorative as the limits and borders of knowledge (Gross, 2010) where new scientific ideas typically propose new ignorance that pushes the

\footnotetext{
${ }^{1}$ Natural scientific and medical journals alike use traditional peer review (and other forms of journal peer review) and researchers can crossover and publish in scientific and medical journals. From this point forward, traditional peer review encompasses scientific and medical journals.
} 
boundaries of knowledge. To reproduce ignorance is to enable the same ignorance to persist whereas to produce ignorance is to enable new ignorance to join or reconstruct existing ignorance. (Re)production reflects both dynamics. Furthermore, traditional peer review is a paradigmatic form of journal peer review used by dominant ${ }^{2}$ journals and countless journals worldwide. By paradigmatic, I mean that traditional peer review acts as the prototype for journal peer review against which other forms are typically compared (related in Flyvbjerg, 2006:230,202; 2001:80-81; Bourdieu et al., 1968:79-80).

The intense debate on purported limitations of journal peer review and the call for journal peer review reform are timely for this work (i.e., Smith, 2010; Hettyey et al., 2012; Whitfield, 2012). I focus on journal peer review ${ }^{3}$ for two main reasons. First, because it is one of the most ubiquitous of peer review processes, yet it remains ill understood (discussion in Biagioli, 2002; Hirschauer, 2010). Second, because scientists (and non-scientists) are less inclined to overtly acknowledge and use ${ }^{4}$ scientific $^{-}$ knowledge and ignorance that has not undergone peer review. A case in point is the epistemic community of mathematicians who boycotted and attempted to circumvent commercial publisher dominance of scientific exchange, but without the services of these publishers would need to "... replicate or replace the role that journals play in reviewing work and conferring prestige" (Whitfield, 2012). Thus, one reason why contemporary scientists (and non-scientists) are less inclined to use non-peer reviewed knowledge or ignorance is that without having undergone peer review, it is perceived as holding limited value (see Biagioli, 2002:11), validity, and prestige (Guédon, 2001). Finally, understanding how journal peer review (re)produces ignorance is significant in an era grappling with complex issues where maximizing the flow of new ignorance could help shed new light on existing problems and point to alternative solutions (see Aarssen, 2012; Horrobin, 1990; Sample, 2013).

To reach the main goal, the paper mostly draws from and contributes to

\footnotetext{
${ }^{2}$ It is important to note that publishers managing dominant (flagship) journals typically manage more than one journal. Other journals in a suite can make use of alternative social forms of peer review. For example, Science, Nature, and The Lancet are flagship journals using traditional peer review within a wider array of journal peer review forms that can include open access to editorial judgements and decisions.

${ }^{3}$ It is difficult to estimate the number of journals that make use of traditional peer review. It is used worldwide by journals with an estimate of at least 2.5 million articles annually from approximately 24,000 peer-reviewed journals (Chemical Sciences Roundtable National Research Council, 2005:25).

${ }^{4}$ I distinguish between overtly acknowledging and using non-peer reviewed written works such as citing a preprint paper and covertly using and not acknowledging non-peer reviewed written works because it is used 'indirectly' to help construct new ignorance or is plagiarized. There are notable differences in disciplinary practices and meanings. For physicists, bioinformaticians, and mathematicians, it appears that scientific exchange through a preprint server (cf., ArXiv, Nature Precedings) has come to impart some value to the content of exchange. For example, posting a paper on such a server can secure priority claims in these disciplines (i.e., Seppänen et al., 2012). See Simmel's (1907) sociological analysis of the difference between appropriation and exchange. Appropriation is a mode of changing ownership for a given 'object' that hinges completely on the subject engaged in appropriation where the mode of exchange is not valued. In the case of preprint servers, in disciplines other than above, these are not valued therefore plagiarizing content is not framed as problematic. Exchange, in contrast, is a mode of changing the ownership of a given object that is more institutionalized and formal (and thus more distant from the subject), that imparts value to the mode of changing ownership. In the case of physicists (et al.) preprint servers are valued (1907:6364), and therefore content is not appropriated but exchanged and holds at least some value (though perhaps not equivalent to the perceived value following peer review).
} 
scholarship on ignorance (re)production in journal peer review ${ }^{5}$ (i.e., Jasanoff, 1990; Campanario, 2009; Horrobin, 1990) and in the sociology of ignorance (i.e., Gross, 2010; Wehling, 2006). The former is typically framed as a specific type of resistance - focused on journal peer review - within a broader area of 'resistance to new ideas' by scientists themselves (i.e., Barber, 1961; Aronson, 1986; Brannigan, 1981:chapter six).

Moreover, this type of paper can itself face resistance. Barber (1961) captured a first type of resistance when he advanced that "[ $\mathrm{t}]$ he mere assertion that scientists themselves sometimes resist scientific discovery clashes, of course, with the sterotype of the scientist as "the open-minded" man" (1961:596). Research here circumvents this first type, I hope, by focusing on structural properties in traditional peer review, not actor mindsets. Second, adapting Lips' (1991) analysis of institutionalized power relations, it appears that

[t]he apparent naturalness [of peer review] is a source of power for those who would maintain things as they are. Even if no one wants to maintain things as they are, however, institutionalized power relations help to maintain a general system of power, such as [peer review power relations], because they help to make the system invisible, like water to a fish (1991:11)

Given entrenched and invisible power relations, it is therefore not surprising that the mere idea of studying peer review as an object of study "... still seems radical to some - rather like conducting experiments with God or love" (Smith, 2011:91). As a reflexive researcher in the social sciences who wishes to engage with natural scientists where the bulk of research on journal peer review has been performed, I have therefore enhanced my relation of accountability to empiricism with a qualitative multi-case research design.

To start, I situate the paper with respect to four apparent knowledge gaps in existing scholarship. First, as I have analyzed elsewhere (Gaudet, 2014a), journal peer review has consistently been ill-constructed as an object of study based on common experience (Hirschauer, 2010; related in Bourdieu, et al., 1968:59-62) - typically framing journal peer review as process (i.e., Bornmann et al, 2010; Campanario, 2009; Ioannidis, 2005). This approach, unfortunately, does not lead to the careful construction of a scientific object of study (Bourdieu, et al., 1968:59-62).

One researcher who avoided journal peer review pre-constructed as process, Hirschauer (2010), proposed that contemporary peer review can be understood as reciprocal accountability of judgements among peers (2010:71). Reciprocity means that authors and editorial readers are actively engaged in a process of mutual relations of accountability where the author is not unilaterally submitted to peer review. Hirschauer's (2010) conceptualization, though robust, was based on empirical research from the social sciences; it therefore appears to lack sensitivity to relations for journal peer review in the natural sciences. This knowledge gap on relations includes a need to account for a pronounced relation of accountability to empiricism and multiple relations of accountability with sometimes conflicting goals for authors, referees, and editors (i.e., to

\footnotetext{
${ }^{5}$ I refer to ignorance (re)production, but scholarship in this area can frame the dynamics in terms of 'knowledge', 'innovation' and 'novelty'. Some social scientists refer to "conjectures or speculation" (Latour and Woolgar, 1986:79) and "margins of existing knowledge" (Jasanoff, 1990:79).
} 
funding bodies, journal publishers, and advertisers). I address the gap by using the theoretical concept of social forms (Levine, 1971). Traditional peer review is thus one of several historical and contemporary forms of journal peer review (see precursor forms in Gaudet, 2014a). Viewed this way, traditional peer review is an example of a 'boundary judgement' (Gaudet, 2014a) social form where content refers to decisions from the judgement of scientific written texts held to account to an overarching knowledge system - creating boundaries between what is and what is not considered science. Here I investigate traditional peer review's structural properties - elements that contribute to shaping relations in a form - to understand ignorance (re)production.

The above knowledge gap is related to a second: a need to differentiate among forms of peer review. New contemporary forms of journal peer review join traditional peer review. Many are possible in great part owing to the rise of the Web since the late 1980s with its extensive relational potential (see Donati, 2011:217-224) and its escalading use by academics and journal publishers (Weller, 2000). Examples of other forms of peer review include: a form that omits a criterion for originality - lite traditional peer review (i.e., PLOS ONE journal), and a post-publication open access review form that features anonymous/non-anonymous referees, open access to submitted manuscripts, and open access to editorial judgements and decisions - public space peer review (i.e., Pöschl, 2012).

To study traditional peer review is difficult compared to more open forms, however, owing to secrecy for original manuscripts and editorial judgements and decisions (Couzin-Frankel, 2013; Campanario, 2009:560). In order to circumvent these difficulties, some researchers opt to investigate more open forms (Hopewell et al., 2013) with access to submitted manuscripts, editorial judgements and decisions and then generalize their findings to journal peer review (see Couzin-Frankel, 2013). I argue that this creates problems of validity when generalizing findings, however, because peer review social forms with open access judgements and decisions can increase the potential for rational decision-making (Gaudet, 2014a:8-9) whereas traditional peer review tends to decrease the potential for rational decision-making (Gaudet, 2014a:9). Other researchers circumvent the task of attempting to secure traditional peer review submitted manuscripts, and editorial judgement and decision data. They do so by relying solely on self- and third-party accounts ${ }^{6}$ of purported ignorance (re)production and do not investigate structural secrecy itself (i.e., Campanario, 2009). A gap here therefore is one of delineating the form of journal peer review under study and dealing with absence. If the form is traditional peer review, absence of data following attempts to gain access to secretive editorial judgements and decisions can be understood as data in itself (see Pascale, 2011:144; Rappert and Bauchspies, 2014; Gaudet, 2014b).

Third, most research into purported resistance to new ideas by scientists at peer review has focused explanations for resistance outside of peer review. Existing explanations include those pertaining to referee and editor deficiencies or psychological traits (Mahoney 1977; Fang 2014), to social causes such as epistemic path dependency or Kuhn's theory of paradigms (Gale 2011; Pritchard 2010; Smith 2006; Young et al. 2008; Campanario, 2009:559), and to philosophical foundations (Horrobin, 1990) including

\footnotetext{
${ }^{6}$ I refer to 'self-accounts' as accounts constructed by scientists themselves, whereas 'third-party' accounts are secondary constructed accounts by others (i.e., researchers, biographers). See Aronson (1986) and Brannigan (1981:chapter six) for a discussion of potential limitations with self- and third-party accounts.
} 
epistemic conservatism (Shatz 2004; Dreisbach 2010). Some social scientific researchers (i.e., Jasanoff, 1990; Latour and Woolgar, 1986), in contrast, advance that it is normal that journal peer review reproduces ignorance. Jasanoff (1990) constructs reproduction as normal because "... standards for deciding what is acceptable are matters of negotiation and compromise, and that peer review is simply part of the process of construction by which scientists certify some claims and conventions as valid" (Jasanoff, 1990:62). These understandings reveal a gap therefore on how traditional peer review itself can (re)produce ignorance when it is not taken as a self-evident object of study. By this I mean when it is not pre-constructed as a common experience process (see Gaudet 2014a) that inevitably leads to ignorance reproduction. In this study I do not discount that explanations external to peer review can contribute to understanding. Instead, however, I focus on journal peer review itself as a starting point.

A fourth knowledge gap results from the knowledge-only lens in most scholarship above. Researchers tend to focus downstream on knowledge instead of focusing upstream on ignorance. Can ignorance be discounted in science? It would appear that doing so fails to acknowledge that ignorance in science is an intellectual resource that drives knowledge production (Ivainer and Lenglet, 1996; Firestein, 2010). Roberts and Armitage (2008) for example, proposed an ignorance economy as foundation for a supposedly knowledge economy. Or alternatively, as Smithson (1985) argued, "[c]onscious attention to what one does not know must occur before learning or invention can take place" (1985:153). I tend to the gap by considering ignorance and knowledge (Gross, 2010; Gaudet, 2013), and their interplay in science peer review practices.

The paper proceeds in five phases. First, I build a social form theoretical context to capture how traditional peer review (re)produces ignorance. I situate it with respect to other forms of peer review and ignorance (re)production. The focus then shifts to a proposed model for the form of traditional peer review (Gaudet, 2014a). I also briefly compare traditional peer review and public space peer review. Second, in research design I detail the case study qualitative design and justify my case (theoretical and empirical) approach. Third, in methods I address data construction and analysis. Fourth, I present the data. Finally, I discuss how traditional peer review mostly reproduces ignorance. Reproduction appears to rest in great part on four structural properties: (1) the contingency traditional peer review places on scientific exchange; (2) secrecy for original manuscripts and editorial judgements and decisions; (3) editorial readers' relation of accountability to empiricism; and, (4) a relation of accountability to readers enhanced by a criterion of originality for manuscript. I conclude with implications from this science in practice research set against Kuhn's theory of paradigms. I also look to implications for authors, policymakers, editors, and journal publishers.

\section{B - Constructing a social form theoretical context}

This phase constructs a theoretical context to help capture how traditional peer (re)produces ignorance. First is an overview of how I harness social forms. Second is an overview of temporality for peer review and ignorance (re)production situating traditional peer review within wider dynamics. Third is a model for traditional peer review (Gaudet, 2014a) highlighting its structural properties. Fourth is a brief comparison of the social forms of traditional and public space peer review to bring structural 
properties and ignorance (re)production dynamics into sharp contrast. Finally is an overview of how I conceptualize scientific ignorance.

\section{Harnessing the theoretical concept of social form}

A social form is a sociological concept that refers to "... a mode of interaction among individuals through which, or in the shape of which, [a specific type of] content attains social reality" (Levine, 1971:24). In other words, I am not interested in how individuals randomly associate or aggregate. I am also not solely interested in the content of journal peer review (cf., editorial decisions). This work focuses mainly on the proposed social form of 'boundary judgement' (Gaudet, 2014a) where individuals aggregate and relate around a common content - decisions as to what can be deemed scientific (or not) - based on the judgement of scientific written texts against an overarching knowledge system.

The main social form here, boundary judgement, interacts with a second social form, scientific exchange (latter in Levine, 1971:43-44) (cf., the communication of scientific knowledge). For example, a scientist who presents a paper at a conference or submits a paper for publication in a journal is an actor engaging in the form of scientific exchange. An example of interaction between the two forms is when a boundary judgement form such as traditional peer review makes exchange possible only if it is contingent on the boundary judgement. This contrasts with other boundary judgement forms as explored below in the temporal model of peer review that do not impede scientific exchange.

What is more, to investigate social forms is to "...identify and classify the different forms of social interaction; [...] to study the conditions under which they emerge, develop, flourish, and dissolve; and to investigate their structural properties" (Levine, 1971:xxvii-xxviii; related in Donati, 2011:90-91). I have investigated historical conditions of emergence, development, flourishing, and dissolution elsewhere (Gaudet, 2014a). Here I focus on structural properties. Structural properties refer to elements that shape relations in a social form (i.e., types of relations (cf., economic, power, political, accountability), and structural dynamics such as anonymity, temporality of review, secrecy of review, and actors). An example of a structural property in traditional peer review is closed access to editorial judgements and decisions that shields these from outside actors while they are being constructed through negotiations among authors, referees, and editors and regulates closed access following an editorial decision for a manuscript. Before focusing on the specific form of traditional peer review, however, it is instructive to first situate it within a wider span of temporality in peer review and ignorance (re)production dynamics.

\section{Temporality of peer review and ignorance (re)production}

Temporality is a characteristic that merits comparative scrutiny in peer review because it helps situate traditional peer review within wider peer review and ignorance (re)production dynamics. On a continuum of boundary judgement social forms, there are generally two main temporal timeframes: pre-publication and post-publication. In prepublication, temporality is further subdivided into two phases: before manuscript 
submission and following manuscript submission at a journal.

Pre-publication

Peer review before manuscript submission includes pre-submission review (Hames, 2007:275) by colleagues or scholars with whom a draft of written work is shared. Pre-submission review can also take place following the upload of work on a digital repository (i.e., ArXiv or a university repository, Cassella and Calvi, 2010:9-10; Hames, 2007:275) where it is exchanged with colleagues and a broader scholar readership. Scientific exchange here holds the potential for ignorance production (higher on repositories with wider distribution and ease of access), but informal review typically imparts limited value to the content of exchange (see footnote above).

More formal, overlay journals offer a pre-publication social form of boundary judgement. The journals select manuscripts already uploaded to digital repositories to submit them to peer review (i.e., Symmetry, Integrability and Geometry: Methods and Applications (SIGMA) and Lund Virtual Medical Journal, Cassella and Calvi, 2010:910). The form of overlay journals holds potential for greater ignorance production if it maintains a relation between the original manuscript and the published paper (cf., as a link or a reference). The new ignorance in the original manuscript before review would therefore remain visible and accessible for mobilization by a wide range of actors.

Moving along the proposed continuum, traditional peer review follows manuscript submission and remains pre-publication. The form holds potential for maximal ignorance reproduction where the original manuscript and editorial judgements and decisions are inaccessible to outside readers. I return to the form in the next section.

Peerage of science, a four-stage peer review process that is not journal-specific, likewise performs pre-publication review for solicited and unsolicited manuscripts (Seppänen et al., 2012; Hettyey et al., 2012). Peerage of science can lead to incrementally lower ignorance reproduction in comparison to traditional peer review because it is not journal specific, exposes a manuscript to several potential editors simultaneously (Seppänen et al., 2012; Hettyey et al., 2012), and editorial judgements ('peerage essays') can be published anonymously or non-anonymously and cited by the author to give credit to referees (Hettyey et al., 2012). The original manuscript, however, remains invisible therefore contributing to potential pilfering (2012:189) and ignorance reproduction.

Finally, in public space peer review an editor enters into relation with a submitted manuscript through an 'access review' that serves as pre-screening (i.e., Atmospheric Chemistry and Physics, Pöschl, 2012). The 'access review' is the only interaction prepublication in the form. From pre-publication, the continuum moves to post-publication.

\section{$\underline{\text { Post-publication }}$}

Post-publication peer review includes open access and open peer review social forms, such as public space peer review at the Copernicus suite of journals (i.e., Pöschl, 2012; see post publication evaluation at Faculty of 1000 (F1000), House of Commons Science and Technology Committee, 2011:69-70). Post publication review social forms hold maximal potential for ignorance production when the original manuscript, editorial judgements and decisions, author responses, and interaction with a wider community are 
accessible for potential relation with a range of actors inside and outside of science.

Finally, wider post-publication informal peer review by scholars and non-scholars can occur post-publication for all journal publications (i.e., Aarssen 2012; House of Commons Science and Technology Committee, 2011:66-69). Web-based forms of postpublication informal peer review include that performed on Twitter (Mandavilli, 2011) and on blogs. As with informal pre-publication peer review, however, valuation from informal post-publication peer review is not overt as it is not directly tied with boundary judgement dynamics as with public space peer review. Informal post-review can, however, lead to retractions or expressions of concern for papers (Mandavilli, 2011) that points to a wider scientific community holding published papers to account beyond traditional peer review. From theoretically situating traditional peer review within broader peer review, the next model focuses specifically on traditional peer review.

\section{Model for the social form of traditional peer review}

Figure 1 features a model for the social form of traditional peer review (Gaudet, 2014a:7). Proposing such a model moves understanding of ignorance (re)production away from an onus on individual authors and manuscript failures. Such a model also moves understanding away from social, psychological, and philosophical explanations that are not specific to journal peer review as discussed in the introduction.

It is a 'traditional' form used at journals framed as dominant (i.e., Nature, Science, The Lancet) and by innumerable other journals worldwide. It attained greater capacity to restrict scientific exchange when in the mid-1960s, the Ingelfinger rule ${ }^{7}$ was put in place that prevented authors from submitting a manuscript to several journals or publication venues (Altman, 1996:1382).

In contrast with research that focuses on journal peer review as process, the model (Fig. 1) brings attention to structural properties. These can otherwise remain invisible: economic and political relations, relations of accountability, structural closure in prepublication, a confluence of relations to the role of editor that contributes to potentially increased power in the role, and strictly guarded duplication of papers.

To start, main structural properties are outlined in the figure's caption. Expanding on the model, the role of author holds additional relations of accountability to editorial guidelines, readers, sponsors/funders, and empiricism. In addition, when submitted manuscripts remain invisible this can lead the author role to hold lower accountability to a manuscript and submit less optimal writing with a goal to gather feedback for subsequent submissions. Structurally secret submitted manuscripts could lead to decreased ignorance production where a published paper can have eliminated some new ignorance and where an unpublished paper means new ignorance remains invisible.

\footnotetext{
${ }^{7}$ Proposed by Franz Ingelfinger (then editor of the New England Journal of Medicine (NEJM)) the rule stated that "...that henceforth NEJM's policy would be to reject a paper if it had been published elsewhere, in whole or substance" (Altman, 1996:1382). The rule was explicitly designed to retain the "newsworthiness" value of papers and thus support the reader-pay business model (Altman, 1996:1382).
} 
Figure 1: Model of the boundary judgement social form of traditional peer review at natural science and medical journals (Gaudet, 2014:7)

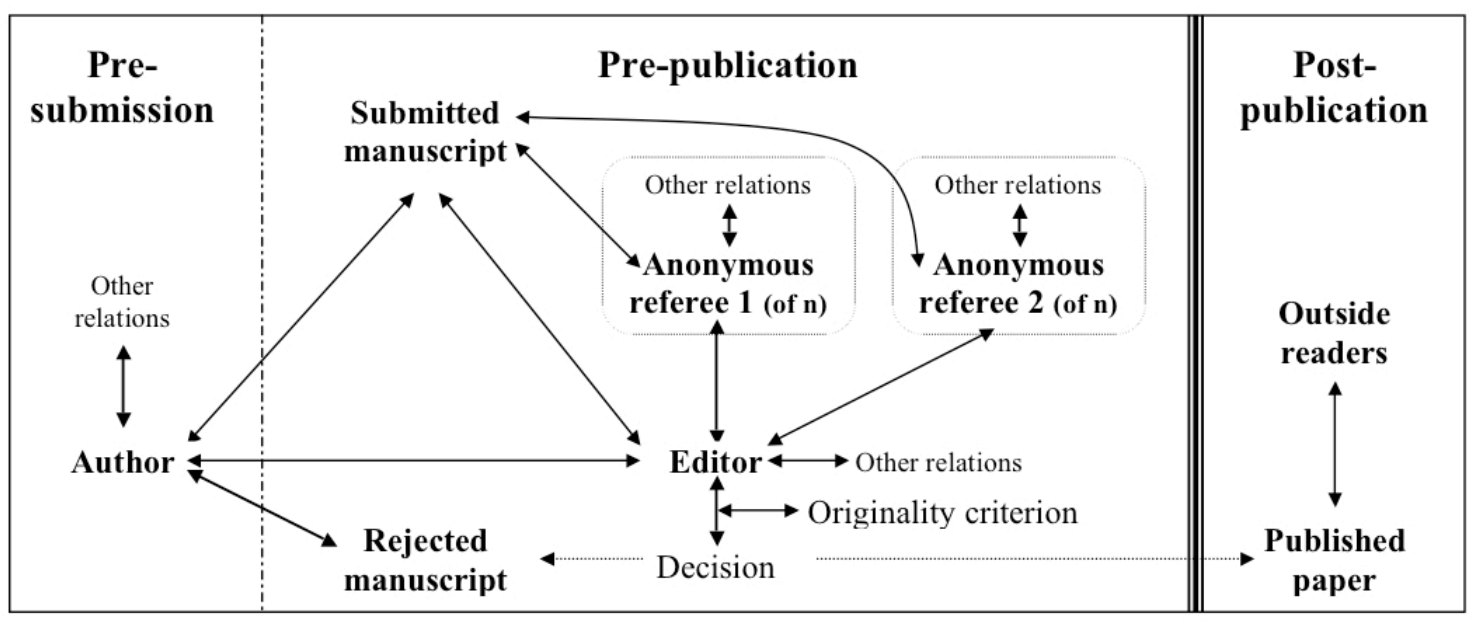

Structural properties start with 3 temporal periods from left to right: pre-submission, pre-, and post-publication. Main actor roles depicted are author, submitted manuscript, editor, anonymous referees ( 1 and 2 of $n$ ), and in the post-publication period, outside readers. Each actor role holds relations as depicted with arrows and additional respective social relations and relations of accountability as 'Other relations'. The editor role uses a criterion of originality to construct a decision. The boundary judgement decision relates with the editor and either a rejected manuscript or a published paper. Scientific exchange contingent on review is designated with bold vertical lines between pre- and post-publication that also depicts pre-publication as structurally closed to outside actors.

For the role of editor, additional political and economic social relations and relations of accountability include those with board members, advertisers, the journal publishers/owners, empiricism, guidelines, the boundary judgement decision, and readers. The criterion for originality is one through which the role of editor purportedly constructs value for the reader by increasing selectivity in manuscript selection. Increasing selectivity can lead to the rejection of new ignorance and therefore reproduction.

For anonymous referees in contrast, relations of accountability are limited whereby anonymous judgements hold less potential for impact on an 'unknown' referee. At worst, editors can stop asking a referee to peer review or can refuse to consider a judgement from a referee. Nonetheless, potential accountability relations for referees include those to editorial guidelines, empiricism, funders/sponsors, and their judgement that contributed to the boundary judgement decision. The 'competing interests' forms that authors and referees are frequently required to complete prior to engagement in journal peer review substantiate the importance of these potentially conflicting relations. As situated knowers engaged in relations in boundary judgement, referees can contribute to ignorance reproduction or production depending on potentially conflicting relations.

In addition, implementation of the Ingelfinger rule continues to this day at journals using traditional peer review. Increased use of the Web and mandated open access, however, means that at least one copy can usually be uploaded to an institutional repository or other types of electronic storage. Restricting copies of a paper, and therefore potential relations it can engage in, can constrict ignorance production.

Structural secrecy for pre-publication documents including editorial judgements and editorial decisions can further contribute to ignorance reproduction. As for submitted 
manuscripts above, when a manuscript is rejected there is potential for reproduction as no outside actors can access the secretive content. Once a paper is published, it is assumed that editorial judgements and decisions exist - though these remain invisible.

Moreover, and linked with structural secrecy, the contingency that traditional peer review places on scientific exchange can contribute to ignorance reproduction. Judging a manuscript (most likely after having altered its content) prior to publication can increase ignorance reproduction instead of production because the original manuscript remains invisible (transition from post- to pre-publication in Gaudet, 2014a).

Lastly, outside readers hold a relation of accountability to empiricism that can contribute to post-publication corrections and retractions and therefore ignorance production or reproduction. Potential for outside reader participation and access to new ignorance is limited to one outcome from traditional peer review - the published paper whereas outside reader participation in public space peer review can access new ignorance from the original manuscript through to a final outcome. To better understand ignorance (re)production in the form of traditional peer review therefore, comparison with a post-publication open form such as public space peer review is warranted.

Comparing traditional peer review and public space peer review

I compare and contrast the social form of traditional peer review with another contemporary form of boundary judgement - public space peer review - in order to draw sharper insights into traditional peer review. To be sure, what I construct as seemingly 'fixed' and stable forms are more fluid with potential relational changes - the idealized forms here are conceptual and capture core relations.

I compare the two forms as they reflect a likely extreme contrast in ignorance (re)production dynamics where I argue that structural properties for public space peer review can potentially enable higher ignorance production than those in traditional peer review. Following a short description for the alternative social form, I compare it with traditional peer review. I use structural properties as indicators for comparison: structural dynamics, social relations, and relations of accountability.

\section{Overview of the social form of public space peer review}

Public space peer review is performed at some open access journals (i.e., Atmospheric Chemistry and Physics as one of the suite of journals at Copernicus Publications, Pöschl, 2012; BioMed Central, Biology Direct (Koonin et al., 2013; BioMed Central, 2013). Open review in this case refers to the permanent open access to referee judgements (anonymous or non-anonymous) and to editorial comments and judgements.

The Copernicus model is used here to construct the social form of public space peer review. In pre-publication the editor enters into relation with a manuscript in a prescreening 'access review' (to confirm alignment of the manuscript with the journal scope and to identify and correct potential technical errors). The form then becomes fully 'open'. The original manuscript (a.k.a., the discussion paper at Copernicus journals) is visible and therefore the author holds an explicit relation of accountability to it. Referees (anonymous or non-anonymous) are held to account to visible editorial judgements and 
editors are held to account to visible decisions. Scholars and non-scholars can relate with the discussion paper and all other comments, judgements, and decisions through short comments. The author can relate with these through comments as well. Even if the final editorial decision is to reject a manuscript for publication, the outcome is therefore not dichotomous and does not contribute to ignorance reproduction. If a paper is 'published', the author's final paper relates with the discussion paper and all comments, judgements, and decisions. Finally, as with traditional peer review, actors can hold additional potential political and economic relations (cf., to funders, to journal owners/publishers, advertisers) as well as a relation of accountability to empiricism under public gaze.

\section{Comparing and contrasting the two forms}

Overall, I advance that public space peer review leads to higher potential ignorance production than traditional peer review because the whole content of scientific exchange (including new ignorance) in manuscript to decision, remains visible and accessible. It simultaneously potentially reduces ignorance reproduction to a minimum (with potential for self-correction with a wide readership) by eliminating the role of gatekeeper for peer review in traditional peer review (save for the initial access review).

Relations in the form also reduce the potential for plagiarism in two ways. First, with open referee judgements, referees cannot reject a paper in order to plagiarize its new ignorance (or knowledge). Godlee (2002) referred to non-anonymous referees as "..giving less scope for [...] misappropriation of data under the cloak of anonymity"(2002:2762). Second, open access to the original manuscript (cf., discussion paper) implicitly assigns priority to the author even if the manuscript is changed during peer review or is rejected. In a way, this can circumvent peer review as purveyor of priority - here priority is established following initial pre-screening access review if the manuscript is retained for public space peer review.

Furthermore, no matter if a referee opts to remain anonymous, I advance that open judgements in conjunction with wider (non-)scientific community involvement (public gaze) and the possibility of open exchange with authors, can reduce the quasiabsolute power relations in the roles of referee and editor. Non-anonymous referees, as opposed to those who remain anonymous, further dissolve these power dynamics. Here referee knowledge and ignorance are not dematerialized and depoliticized.

With respect to trust, non-anonymous relations with referees restore the possibility of trust in the role(s) and in judgements for all actors engaged in the social form of public space peer review. This is due in large part to the reciprocity of knowledge that individuals engaged in roles in peer review relations now hold for each other's identity as knowledge and ignorance producers. This mutual knowledge, as a positive condition for a social relationship, can engender trust (Simmel, 1906:448). A non-anonymous referee role combined with open access to editorial judgements and decisions also most likely to contribute to rational decision-making (Gaudet, 2014a:8-9).

In addition, non-anonymous referees or anonymous referees in public space peer review must endeavour to engage in civil dialogue, free of unjustified judgements (Godlee, 2002:2762), thus engendering further trust and civility and perhaps increased ignorance production. Pulverer (2010:30) provided the example of referees and he as editor spending more time on how to effectively communicate judgements (2010:30). 
A related dynamic is that public space peer review can no longer be understood to provide the fundamental condition of possibility of scientific knowledge (Biagioli, 2002:11) and ignorance. Open access to the discussion paper strips away this function where scientific exchange is no longer contingent on peer review as is the case in traditional peer review.

For ignorance production public space peer review opens up a new temporal space. Potential new ignorance is no longer evaluated in temporally finite, closed, and secret spaces. It is fully open and accessible for future scrutiny and valuation. As Horrobin (2004) proposed

[t]he history of science has repeatedly shown that when hypotheses are proposed it is impossible to predict which will turn out to be revolutionary or ridiculous. The only safe approach is to let all see the light and to let all be discussed, experimented upon, vindicated or destroyed (2004:4)

Public space peer review allows for temporally prospective dynamics for ignorance production in comparison with traditional peer review. To this point I have used but not explicitly addressed how I conceptualize scientific ignorance, a topic to which I now turn.

\section{Conceptualizing ignorance in science}

As alluded to above, I conceptualize ignorance as the limits and borders of knowing and as dynamically related with knowledge in science (Gross, 2007, 2010; Ivainer and Lenglet, 1996; Gaudet, 2013). In one way, I use ignorance like natural scientists themselves, understood as non-pejorative and in dynamic interaction with knowledge. This corresponds to what anthropologists designate as an emic cultural understanding of ignorance, or which is self-understood by the community under study (in this work, natural scientists). Where I potentially deviate from natural scientists' conception of ignorance is by also espousing ignorance as socially constructed. As a researcher, I am theoretically imposing the second understanding as an analytical device. As such, the second is thus an etic, or theoretical understanding of ignorance in science (typically) outside of natural scientists' own cultural understanding. By using both, I am effectively combining (or more precisely layering) emic and etic understandings.

Finally I recall Smithson's (1985) characterization of scholars' reluctant stance in response to epistemologies of ignorance different then their own (perhaps such as the one that I espouse), which renders them seemingly unable to accommodate alternative conceptualizations. He proposed that failure to acknowledge alternative understandings "...is a naively absolutist epistemology which holds that there is always one correct way to think of anything" (1985:151). I do not purport that ignorance as I use it in this work is the only way to conceptualize ignorance in science, or that it supersedes other understandings. Rather, I propose that it can (hopefully) contribute to understanding for ignorance (re)production in journal peer review. From a theoretical context to investigate ignorance (re)production in traditional peer review, I delve into research design. 


\section{C - Research Design}

I employed a case study qualitative research design. Given that each case is contextualized, a case study approach allowed me to take account of the context in which ignorance (re)production was taking place (see Compton-Lilly, 2013; Yin, 2009:18). Structural secrecy and barriers to access data, however, yielded 'leaner' case descriptions in Appendix A than is expected of a sociological case study design.

I used a qualitative research design because I was interested in focusing on relations among actors and publication dynamics in which they engaged in ignorance (re)production (see Maxwell, 2005:22). Given the apparent scarcity of theorizing on ignorance (re)production in peer review outlined in the introduction, a qualitative design was conducive to exploring relational and contextual perspectives and contributing to theoretical understanding.

Moreover, a qualitative research design allowed me to make use of the inductive approach. As Maxwell (2005) argued, and as I draw on here, the inductive approach underlying qualitative research contributes to its strengths (2005:22). Borrowing from Pascale (2011), in this work analytic induction "... refers to the systematic examination of similarities within and across cases to develop concepts, ideas, or theories" (2011:53). Complementary to the theoretical context I constructed above, I concentrated on building explanations as theory across several cases (see 28 cases in Stake, 2006:chapter 9).

Overall, I used analytic induction across twenty-five cases with empirical data and self- and third-party account data of ignorance (re)production in traditional peer review and data from eleven semi-structured interviews. The cases are manifestations of the theoretical case of traditional peer review as a paradigmatic case of ignorance (re)production in journal peer review. A challenge for me as a researcher was to construct visible manifestations of ignorance (re)production in journal peer review.

I advance that there are at least three levels at which ignorance (re)production in journal peer review can become visible: a 'micro' individual level, a 'meso' journal level, and a 'meta' research area or disciplinary level. First, manifestations at the individual author level can become visible for Nobel Prize ${ }^{\circledR}$ laureates (Campanario, 2009) and individual researchers that win other prizes or create impact in their epistemic communities (i.e., Redner, 1987; Barber, 1961; Garland, 1995). The tension that renders ignorance (re)production visible is typically tied with valuation. When the content of exchange is eventually constructed as highly valuable scientific ignorance (cf., with a prestigious prize), it renders visible the initial rejection at journal peer review - and the initial non-valuation of new ignorance in these manuscripts. In these cases, individual researcher attempts at scientific exchange initially met with rejection or delay (ignorance reproduction) instead of publication (ignorance production) at journal peer review.

Second, at the meso level, controversy over the publication of new ignorance can trigger changes in journal peer review practices (i.e., Medical Hypotheses journal, Enserink, 2010). These changes in turn render ignorance (re)production dynamics visible.

Third, ignorance (re)production can also become visible at a meta level. I advance two meta levels. Meta-level ignorance reproduction is visible, for example, when science fails to consider or only partially considers new areas of research. An example of this first type of meta-level dynamics is (controversial) complementary and alternative medicine (see Caulfield and DeBow, 1005; Polich et al., 2010; Charlton, 2004) referred by Hess 
(2010) as 'undone' science neglected by the mainstream medical establishment (2010:6).

A second proposed meta level is when established areas of research apparently fail to construct new ignorance. Two examples proposed by natural scientists highlight stagnation for areas of research. First is the apparent dearth of insights into the link between virus infection and human type 1 diabetes, in spite of forty years of research (Gale, 2011). Second is apparent stagnation in ecology and evolution research (Aarssen, 2012). Arguably, micro-level author exchange helps construct meso- and macro-level dynamics. In the next section, I justify traditional peer review as a paradigmatic case and then justify my selection of the twenty-five cases.

\section{Justifying, constructing, and bounding traditional peer review as a paradigmatic case}

I refined my understanding for the theoretical case over the course of my research. The question to which I responded to shape the theoretical case is from Ragin (1992): "What is this - [traditional peer review] - a case of?" (1992:19). The theoretical case of traditional peer review is a contemporary case of boundary judgement that potentially exacerbates ignorance reproduction. As discussed above, it holds structural properties that appear to contribute to higher potential for ignorance reproduction in comparison to other contemporary forms (see need to use paradigmatic case in comparative perspective in Bourdieu et al., 1968:80).

Stake (1995) identified this type of case as 'instrumental' where the case as object of study does not constitute the final goal of research understanding. Rather, as a researcher I use the case as an instrument in order to gain insights to broader understanding (1995:3) of ignorance (re)production in peer review.

Furthermore, I designate the theoretical case choice as a paradigmatic case (Flyvbjerg, 2006:230, 232; 2001:80-81; Bourdieu et al., 1968:79-80). By paradigmatic, I mean that traditional peer review sets the standard or acts as the prototype for peer review against which all other social forms are compared. For example, those engaged in scientific publication use it as a benchmark to 'evaluate' other social forms of boundary judgement and even other emergent forms of scientific exchange that do not include review (cf., papers uploaded to repositories, blog posts). Those engaged in such 'evaluations' can devalue other forms when they allow for greater ignorance production (cf., devaluation of forms without an originality criterion) owing in great part to the perceived naturalness of ignorance reproduction practices in traditional peer review. The empirical cases constructed in the next section build on the theoretical case.

\section{Justifying multiple cases}

Other researchers have employed multiple cases such as Campanario (2009) in his study of Nobel Prize ${ }^{\circledR}$ laureates encountering resistance at journal publication (see 28 cases in Stake, 2006). I started with two cases ${ }^{8}$ of ignorance (re)production at traditional peer review. For these cases, I first mailed letters of invitation to authors and followed-up by telephone and email (using institutional contact details). Given lack of response by authors to participate in the study, I revised my approach to increase the number of cases.

${ }^{8}$ See cases 19 and 21 in Appendix A. 
The first of two advantages I saw for constructing additional cases was to minimize requests for collaboration from journals. This is because I noticed that several Nobel Prize ${ }^{\circledR}$ laureate and individual author cases had submitted to the same journals (cf., Science, Nature, The Lancet). By constructing multiple cases at once, I could therefore minimize requests for editor and referee interviews, for editorial judgements and decisions, and for original manuscripts. The second advantage of constructing multiple cases became apparent as I increased my understanding of inductive analysis with potential for comparative analysis to identify emergent patterns that might contribute to ignorance (re)production (see related Pascale, 2011:44, 45, 55). For this study, this meant multiple instances of potentially varying structural properties in cases. I opted therefore to construct twenty-five cases - including the original two cases.

The number of cases I include in this work does not reflect the totality of potential documented cases of ignorance (re)production at peer review. Campanario (2009), for example, explored five Nobel Prizes ${ }^{\circledR}$ Laureates that I did not include in my study (2009), in another paper he explored at least five non-Nobel Prizes ${ }^{\circledR}$ laureates that I did not include (Campanario, 1998), and Redner (1987) explored researchers who purportedly encountered ignorance (re)production at peer review that I also did not include. I limited my selection of cases to twenty-five for two main reasons. First, in order to maintain a manageable number of cases that I deemed I could contextualize and analyse. This first selection criterion for the total number of cases means that I eventually excluded cases that could just have well met the case-level selection criteria detailed in the next section. Second, given that I wished to engage in dialogue with natural scientists, I deemed that the relation of accountability to empiricism that I observed in natural scientists' scholarship would probably shun the validity of a small number of cases.

I provide an overview of the twenty-five cases of ignorance (re)production in traditional peer review in Table 1. Case descriptions are in Appendix A. To refine the cases further, I bound and justify them.

\section{Bounding and justifying the twenty-five cases}

In this section, I bound and justify the selection of cases. I start with Nobel Prize ${ }^{\circledR}$ laureate cases, move to individual non-Nobel Prize ${ }^{\circledR}$ author cases, and finally to area of study and journal-level cases. For all the cases, selection does not reflect an endorsement or validation of the oftentimes controversial new ignorance proposed by authors.

At the individual author micro level, the final selection of nineteen cases consisting of twenty-two Nobel Prize ${ }^{\circledR}$ laureates (two cases include multiple laureates) who encountered resistance at peer review builds on case research in Campanario (1995, 2009) and Campanario and Acedo (2007). These researchers investigated rejection of manuscripts and resistance to what they constructed as 'Nobel class discoveries' (Campanario, 1995, 2009). My second main selection criterion for Nobel Prize ${ }^{\circledR}$ laureate cases was having access to self-accounts and/or third party accounts of ignorance dynamics in order to construct cases of ignorance (re)production at traditional peer review. Finally, in eighteen of the nineteen cases of Nobel Prize ${ }^{\circledR}$ laureate cases (all except John Bardeen), the papers that purportedly engendered ignorance (re)production dynamics at traditional peer review were related with and preceded award of the Prize. 
Table 1: Overview of Twenty-Five Purported Cases of Ignorance (Re)Production in Traditional Peer Review by Level of Ignorance (Re)Production (in alphabetical order of Identification)

\begin{tabular}{|c|c|c|c|c|}
\hline $\begin{array}{l}\text { Case } \\
\text { ID }\end{array}$ & $\begin{array}{l}\text { Level } \\
\text { (micro, } \\
\text { meso, } \\
\text { macro) }\end{array}$ & $\begin{array}{l}\text { Identification of Focal Actor, } \\
\text { Area, or Journal }\end{array}$ & Year(s) & $\begin{array}{l}\text { Journal(s) that rejected or } \\
\text { eventually published manuscript }\end{array}$ \\
\hline 1 & Micro level & $\begin{array}{l}\text { Bardeen, John* (1956 and } 1972 \\
\text { Nobel Prizes }{ }^{\circledR} \text { in Physics) }\end{array}$ & $\begin{array}{l}\text { From } 1980 \\
\text { to } 1991\end{array}$ & $\begin{array}{l}\text { Physical Review Letters (papers } \\
\text { rejected/published) }\end{array}$ \\
\hline 2 & Micro level & 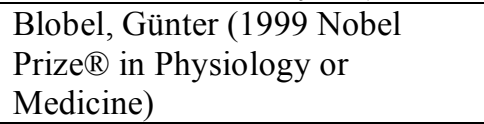 & $\begin{array}{l}\text { From } 1971 \\
\text { to } 1999\end{array}$ & Not known \\
\hline 3 & Micro level & $\begin{array}{l}\text { Blumberg, Baruch S.* (1976 } \\
\text { Nobel Prize } \AA \text { in Physiology or } \\
\text { Medicine) }\end{array}$ & 1967 & $\begin{array}{l}\text { Annals of Internal Medicine (reject } \\
\text { 1967/publish 1969) }\end{array}$ \\
\hline 4 & Micro level & $\begin{array}{l}\text { Boyer, Paul (1997 Nobel Prize } \mathbb{R} \\
\text { in Chemistry) }\end{array}$ & 1973 & $\begin{array}{l}\text { Journal of Biological Chemistry } \\
\text { (reject) and Proceedings of the } \\
\text { National Academy of Sciences } \\
\text { (PNAS) (publish) }\end{array}$ \\
\hline 5 & Macro level & Cancer as stem cells & $\begin{array}{l}1994 \text { to } \\
2003\end{array}$ & $\begin{array}{l}\text { Nature and Proceedings of the } \\
\text { National Academy of Sciences } \\
\text { (PNAS) (publish) }\end{array}$ \\
\hline 6 & Micro level & $\begin{array}{l}\text { Cech, Thomas ( } 1989 \text { Nobel } \\
\text { Prize } \AA \text { in Chemistry) }\end{array}$ & 1984 & $\begin{array}{l}\text { Nature (referees critical } \\
\text { delay/publish) }\end{array}$ \\
\hline 7 & Micro level & $\begin{array}{l}\text { Ernst, Richard R. (1991 Nobel } \\
\text { Prize } \AA \text { in Chemistry) }\end{array}$ & $1965-1966$ & $\begin{array}{l}\text { Journal of Chemical Physics } \\
\text { (rejected twice in 1965) and } \\
\text { Review of Scientific Instruments } \\
\text { (publish) }\end{array}$ \\
\hline 8 & Micro level & Feigenbaum, Mitchell & $1976-1977$ & Not known \\
\hline 9 & Micro level & 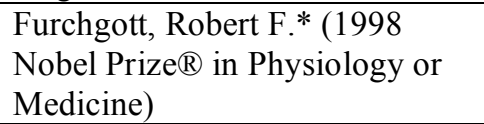 & 1980 & $\begin{array}{l}\text { Nature (considerable } \\
\text { rebuttal/publish) }\end{array}$ \\
\hline 10 & Micro level & $\begin{array}{l}\text { Gell-Mann, Murray (1969 Nobel } \\
\text { Prize® in Physics) }\end{array}$ & 1953 & Physical Review (reject/publish) \\
\hline 11 & Micro level & $\begin{array}{l}\text { Ignarro, Louis J. (1998 Nobel } \\
\text { Prize } \AA \text { in Physiology or } \\
\text { Medicine) }\end{array}$ & $\begin{array}{l}\text { Prior to } \\
1998\end{array}$ & Not known \\
\hline 12 & Micro level & $\begin{array}{l}\text { Kroemer, Herbert ( } 2000 \text { Nobel } \\
\text { Prize } \AA \text { in Physics) }\end{array}$ & 1963 & $\begin{array}{l}\text { Applied Physics Letters (reject) and } \\
\text { Proceedings of the IEEE (publish) }\end{array}$ \\
\hline 13 & Micro level & $\begin{array}{l}\text { Lauterbur, Paul C.* (2003 Nobel } \\
\text { Prize } ® \text { in Physiology or } \\
\text { Medicine) }\end{array}$ & 1973 & Nature (reject/publish) \\
\hline 14 & Micro level & $\begin{array}{l}\text { Lee, David M.; Osheroff, } \\
\text { Douglas D.; Richardson, } \\
\text { Robert C. } \\
\text { (1996 Nobel Prize }{ }^{\circledR} \text { in Physics) }\end{array}$ & 1972 & $\begin{array}{l}\text { Physical Review Letters } \\
\text { (reject/publish) }\end{array}$ \\
\hline 15 & Micro level & $\begin{array}{l}\text { Marshall, Barry J. } \\
\text { Warren, J. Robin } \\
\text { (2005 Nobel Prize }{ }^{\circledR} \text { in } \\
\text { Physiology or Medicine) }\end{array}$ & 1984 & The Lancet (delay/publish) \\
\hline 16 & Meso level & Medical Hypotheses journal & 2010 & Medical Hypotheses \\
\hline 17 & Micro level & $\begin{array}{l}\text { Mullis, Kary B. (1993 Nobel } \\
\text { Prize } ® \text { in Chemistry) }\end{array}$ & 1987 & $\begin{array}{l}\text { Nature and Science (reject) and } \\
\text { Methods in Enzymology (publish) }\end{array}$ \\
\hline
\end{tabular}




\begin{tabular}{|c|c|c|c|c|}
\hline $\begin{array}{l}\text { Case } \\
\text { ID }\end{array}$ & 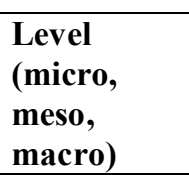 & $\begin{array}{l}\text { Identification of Focal Actor, } \\
\text { Area, or Journal }\end{array}$ & Year(s) & $\begin{array}{l}\text { Journal(s) that rejected or } \\
\text { eventually published manuscript }\end{array}$ \\
\hline 18 & Micro level & $\begin{array}{l}\text { Polanyi, John C. ( } 1986 \text { Nobel } \\
\text { Prize } ₫ \text { in Chemistry) }\end{array}$ & 1961 & $\begin{array}{l}\text { Physical Review Letters (reject) } \\
\text { and Journal of Chemical Physics } \\
\text { (publish) }\end{array}$ \\
\hline 19 & Micro level & $\begin{array}{l}\text { Prusiner, Stanley ( } 1997 \text { Nobel } \\
\text { Prize } \AA \text { in Physiology or } \\
\text { Medicine) }\end{array}$ & $\begin{array}{l}\text { From } 1982 \\
\text { to } 2012\end{array}$ & $\begin{array}{l}\text { Potentially: Science and } \\
\text { Proceedings of the National } \\
\text { Academy of Science (publish) }\end{array}$ \\
\hline 20 & Micro level & $\begin{array}{l}\text { Shechtman, Dan (2011 Nobel } \\
\text { Prize } ₫ \text { in Chemistry) }\end{array}$ & $1984-1985$ & $\begin{array}{l}\text { Journal of Applied Physics (reject) } \\
\text { and Metallurgical Transactions A } \\
\text { (publish) }\end{array}$ \\
\hline 21 & Macro level & Virus infection and diabetes & 1974 & The Lancet (delay/publish) \\
\hline 22 & Micro level & $\begin{array}{l}\text { Von Klitzing, Klaus (1985 } \\
\text { Nobel Prize } 囚 \text { in Physics) }\end{array}$ & 1980 & $\begin{array}{l}\text { Physical Review Letters } \\
\text { (reject/publish) }\end{array}$ \\
\hline 23 & Micro level & Waterston, J.J.* & $\begin{array}{l}1845 \\
\text { (reject)/1892 } \\
\text { (publ.) }\end{array}$ & $\begin{array}{l}\text { Philosophical Transactions } \\
\text { (reject/publish) }\end{array}$ \\
\hline 24 & Micro level & Wilson, J. Tuzo* & 1963 & $\begin{array}{l}\text { Journal of Geophysical Research } \\
\text { (reject) and Canadian Journal of } \\
\text { Physics (publish) }\end{array}$ \\
\hline 25 & Micro level & $\begin{array}{l}\text { Yalow, Rosalyn S.* (1977 Nobel } \\
\text { Prize } ₫ \text { in Physiology or } \\
\text { Medicine) }\end{array}$ & 1956 & $\begin{array}{l}\text { Science (reject) and Journal of } \\
\text { Clinical Investigation } \\
\text { (reject/publish) }\end{array}$ \\
\hline
\end{tabular}

*Deceased

To these Nobel Prize ${ }^{\circledR}$ laureates I added three individual authors. I used the same criteria as above for selection. First, that the ignorance they ultimately published was visible, though not with Nobel Prizes ${ }^{\circledR}$. Visibility in these cases owed mostly to the award of other prizes, recognition from their epistemic communities, or researchers analyzing these examples as resistance to new 'scientific discovery'. Second, that I had access to adequate self-accounts and/or third party accounts of ignorance dynamics in order to construct cases of ignorance (re)production at traditional peer review. The three individual authors are Mitchell J. Feigenbaum (Redner, 1987; Campanario, 1998), J. J. Waterston (Barber, 1961:601), and J. Tuzo Wilson (Garland, 1995:545).

I then constructed two meta-level area of study cases. First, type 1 diabetes. More precisely, the case focused on a hypothesis (ignorance) that a virus might be a causal agent in type 1 diabetes (Gale, 2011:1) for manuscripts submitted to The Lancet journal from 1974 to 2011 . The case is potentially significant in that over 40 years (since the 1960s), in spite of over 15,000 papers (estimated in 2001, all journals, not only The Lancet (Gale, 2001:224)) on the topic, the same dominant ignorance prevailed in 2011 (Gale, 2011), revealing apparent stagnation with ignorance.

Second, the meta-level area case of cancer stem cells (i.e., Bains, 2009; Lapidot et al., 1994; Dick, 2003). According to Bains (2009) before the construction of new ignorance on cancer stem cells, "[t] he standard view of cancer was one of a bulk of mutating cells, not a source and a sink" (2009:280). Bains bemoaned the purported "high wall of peer consensus', including journal editorial peer review, in delaying cancer stem cell research. I selected this meta-level case because it contrasted with the type 1 diabetes meta-level case. In this case, ignorance reproduction is not due to long-term stagnation 
but is rather purportedly due to resistance to new ignorance on cancer stem cells.

Finally, I constructed the case of a journal (Medical Hypotheses) that had been editorial-only but adopted peer review after the publication of a paper with controversial ignorance (i.e., Enserink, 2010). The case highlights how controversy can render visible a relation of accountability to readers and the editor's accountability relations to the publisher and to political and economic relations. Reverting to peer review here was framed as reverting to conservatism.

In addition to the cases above, I added two contextual interviews to the list of potential interviewees. I selected these individuals as potential interviewees based primarily on their role as editor and published authors on peer review. Some of their publications on peer review helped shape my understanding for ignorance (re)production in peer review from an emic perspective. Both individuals accepted to be interviewed, but one requested to remain anonymous, which means that in what follows I only summarily justify the selection for this individual and use the masculine as default.

First, the contextual anonymous editor currently holds editorial-related roles at three journals (including a high impact journal and one that he launched). In addition, he published papers and editorials on peer review. Second, Richard Smith, was an editor for several years at the $B M J$ medical journal, is a well-published author on peer review with editorials, papers, letters to the editor, and a book (i.e., Smith 2005; 2006; 2011), and while at the $B M J$, he oversaw research on peer review. Having elaborated and justified my study design and case study (theoretical and empirical) approach, I tend to methods.

\section{D - Methods}

This section on methods is divided into two parts. First, I explore data construction. This part starts with a note on 'data' then provides details for data on ignorance (re)production in traditional peer review, for semi-structured interviews, and for traditional peer review non-human actors. Second, the focus shifts to data analysis with three main elements. Firstly, how I performed analytic induction to saturation for the twenty-five cases (Pascale, 2011:55). Secondly, an analytical tool I developed based on Dawes' (2009) explanatory virtues for scientific explanations. Finally, how I performed discourse and narrative analysis.

\section{Part 1: Data construction}

Prior to launching into data construction considerations, I propose a note on the ontological assumptions that underlie 'data' in this work. I do not understand 'data' from a positivist stance as simply being out there and ready for collection and analysis (see Pascale, 2011:69). Rather, I propose that I constructed data over the course of the research including the co-construction of interview knowledge (see Kvale and Brinkmann, 2009:53, 54). Having outlined how I conceptualize data, the attention veers to data construction for ignorance (re)production in traditional peer review. 


\section{Data construction for ignorance (re)production in traditional peer review}

Data construction for ignorance (re)production in traditional peer review pooled from two empirical sources and from secondary data sources. First, primary data from traditional peer review non-human actors (cf., editorial judgements and decisions, editorial guidelines, original manuscripts, and final published papers). Second, semistructured interview co-constructed knowledge. Finally, from secondary source self- and third-party accounts of ignorance (re)production in traditional peer review. In Table 2, I provide an overview of the data construction approach.

Table 2: Overview of Data Construction Approach for Twenty-Five Cases and Contextual Interviews

\begin{tabular}{|c|c|c|}
\hline Type of Data & Type of Contact and Data Source & \begin{tabular}{|l} 
Timeframe for \\
Construction*
\end{tabular} \\
\hline Interviews with authors & $\begin{array}{l}\text { Mailed letter of invitation, follow- } \\
\text { up telephone calls and/or e-mails, } \\
\text { and interviews for authors (22) } \\
\text { related with cases listed in Table } 1 .\end{array}$ & $\begin{array}{l}\text { Contact: May 1, } \\
2013 \text { to February 5, } \\
2014 \\
\text { Interviews: June } \\
\text { 12, } 2013 \text { to July 24, } \\
2013\end{array}$ \\
\hline $\begin{array}{l}\text { Interviews with editors, } \\
\text { editorial board members, } \\
\text { and referees }\end{array}$ & $\begin{array}{l}\text { Mailed letter of invitation, follow- } \\
\text { up telephone calls and/or e-mails, } \\
\text { and interviews with journal editors } \\
\text { at journals listed in Table } 1 \text { and two } \\
\text { explicitly contextual interviewees. }\end{array}$ & $\begin{array}{l}\text { Contact: May 1, } \\
2013 \text { to February 5, } \\
2014 \\
\text { Interviews: June } \\
\text { 13, 2013 to July 25, } \\
2013\end{array}$ \\
\hline $\begin{array}{l}\text { Editorial judgements and } \\
\text { decisions, and original } \\
\text { submitted manuscripts }\end{array}$ & $\begin{array}{l}\text { - Included in letters of invitation to } \\
\text { authors (above). } \\
\text { - Included in letters of invitation to } \\
\text { journal editors (above). } \\
\text { - Mailed letter of invitation and } \\
\text { follow-up mail and email to the } \\
\text { Nobel Foundation specifically for } \\
\text { Nobel Prize }{ }^{\circledR} \text { winners. } \\
\text { - Author-based searches on the } \\
\text { Web. }\end{array}$ & $\begin{array}{l}\text { - As above } \\
\text { - As above } \\
\text { - June 26, } 2013 \text { to } \\
\text { March 20, } 2014 \\
\\
\text { - October 18, } 2012 \\
\text { to May 1, 2014 }\end{array}$ \\
\hline $\begin{array}{l}\text { Editorial Guidelines and } \\
\text { Published Papers }\end{array}$ & $\begin{array}{l}\text { Individual journals listed in Table } 1 \\
\text { with access made available through } \\
\text { the University of Ottawa's library } \\
\text { subscriptions and inter-library loan } \\
\text { service. }\end{array}$ & $\begin{array}{l}\text { May } 1,2013 \text { to May } \\
1,2014\end{array}$ \\
\hline $\begin{array}{l}\text { Self- and Third-Party } \\
\text { Accounts }\end{array}$ & $\begin{array}{l}\text { Scholarship on resistance to new } \\
\text { scientific ideas and author-based } \\
\text { searches (on the Web and in library } \\
\text { databases) for self-accounts. }\end{array}$ & $\begin{array}{l}\text { May } 1,2013 \text { to May } \\
1,2014\end{array}$ \\
\hline
\end{tabular}


*From initial contact or search to data construction. Contact with human subjects was performed within the ethics approval certificate period of $03 / 26 / 2013$ to $03 / 25 / 2014$.

$\underline{\text { Semi-structured interview data }}$

For interviews, I constructed an interview guide that I adapted for each interviewee. The questions were generally of two types: centered on the interviewee's peer review practices and on meanings. Ontologically, therefore, by focusing on practices and meanings in peer review this work is nestled within a postconstructivism understanding of science. In postconstructivism, science is constructed as situated practices - that I further distinguish as situated relations - instead of science as knowledge (Wehling, 2006:86). Such practices integrate material and performative elements where the agency of human and non-human actors are interrelated (2006:91) and evident in the relational dynamics of traditional peer review as social form (Fig. 1).

From a starting point of situatedness, it is all the more pertinent that the interview guide was tailored to each interviewee. Adapting the guide thus respected that 'ultraelite' interviewees (cf., Nobel Prize ${ }^{\circledR}$ laureates and busy researchers) “... resent being encased in the straightjacket of standardized questions", according to Zuckerman (1972:168) - each interviewee as situated knower. Adaptations included lists of interviewees' most recent papers, identifying the types of journals they published in, and identifying new ignorance they constructed. In preparation for each interview I also familiarized myself with their professional resume and publications more generally.

By mail, I invited authors and main journal editors (and their co-editors and referees) to participate in one-hour semi-structured telephone interviews for the twentyfive cases and for two contextual interviewees. I opted for telephone interviews because ethics requirements stipulated that if I interviewed in person outside of Canada, I would also need to obtain ethics approval within those jurisdictions. To avoid lengthy approval processes, I performed telephone interviews with individuals in and outside of Canada.

For those who did not respond within about three to four weeks of my initial invitation, I followed-up by telephone and via email. In all, nine case-related authors and editors participated in interviews. Three were Nobel Prize ${ }^{\circledR}$ laureates in the role of authors, five were primarily in the role of editor, and one was primarily in the role of author. The two contextual interviews were in the role of editor, yielding eleven interviews in all. Interviews lasted from forty-five minutes to a little over an hour.

Of the two editors who specifically informed me that they would ask referees if they wished to participate in my study and would instruct them to contact me, I did not receive any follow-up from a referee. All but one of the eleven interviewees, however, had already taken on the role of referee. In addition, all the editors had been in the role of author. Therefore, during interviews the interviewees often shifted among the roles of author, referee, and editor (see Lipworth et al., 2011:1058).

Finally, apart from three authors and one editor, all other actors with whom I interacted were not directly related to the cases themselves. In effect, all other interviews can be understood as case-contextual. Editors might be working at a journal that rejected a now Nobel Prize ${ }^{\circledR}$ laureate, for example, but had not been editors at the time. This disjuncture could be viewed as a potential limitation. Yet, when combined with structural barriers to accessing traditional peer review non-human actors as I explore next, I advance that the disjuncture contributes to understanding for the object of study. 
For all cases with identified publications, I obtained published papers and letters to the editor. These non-human actors were mostly available electronically on the Web.

Other traditional peer review non-human actors were not readily accessible, however. In the letters of invitation to journal editors and to authors, I had requested that these actors share traditional peer review editorial judgements and decisions, and original manuscripts for papers that had encountered resistance at peer review. For journals, I consolidated a list if numerous authors had attempted to, or eventually published. For Nobel Prize ${ }^{\circledR}$ laureates, I also requested these documents from the Nobel Foundation. For example, some Nobel Prize ${ }^{\circledR}$ laureates were rejected at one journal, and eventually published at another. This meant that I requested the documents from the author (if alive), from the Nobel Foundation, from the rejecting journal, and from the journal that eventually published the paper. In spite of these numerous requests with multiple actors, of the twenty-five cases, I only obtained two editorial judgements for the oldest case of ignorance reproduction - that of J.J. Waterston in 1892 at Philosophical Transactions. In addition, I accessed a published partial editorial letter of rejection for the case of Nobel Prize ${ }^{\circledR}$ Laureate Rosalind S. Yalow (portions of text removed, Case 25, Yalow, 1977:449). Finally, on the Web I accessed the editorial decision for the case of Nobel Prize ${ }^{\circledR}$ Laureate Klaus von Klitzing (only editorial decision text, Case 22, Holme, 2012).

The reasons for not sharing editorial judgements were varied. Several individual authors indicated that they had not kept these documents, some pointed to difficulties in accessing their archives, and yet another indicated that he felt it would be inappropriate to share editorial judgements that might embarrass a journal editor who had regretted rejecting a future Nobel Prize ${ }^{\circledR}$ laureate. For journals, several indicated that their archives only contained documents for a limited period of time (i.e., ten to fifteen years). Others stated that their editorial documents were confidential. One journal at a learned society responded that they would inquire with their membership about sharing this type of information. I have yet to hear from them.

Contrary to sociological research that can use coercion and bluffing in order to negotiate the disclosure of data from public entities such as governments (Piché, 2012:58), research into journal peer review not embedded within a journal's editorial environment (Hirschauer, 2010) ${ }^{9}$ meets high walls of secrecy and closure (i.e., CouzinFrankel, 2013; Campanario, 2009). Original manuscripts and editorial judgements and decisions can appear impenetrable at science and medical journals that engage in traditional peer review ${ }^{10}$. Even lawsuits fail to allow access to editorial judgements and decisions (Anonymous, 2008). Moreover, one editor whom I interviewed was warned by a member of his editorial committee not to share editorial judgements because he feared I might be a Latour-type researcher who socially constructs everything. Such exclusion of, and potential concerns with, sociological and social scientific research of science is not uncommon. The American Astronomical Society, for example, changed its editorial

\footnotetext{
9 See 10-year data collection as member of a social scientific editorial committee in Hirschauer (2010).

${ }^{10}$ With exceptions, The Lancet for example, advises authors that with regard to 'Participation in Editorial Research at The Lancet', '[w]e are keen to better understand and improve editorial conduct, decision making, and issues related to peer review. Therefore, we occasionally take part in or conduct editorial research" (The Lancet, 2012).
} 
policy to only give access to 'qualified historians' for their journal's peer review-related documents (Gallagher, 2013).

Absence of case study editorial judgements and decisions and original manuscripts was therefore expected (i.e., Couzin-Frankel, 2013; Campanario, 2009). The partial data constructed in this work, thus, can only contribute to partial accounts for the cases in Appendix A and only partially account for ignorance (re)production in traditional peer review (see partial account of the reproduction of the prison idea in Piché (2012:63)). Conversely, absence here can also contribute to theoretical understanding of traditional peer review - absence as data (see Pascale, 2011:144; Rappert and Bauchspies, 2014; Gaudet, 2014b).

\section{Part 2: Data analysis}

The main method of analysis used was analytic induction across cases (see 28 case cross-case analysis in Stake, 2006). With the multiple cases in this work, I reached saturation points beyond which additional cases would not necessarily have led to new information (Pascale, 2011:55). For example, as I alluded to above, the absence of editorial judgements and decisions, and original manuscripts for twenty-two of the twenty-five cases, and only partial documents for three, is theoretically insightful given the number of cases. Adding one or two more cases of absence would not contribute to further understanding of structural secrecy and temporally limited valuation of these documents by contemporary journals. This is in comparison to one of the first journals launched in 1665, Philosophical Transactions, that holds archives dating back to 1665 and provides access to archival materials (with restrictions linked with British access to information regulation and pay-per use). Next I turn to a tool I developed using analytic induction drawing on Dawes' (2009) explanatory virtues for scientific explanations.

From Dawe's explanatory virtues to scientific explanation imperatives in peer review

Dawes' (2009) proposed explanatory virtues for scientific explanations that help delineate what can be deemed 'scientific', and by extension, what can be deemed as not 'scientific'. Using inductive analysis on the cases, here I reconstruct select explanatory virtues into analytical tools to explore how those in the role of editorial readers judged explanations for new ignorance in manuscripts. These judgements stem largely from editorial readers' relation of accountability to empiricism. Looking across the high number of cases described in Appendix A, it became clearer to me that framing editorial decisions based on individual bias or individual epistemic convictions could not capture how those engaged in an editorial reader role appeared to judge manuscripts with new ignorance. The missing link as I propose here, is an understanding of how an editorial reader might judge the scientific nature of an explanation for new ignorance.

Dawes (2009) provided the basis for this. He advanced that to be able to judge a proposed explanation in the context of contemporary science, it would be best to stipulate a list of explanatory virtues against which an explanation could effectively be judged. $\mathrm{He}$ proposed that

[o]ur preferred [explanation] will have a high degree of testability; 
indeed, it will have survived independent tests. It will posit mechanisms that are at least analogous to those with which we are already familiar, and will form part of a previously successful research tradition. It will also be simple, ontologically economical, and informative. (2009:116)

I reframe select explanatory virtues into analytical scientific explanation imperatives. By scientific explanation imperatives, I mean core elements that those in the editorial reader role appear to look for in a manuscript's account for new ignorance in order to deem it a suitable scientific explanation.

I retain the following four imperatives, as inspired by Dawes (2009:115-142). First, testability rests on notions of empirical intersubjectivity that requires empirical evidence and that an explanation can be tested and corroborated. Second, an explanation retains the imperative to hold ties to already established knowledge and ignorance that is independent of the proposed explanation and with related research programs that have demonstrated past success in explanation. The latter touts potential relations between established and new ignorance. Third, there is an imperative of being economical ontologically. This means not proposing too many new entities such as supernatural entities, or unobservable entities. A final imperative is being informative. Informativeness proposes some empirical content that will help decipher the details related with a given postulated effect. This includes specifying “... in some detail just what [an explanation] does and does not predict" (Dawes, 2009:138). The imperatives are an analytical tool to examine how editorial readers construct judgements on new ignorance that can otherwise seem 'speculative' given limited empirical support. In addition to constructing a new tool, I performed discourse and narrative analysis.

\section{Discourse and narrative analysis}

Through narrative analysis of interviews, I constructed meanings and value that interviewees gave to the social forms of boundary judgement and scientific exchange, and co-constructed knowledge on relations. More in-depth, the interview transcripts were coded in NVivo and then analyzed along organizational and theoretical categories reflecting ignorance (re)production dynamics.

Category details are as follows. First, relations of accountability (i.e., to readers, to journal guidelines, to judgements, to the manuscript, to advertisers, to empiricism, to the author, to the editor, to the referee, to the publisher, and to funders). Second, other relations (i.e., political, power, and economic). Third, structural secrecy (i.e., editor only communicates with authors, no communication among referees, anonymous/nonanonymous, and restrictive access to judgements). Fourth, social forms (i.e., contingency of review over exchange, editorial only review, traditional peer review, scientific exchange, and relations within the forms). I identified contingency of scientific exchange on traditional peer review when there were dynamics of delay for publication or rejection of a submitted manuscript. Finally, four scientific explanation imperatives for scientific explanations (adapted from Dawes (2009): informativeness, ontological economy, testability, and ties with the past). Inductive analysis was also performed separately from these categories, especially where absence was relevant given that absence cannot readily be coded categorically. 
Finally, I performed discourse analysis on self- and third-party accounts of ignorance (re)production in peer review that I deemed as valid secondary data sources. I used the same categories as for interviews above. The challenge of presenting the constructed data is one to which I now turn.

\section{E - Data}

Deciding on how to present data constructed over the course of this research was challenging. A main challenge was that I do not focus on a specific case or on a small number of cases, but rather on twenty-five cases. I propose case descriptions in Appendix A and two data tables.

In the case descriptions (Appendix A), I identified references for primary empirical data constructed or co-constructed (during interviews) over the course of the research with an asterisk $(*)$. Other references in Appendix A consist of self- and thirdparty accounts.

In the first data table, Table 3, I detail the 'presence and absence' of empirical data constructed. They are captured in the Data Collection Matrix (Creswell, 2013:404) at the right of Table 3. Included are presence (yes) and absence (no) for interview coconstructed data, editorial judgements and decisions, original submitted manuscripts, and published papers. Where a case did not allow for a specific type of data, such as if a case did not refer to specific journals, I could not request editorial judgements and other such documents. Instead of presence or absence, I identified these as not applicable (n/a).

Table 3: Presence (Yes) and Absence (No) of Empirical Data for Twenty-Five Cases of Purported Ignorance (Re)Production in Traditional Peer Review

\begin{tabular}{|c|c|c|c|c|c|c|c|c|}
\hline & \multicolumn{2}{|c|}{ Descriptive Details } & \multicolumn{6}{|c|}{ Data Collection Matrix } \\
\hline \multirow[t]{2}{*}{$\begin{array}{l}\text { Case } \\
\text { ID }\end{array}$} & \multirow[t]{2}{*}{$\begin{array}{l}\text { Identification of } \\
\text { Focal Actor, } \\
\text { Area, or Journal }\end{array}$} & \multirow[t]{2}{*}{$\begin{array}{l}\text { Journal(s) that } \\
\text { rejected or } \\
\text { eventually } \\
\text { published } \\
\text { manuscript } \\
\end{array}$} & \multicolumn{2}{|c|}{ Interviews $^{11}$} & \multicolumn{3}{|c|}{$\begin{array}{l}\text { Editorial } \\
\text { Judgements (EJ) } \\
\text { and Decision (ED), } \\
\text { \& Original } \\
\text { Manuscript (OM) }\end{array}$} & \multirow[t]{2}{*}{$\begin{array}{l}\text { Published } \\
\text { paper }\end{array}$} \\
\hline & & & Direct & Cont. & EJ & ED & OM & \\
\hline 1 & $\begin{array}{l}\text { Bardeen, John* } \\
\text { (1956 and } 1972 \\
\text { Nobel Prizes }{ }^{\circledR} \text { in } \\
\text { Physics) }\end{array}$ & $\begin{array}{l}\text { Physical Review } \\
\text { Letters (papers } \\
\text { rejected/published) }\end{array}$ & No & No & No & No & No & $\begin{array}{l}\text { Yes } \\
\text { (potential) }\end{array}$ \\
\hline 2 & $\begin{array}{l}\text { Blobel, Günter } \\
\text { (1999 Nobel } \\
\text { Prize } ® \text { in } \\
\text { Physiology or } \\
\text { Medicine) }\end{array}$ & Not known & No & No & $\mathrm{n} / \mathrm{a}$ & $\mathrm{n} / \mathrm{a}$ & $\mathrm{n} / \mathrm{a}$ & $\mathrm{n} / \mathrm{a}$ \\
\hline
\end{tabular}

11 A direct interview involves an actor that is directly familiar with the case such as an author, editor, editorial committee member, or referee. A contextual (Cont.) interview is one that is indirectly related with a case such as an author, editor, a member of an editorial committee, or a referee at a Journal that either rejected or published a paper with new ignorance. The total presence for interviews surpasses eleven interviewees because contextual interviews with a journal such as Nature, for example, were relevant for several cases. Partial (Part.). 


\begin{tabular}{|c|c|c|c|c|c|c|c|c|}
\hline \multirow{3}{*}{$\begin{array}{l}\text { Case } \\
\text { ID }\end{array}$} & \multicolumn{2}{|c|}{ Descriptive Details } & \multicolumn{6}{|c|}{ Data Collection Matrix } \\
\hline & \multirow[t]{2}{*}{$\begin{array}{l}\text { Identification of } \\
\text { Focal Actor, } \\
\text { Area, or Journal }\end{array}$} & \multirow[t]{2}{*}{$\begin{array}{l}\text { Journal(s) that } \\
\text { rejected or } \\
\text { eventually } \\
\text { published } \\
\text { manuscript } \\
\end{array}$} & \multicolumn{2}{|c|}{ Interviews $^{11}$} & \multicolumn{3}{|c|}{$\begin{array}{l}\text { Editorial } \\
\text { Judgements (EJ) } \\
\text { and Decision (ED), } \\
\text { \& Original } \\
\text { Manuscript (OM) }\end{array}$} & \multirow[t]{2}{*}{$\begin{array}{l}\text { Published } \\
\text { paper }\end{array}$} \\
\hline & & & Direct & Cont. & EJ & ED & OM & \\
\hline 3 & $\begin{array}{l}\text { Blumberg, Baruch } \\
\text { S.* (1976 Nobel } \\
\text { Prize } \circledR \text { in } \\
\text { Physiology or } \\
\text { Medicine) }\end{array}$ & $\begin{array}{l}\text { Annals of Internal } \\
\text { Medicine (reject } \\
\text { 1967/publish 1969) }\end{array}$ & No & No & No & No & No & Yes \\
\hline 4 & $\begin{array}{l}\text { Boyer, Paul (1997 } \\
\text { Nobel Prize }{ }^{\circledR} \text { in } \\
\text { Chemistry) }\end{array}$ & $\begin{array}{l}\text { Journal of Biological } \\
\text { Chemistry (reject) } \\
\text { and Proceedings of } \\
\text { the National } \\
\text { Academy of Sciences } \\
\text { (PNAS) (publish) }\end{array}$ & No & No & No & No & No & Yes \\
\hline 5 & $\begin{array}{l}\text { Cancer as stem } \\
\text { cells }\end{array}$ & $\begin{array}{l}\text { Nature and } \\
\text { Proceedings of the } \\
\text { National Academy of } \\
\text { Sciences (PNAS) } \\
\text { (publish) }\end{array}$ & No & Yes & No & No & No & Yes \\
\hline 6 & $\begin{array}{l}\text { Cech, Thomas } \\
\text { (1989 Nobel } \\
\text { Prize® in } \\
\text { Chemistry) }\end{array}$ & $\begin{array}{l}\text { Nature (referees } \\
\text { critical/publish) }\end{array}$ & Yes & Yes & No & No & No & Yes \\
\hline 7 & $\begin{array}{l}\text { Ernst, Richard R. } \\
\text { (1991 Nobel } \\
\text { Prize } ® \text { in } \\
\text { Chemistry) }\end{array}$ & $\begin{array}{l}\text { Journal of Chemical } \\
\text { Physics (rejected } \\
\text { twice in 1965) and } \\
\text { Review of Scientific } \\
\text { Instruments (publish) }\end{array}$ & No & No & No & No & No & Yes \\
\hline 8 & $\begin{array}{l}\text { Feigenbaum, } \\
\text { Mitchell }\end{array}$ & Not known & No & No & $\mathrm{n} / \mathrm{a}$ & $\mathrm{n} / \mathrm{a}$ & $\mathrm{n} / \mathrm{a}$ & $\mathrm{n} / \mathrm{a}$ \\
\hline 9 & $\begin{array}{l}\text { Furchgott, Robert } \\
\text { F.* (1998 Nobel } \\
\text { Prize } \AA \text { in } \\
\text { Physiology or } \\
\text { Medicine) }\end{array}$ & $\begin{array}{l}\text { Nature (considerable } \\
\text { rebuttal/publish) }\end{array}$ & No & Yes & No & No & No & Yes \\
\hline 10 & $\begin{array}{l}\text { Gell-Mann, } \\
\text { Murray (1969 } \\
\text { Nobel Prize® in } \\
\text { Physics) }\end{array}$ & $\begin{array}{l}\text { Physical Review } \\
\text { (reject/publish) }\end{array}$ & No & No & No & No & No & Yes \\
\hline 11 & $\begin{array}{l}\text { Ignarro, Louis J. } \\
\text { (1998 Nobel } \\
\text { Prize } \AA \text { in } \\
\text { Physiology or } \\
\text { Medicine) } \\
\end{array}$ & Not known & No & No & $\mathrm{n} / \mathrm{a}$ & $\mathrm{n} / \mathrm{a}$ & $\mathrm{n} / \mathrm{a}$ & $\mathrm{n} / \mathrm{a}$ \\
\hline 12 & $\begin{array}{l}\text { Kroemer, Herbert } \\
(2000 \text { Nobel } \\
\left.\text { Prize }{ }^{\circledR} \text { in Physics }\right)\end{array}$ & $\begin{array}{l}\text { Applied Physics } \\
\text { Letters (reject) and } \\
\text { Proceedings of the } \\
\text { IEEE (publish) }\end{array}$ & No & Yes & No & No & No & Yes \\
\hline 13 & $\begin{array}{l}\text { Lauterbur, Paul } \\
\text { C.* (2003 Nobel }\end{array}$ & $\begin{array}{l}\text { Nature } \\
\text { (reject/publish) }\end{array}$ & No & Yes & No & No & No & Yes \\
\hline
\end{tabular}




\begin{tabular}{|c|c|c|c|c|c|c|c|c|}
\hline \multirow{3}{*}{$\begin{array}{l}\text { Case } \\
\text { ID }\end{array}$} & \multicolumn{2}{|c|}{ Descriptive Details } & \multicolumn{6}{|c|}{ Data Collection Matrix } \\
\hline & \multirow[t]{2}{*}{$\begin{array}{l}\text { Identification of } \\
\text { Focal Actor, } \\
\text { Area, or Journal }\end{array}$} & \multirow[t]{2}{*}{$\begin{array}{l}\text { Journal(s) that } \\
\text { rejected or } \\
\text { eventually } \\
\text { published } \\
\text { manuscript } \\
\end{array}$} & \multicolumn{2}{|c|}{ Interviews $^{11}$} & \multicolumn{3}{|c|}{$\begin{array}{l}\text { Editorial } \\
\text { Judgements (EJ) } \\
\text { and Decision (ED), } \\
\text { \& Original } \\
\text { Manuscript (OM) }\end{array}$} & \multirow[t]{2}{*}{$\begin{array}{l}\text { Published } \\
\text { paper }\end{array}$} \\
\hline & & & Direct & Cont. & EJ & ED & OM & \\
\hline & $\begin{array}{l}\text { Prize } \AA \text { in } \\
\text { Physiology or } \\
\text { Medicine) }\end{array}$ & & & & & & & \\
\hline 14 & $\begin{array}{l}\text { Lee, David M.; } \\
\text { Osheroff, } \\
\text { Douglas D.; } \\
\text { Richardson, } \\
\text { Robert C. } \\
\text { (1996 Nobel } \\
\text { Prize }{ }^{\circledR} \text { in Physics) }\end{array}$ & $\begin{array}{l}\text { Physical Review } \\
\text { Letters } \\
\text { (reject/publish) }\end{array}$ & No & No & No & No & No & Yes \\
\hline 15 & $\begin{array}{l}\text { Marshall, Barry J. } \\
\text { Warren, J. Robin } \\
\text { (2005 Nobel } \\
\text { Prize } \AA \text { in } \\
\text { Physiology or } \\
\text { Medicine) }\end{array}$ & $\begin{array}{l}\text { The Lancet } \\
\text { (delay/publish) }\end{array}$ & Yes & Yes & No & No & No & Yes \\
\hline 16 & $\begin{array}{l}\text { Medical } \\
\text { Hypotheses } \\
\text { journal }\end{array}$ & Medical Hypotheses & Yes & Yes & No & No & No & Yes \\
\hline 17 & $\begin{array}{l}\text { Mullis, Kary B. } \\
\text { (1993 Nobel } \\
\text { Prize } \AA \text { in } \\
\text { Chemistry) }\end{array}$ & $\begin{array}{l}\text { Nature and Science } \\
\text { (reject) and Methods } \\
\text { in Enzymology } \\
\text { (publish) }\end{array}$ & No & Yes & No & No & No & Yes \\
\hline 18 & $\begin{array}{l}\text { Polanyi, John C. } \\
\text { (1986 Nobel } \\
\text { Prize } \AA \text { in } \\
\text { Chemistry) } \\
\end{array}$ & $\begin{array}{l}\text { Physical Review } \\
\text { Letters (reject) and } \\
\text { Journal of Chemical } \\
\text { Physics (publish) }\end{array}$ & No & No & No & No & No & Yes \\
\hline 19 & $\begin{array}{l}\text { Prusiner, Stanley } \\
\text { (1997 Nobel } \\
\text { Prize® in } \\
\text { Physiology or } \\
\text { Medicine) }\end{array}$ & $\begin{array}{l}\text { Potentially Science } \\
\text { and Proceedings of } \\
\text { the National } \\
\text { Academy of Science } \\
\text { (publish) }\end{array}$ & No & No & No & No & No & $\begin{array}{l}\text { Yes } \\
\text { (potential) }\end{array}$ \\
\hline 20 & $\begin{array}{l}\text { Shechtman, Dan } \\
\text { (2011 Nobel } \\
\text { Prize } \AA \text { in } \\
\text { Chemistry) }\end{array}$ & $\begin{array}{l}\text { Journal of Applied } \\
\text { Physics (reject) and } \\
\text { Metallurgical } \\
\text { Transactions A } \\
\text { (publish) }\end{array}$ & Yes & No & No & No & No & Yes \\
\hline 21 & $\begin{array}{l}\text { Virus infection } \\
\text { and diabetes }\end{array}$ & $\begin{array}{l}\text { The Lancet } \\
\text { (delay/publish) }\end{array}$ & No & Yes & No & No & No & Yes \\
\hline 22 & $\begin{array}{l}\text { Von Klitzing, } \\
\text { Klaus (1985 } \\
\text { Nobel Prize }{ }^{\circledR} \text { in } \\
\text { Physics) }\end{array}$ & $\begin{array}{l}\text { Physical Review } \\
\text { Letters } \\
\text { (reject/publish) }\end{array}$ & No & No & No & Part. & No & Yes \\
\hline 23 & Waterston, J.J.* & $\begin{array}{l}\text { Philosophical } \\
\text { Transactions } \\
\text { (reject/publish) }\end{array}$ & No & No & $\begin{array}{l}\text { Yes } \\
(2)\end{array}$ & $\begin{array}{l}1845 \\
\text { (No) } \\
1892 \\
\text { (Yes) }\end{array}$ & Yes** & Yes \\
\hline
\end{tabular}




\begin{tabular}{|c|c|c|c|c|c|c|c|c|}
\hline & \multicolumn{2}{|c|}{ Descriptive Details } & \multicolumn{6}{|c|}{ Data Collection Matrix } \\
\hline \multirow[t]{2}{*}{$\begin{array}{l}\text { Case } \\
\text { ID }\end{array}$} & \multirow[t]{2}{*}{$\begin{array}{l}\text { Identification of } \\
\text { Focal Actor, } \\
\text { Area, or Journal }\end{array}$} & $\begin{array}{l}\text { Journal(s) that } \\
\text { rejected or } \\
\text { eventually } \\
\text { published } \\
\text { manuscript } \\
\end{array}$ & \multicolumn{2}{|c|}{ Interviews $^{11}$} & \multicolumn{3}{|c|}{$\begin{array}{l}\text { Editorial } \\
\text { Judgements (EJ) } \\
\text { and Decision (ED), } \\
\text { \& Original } \\
\text { Manuscript (OM) }\end{array}$} & \multirow[t]{2}{*}{$\begin{array}{l}\text { Published } \\
\text { paper }\end{array}$} \\
\hline & & & Direct & Cont. & $\mathbf{E J}$ & ED & OM & \\
\hline 24 & Wilson, J. Tuzo* & $\begin{array}{l}\text { Journal of } \\
\text { Geophysical } \\
\text { Research (reject) and } \\
\text { Canadian Journal of } \\
\text { Physics (publish) }\end{array}$ & No & No & No & No & No & Yes \\
\hline 25 & $\begin{array}{l}\text { Yalow, Rosalyn } \\
\text { S.* (1977 Nobel } \\
\text { Prize® in } \\
\text { Physiology or } \\
\text { Medicine) }\end{array}$ & $\begin{array}{l}\text { Science (reject) and } \\
\text { Journal of Clinical } \\
\text { Investigation } \\
\text { (reject/publish) }\end{array}$ & No & No & No & Part. & No & Yes \\
\hline
\end{tabular}

*Deceased, $\mathrm{n} / \mathrm{a}=$ not applicable

Based on inductive analysis, in the second data table, Table 4, I aggregate casespecific data for structural properties in traditional peer review that appear to contribute to ignorance (re)production for the twenty-five cases in Appendix A (see cross-case worksheets in Stake, 2006:323-325). The structural properties were identified in Figure 1 and in the above description for the form. For each relevant structural property in traditional peer review, therefore, I identify case(s) where the particular property is rendered visible based on interview data, data in Table 3, and self- and third-party accounts. The properties are also made visible in the case descriptions in Appendix A.

Table 4: Case Data Rendering Visible Structural Properties that can Contribute to Ignorance (Re)Production in Traditional Peer Review for Twenty-Five Cases of Purported Ignorance (Re)Production in Traditional Peer Review (in alphabetical order of structural property)

\begin{tabular}{|c|c|}
\hline Structural Property* & $\begin{array}{l}\text { Case(s) Where Property is } \\
\text { rendered Visible (Data) }\end{array}$ \\
\hline $\begin{array}{l}\text { Control over dissemination of published paper (cf., } \\
\text { Ingelfinger rule) }\end{array}$ & No cases \\
\hline $\begin{array}{l}\text { Editorial Judgements and Decisions - Structurally } \\
\text { Secret }\end{array}$ & $\begin{array}{l}\text { All cases except for two partial } \\
\text { editorial decisions (some text } \\
\text { removed or not visible) for cases } \\
22 \text { and } 25\end{array}$ \\
\hline Originality Criterion (explicit, for editors) & Cases 7,18 \\
\hline Published Paper & All cases \\
\hline Rejected Manuscript - Structurally Secret & All cases \\
\hline $\begin{array}{l}\text { Relation of Accountability to Empiricism (for editorial } \\
\text { readers) }\end{array}$ & $\begin{array}{l}\text { Cases } 2,3,4,6,8,9,10,11,13 \text {, } \\
14,15,23 \text {, and } 25\end{array}$ \\
\hline \multicolumn{2}{|c|}{ Scientific Explanation Imperatives linked with Relation of Accountability to Empiricism } \\
\hline Testability & Cases $2,3,4,6,8,9,11,13,14$, \\
\hline
\end{tabular}




\begin{tabular}{|c|l|}
\hline \multicolumn{1}{|c|}{ Ties with the past } & 15,23, and 25 \\
\hline \multicolumn{1}{|c|}{ Ontological economy } & $\begin{array}{l}\text { Cases } 3,4,6,9,10,11,15,23, \\
\text { and 25. }\end{array}$ \\
\hline \multicolumn{1}{|c|}{ Informativeness } & Cases 3 and 10 12 \\
\hline $\begin{array}{l}\text { Relation of Accountability to Readers (for editors and } \\
\text { journal publishers) }\end{array}$ & Cases $6,9,13$, and 25 \\
\hline $\begin{array}{l}\text { Scientific Exchange Contingent on Boundary } \\
\text { Judgement }- \text { Papers delayed or rejected }\end{array}$ & All cases except case 16 \\
\hline
\end{tabular}

*Based on Figure 1 and the description for the social form of traditional peer review above.

\section{F - How traditional peer review (re)produces ignorance}

In this last phase of the paper I analyse how traditional peer review (re)produces ignorance. The analysis contributes to theoretical insights. In Appendix A, I propose case-specific synopsis of analysis for the twenty-five cases that, in my view, cannot be separated from case descriptions - they are highly contextual. In this section in contrast, I use inductive analysis across the twenty-five cases in order to identify patterns and exceptions of ignorance (re)production in traditional peer review (related in Stake, 2006).

To be sure, the purported delays in publication and rejections at traditional peer review in all the cases in Appendix A, save for the Medical Hypotheses journal case $(\text { Case } 16)^{13}$, support that ignorance reproduction can last from months to years (47 years for Waterston, Case 23). The self- and third-party accounts for the delays and rejections draw attention to the sacrifice and obstacles encountered in traditional peer review that the authors had to purportedly defy in order to impart value to their new ignorance ${ }^{14}$. That the cases eventually led to valuable ignorance therefore also supports that at least some new ignorance can be produced in traditional peer review.

Production is explicitly evident for all the cases in Appendix A where manuscripts with new ignorance were eventually published and some led to Nobel Prizes ${ }^{\circledR}$, other prizes, and new areas of research. Even the highly controversial Duesberg manuscript challenging that AIDS is caused by HIV (Enserink, 2010; Steinhauser et al., 2012:367) was published at a journal that made use of traditional peer review (Duesberg et al., 2011; Steinhauser et al., 2012; Zoe, 2012). New ignorance production is blatant in the Waterston case. Most of the new ignorance he had advanced was proposed by others (admittedly later) who gained priority for their supposedly 'new' contributions. The very selection of the cases rested on these making ignorance (re)production dynamics visible. In spite of publication, however, the scope of ignorance production can be restrained with control over the distribution authors can undertake with a published paper - through enforcement of the Ingelfinger rule ${ }^{15}$. No case in Appendix A rendered such enforcement

\footnotetext{
${ }^{12}$ Case 19 suggests such an imperative, but accounts do not substantiate it sufficiently.

${ }^{13}$ The Medical Hypotheses case (Case 16) had not originally made use of traditional peer review, it only used editorial review to publish the controversial Duesberg manuscript. The published paper was eventually retracted and expurged from the medical literature (Enserink, 2010).

${ }^{14}$ See parallel with how the content of economic exchange acquires value through sacrifice and obstacles in Simmel ([1971]1907:49-56).

${ }^{15}$ Funding agency open access mandates have altered these dynamics, as discussed above.
} 
of control visible. Some authors and editors I interviewed, however, highlighted the rule.

To further support ignorance production in traditional peer review, an editor I interviewed recounted how new ignorance on a scientific method in the late 1970s did not encounter resistance from those in the role of referee (Anonymous, 2013). They had heard of the method and were anxious to get it published in order to be able to use it. The paper had not necessarily convinced him of its worth in his editor-manuscript relationship, but the enthusiasm from peer reviewers contributed to its publication. It went on to be a widely cited paper that led to at least two new areas of research in biology (Anonymous, 2013). Without having access to data for this case or into how referees had been aware of the new ignorance, however, it is difficult to ascertain why and how ignorance production was enthusiastically embraced.

The argument I make here, in contrast, is that ignorance production as above only represents a portion of potential ignorance production - based on one of the dichotomous outcomes of traditional peer review: a published paper. Accounting for rejected papers, changes to manuscripts, and structural secrecy for original submitted manuscripts and editorial judgements and decisions can help shift the focus to ignorance reproduction in traditional peer review. Less visible forms of potential ignorance reproduction include: (1) the invisibility of submitted manuscripts in which there might be new ignorance that was altered by editorial judgements and that therefore remains invisible in spite of a published paper, (2) the invisibility of rejected manuscripts with new ignorance, and (3) the structural secrecy for and therefore the invisibility of editorial judgements and decisions in which new ignorance is evaluated and new ignorance can also be produced. It is this wider range of ignorance (re)production dynamics that I seek to analyze.

Moreover, like all scientific endeavours, this paper rests on a theoretical context (Phase B above) that guided data construction and analysis ${ }^{16}$. Likewise like all scientific endeavours and even more so because of my use of inductive analysis across cases, however, I was open to surprise. By this I mean that "... something is surprising when a pre-existing set of experiences and a horizon of expectation turn out to be inappropriate, since [a given] situation contradicts any anticipation" (my adaptation in brackets, Gross 2010:37). In one example of surprise, looking across cases I realized that my understanding for editorial readers' relation of accountability to empiricism could not readily account for how the relation appeared to contribute to ignorance (re)production in the cases. Case data analysis helped me re-conceptualize my understanding for this relation of accountability. As detailed in the data analysis section above, therefore, I proposed scientific explanation imperatives as an analytical tool and use the tool in the next section. Finally, based on inductive analysis of the twenty-five cases in Appendix A and contextual interviews, I advance that the social form of traditional peer review mostly contributes to ignorance reproduction through four structural properties.

\section{Four properties contributing mostly to ignorance reproduction in traditional peer review}

Inductive analysis across the twenty-five cases in Appendix A, corroborated by contextual interviews, help me advance that the following four structural properties in traditional peer review lead to increased potential for ignorance reproduction for the

\footnotetext{
${ }^{16}$ Grounded theory, though seemingly void of a pre-existing theoretical context is in itself grounded in a theoretical context of 'contextuality'.
} 
form. As discussed in the Methods section, however, absence of editorial judgements and decisions and original submitted manuscripts mean that these remain partial contributions to understanding. Nevertheless, as also discussed in Methods, absence of data can also be understood as data in this work so as not to take structural secrecy in traditional peer review as naturalized and pre-constructed - but rather as a constructed 'finding'.

I propose analyses for four properties that appear to contribute to ignorance reproduction: (1) creating contingency on scientific exchange; (2) ensuring structural secrecy for original submitted manuscripts and editorial judgements and decisions; (3) a relation of accountability to empiricism with scientific explanation imperatives that editorial readers use to evaluate manuscripts; and (4) a relation of accountability to readers that is further enacted through a criterion of originality.

\section{Creating contingency on scientific exchange}

Traditional peer review appears to have created contingency in all the cases involving traditional peer review ${ }^{17}$. Contingency meant that the content of scientific exchange (scientific knowledge and ignorance) contained in a paper was delayed from entering exchange by traditional peer review (from months to years with negotiations in relations among authors and editorial readers), or the content of a manuscript was prevented from entering into exchange following rejection at traditional peer review (until the next submission cycle, if it occurred). Contingency owes to a temporal characteristic for the form of traditional peer review performed pre-publication whereby scientific exchange cannot take place unless it interacts with the social form of boundary judgement (Gaudet, 2014a). Finally, when exchange does take place, partial exchange occurs with only the content of the published manuscript being exchanged.

Contingency here therefore does not mean that an author cannot share the content at conferences, share it informally with other colleagues, or even post it to the Web (see disciplinary differences for preprint servers above). Contingency rather, refers to the content of scientific exchange engaged in traditional peer review being dependent on the form and then constrained to a dichotomous outcome, only one of which leads to partial exchange (cf., a published paper) and value for the content of exchange (valued as a peer reviewed paper). A richer content of scientific exchange (cf., editorial judgements and decisions, original submitted manuscript, exchanges between the editor and author, rejected manuscripts) remains structurally secret.

Data also provides insights into traditional peer review's valuation of scientific knowledge and ignorance. Nobel Prize ${ }^{\circledR}$ laureate Mullis (Case 17), for example, had published a highly speculative paper in Nature as a graduate student (Mullis, 2000:103). Yet a manuscript with new ignorance on future Nobel winning work - how a chemical procedure (polymerase chain reaction) enhanced how scientists could render DNA fragments visible (2000) - encountered rejection at Nature and Science. Publication of the highly speculative paper can be understood to convey a meaning of science as news and newsworthy (see Ingelfinger note above) with potential economic value ${ }^{18}$ for a

\footnotetext{
${ }^{17}$ The excluded case for Medical Hypothesis (Case focuses on a transition from being an editorial-only review journal to a peer reviewed journal.

18 Owing to space constraints, I purposefully do not delve into a related dynamic, that of constructing prestige for individual papers and individual scientists (Guédon, 2001:21; Young et al., 2008).
} 
journal that employs a reader-pay business model. A second meaning for the content of scientific exchange, an epistemic entity with scientific value, is thus relegated to lower potential value in comparison with news. Contingency, it would appear, can therefore be used to constrain scientific exchange, which in turn, constructs and can increase news value, whereas social forms such as public space peer review remove contingency and therefore construct and increase scientific value ${ }^{19}$.

Additional cases in which such news dynamics appear to be visible include cases 7,18 , and 20 . To be sure, these dynamics are tied with a relation of accountability to readers that I analyse below.

Furthermore, contingency in traditional peer review is frequently framed in function of individual author responsibility to deal with rejection by engaging in repeated submission and rejection cycles. In Case 23 for example, following a rejection at Philosophical Transactions Waterston never attempted to publish again. An editor who took it upon himself to 'right 'a' wrong only published his manuscript with new ignorance some fifty years later in 1892 . The editor in 1892 remarked that "[i]t is singular that Waterston appears to have advanced no claim for subsequent publication, whether in the Transactions of the Society, or through some other channel" (Waterston and Rayleigh, 1892:2). As is evident in this example and from the editor's comments, the onus of self-correction on repeated submission and rejection cycles tends to discount the impact of sustained rejection on academics. These include decreased creativity and productivity (Day, 2011). Ultimately, like Waterston, some scientists stop writing or altogether abandon research following rejection (or repeated rejections) at peer review (see Schibuzawa example in Latour and Woolgar, 1986:120).

For Polanyi (Case 18), it is not clear that had he not read about another researcher encountering rejection at peer review that he would have contemplated resubmission - as a young researcher he had assumed that the first rejection of his future Nobel Prize ${ }^{\circledR}$ paper at a leading journal reflected the lack of worth for his new ignorance (NSERC, 2005). Following his reading of the newspaper story, the author "... submitted the identical manuscript to the Journal of Chemical Physics, where it was promptly published" (Polanyi, 1990:243-244).

In another case, Wilson's (Case 24) manuscript was rejected by a leading discipline-specific journal, Journal of Geophysical Research, after which he submitted the manuscript to a new learned society Physics journal, the Canadian Journal of Physics, where it was published (Wilson, 1981:130; Garland, 1995:545). He was one of the first to propose new ignorance on the formation of Hawaiian type chains of islands that differed from then accepted ignorance of the 'rigid Earth-model' (Wilson, 1963:864). The author's selection of the second journal was based on his nationality (Canadian) and his sense that a Canadian-based journal would publish his work, although he acknowledged that the selection was not "...a very obvious place to send it" (Wilson, 1981:130). The selection of a second journal, though it led to publication, did not reflect the disciplinary specificity of his work or an appropriate audience for his work. It was a

\footnotetext{
${ }^{19}$ See public space peer review social form description above. Even if a manuscript is rejected, the content of exchange remains visible and accessible and thus holds (at least partial) scientific epistemic value whereas a published manuscripts confers even higher value to the full content of exchange. Rendering the full content of review visible, however, reveals the messiness of epistemic dynamics at peer review with potentially contradictory knowledge and ignorance claims and counter-claims by situated knowers.
} 
solution that placed the onus on the author to produce new ignorance.

More importantly for this paper, however, onus on individual author responsibility detracts attention from structural properties in traditional peer review that lead to dichotomous outcomes: a published or rejected paper. A dichotomous outcome fails to apprehend the scientific epistemic value of the content of the original manuscript and of the fuller content of scientific exchange at peer review (contributing to ignorance reproduction) and fails to recognize the impact on individual authors (where decreased creativity and productivity can contribute to further ignorance reproduction, related in Day, 2011). A second naturalized structural property in traditional peer review, structural secrecy, works in tandem with contingency.

\section{Ensuring structural secrecy for original submitted manuscripts and editorial judgements and decisions}

To delve into structural secrecy for original submitted manuscripts and editorial judgements and decisions in traditional peer review and to go beyond absence noted in Table 3, I start by contrasting three searches (two I performed and a third hypothetical search) and more formal document requests that I made. First, when I performed a search for published papers related with the twenty-five cases in this work, I readily located these on the Web, through my University's library subscriptions, or inter-library loan. Second, when I performed a similar search for submitted manuscripts and editorial judgements and decisions for the twenty-five cases, I located two partial editorial decisions for Cases 22 (Holme, 2012) and 25 (Yalow, 1977:449). Third, had I made a search for these documents at a journal using an open review social form, such as public space peer review, I would have accessed all the documents. Finally, when I made requests for these case-related documents from the authors, from journals, and from the Nobel Foundation (for Nobel Prize ${ }^{\circledR}$ laureates) I was able to obtain two editorial judgements (for Case 23) from the Royal Society of London Archives - for a fee.

The performed and hypothetical search results and responses to my document requests render visible the structural secrecy surrounding original manuscripts and editorial judgements and decisions at traditional peer review for all cases. Structural secrecy translates into the content of the documents not entering into scientific exchange and therefore contributing to potentially greater ignorance reproduction. As noted above, the original submitted manuscripts and editorial judgements and decisions can contain valuable new ignorance that if invisible - leads to the potential ignorance reproduction.

This data leads to several theoretical insights. The first deals with the role of author. Not only do journals enforce secrecy, but also as noted in the Methods section and as is evident in the overwhelming absence of data above, secrecy extends to authors who generally prefer not to share editorial judgement and decisions. The recursive dynamics of peer review in academia where peer review is an integral component of multiple, heterogeneous, and sometimes dialectic processes might contribute to reluctance to share editorial documents. Careers are intricately tied to peer review social forms for grants applications, paper and book publication, conference presentations, academic promotion, and prestigious prize attribution (Smith, 2006:178; Campanario, 1996:184; Biagioli, 2002:33-34) therefore authors might prefer not to jeopardize these. One example is an author I interviewed who preferred not share these documents for fear 
of embarrassing the editor who had originally rejected his manuscript. In addition, in the area of study stem cell case (Case 5), Bains (2009) drew attention to the recursive nature of peer review. Publications help build careers, that help construct funding applications, that in turn help construct further publications - all mobilizing respective forms of peer review - building largely on traditional peer review.

Moreover, the original manuscripts and editorial judgements and decisions appear to hold limited temporal value. This owes to the short archival time at journals (10 to 15 years) that responded they could not share older judgements and decisions because they no longer had them in archives. Archives at Philosophical Transactions, in contrast, hold documents to its beginning in the seventeenth century. The Philosophical Transactions exception reflects the availability of documents for precursor forms of boundary judgement - inquisition and its censorship function - for which enhanced and centralized record-keeping led to long-term storage. Documents from the Spanish Inquisition, for example, are still available to this day (Peters, 1988:93; Gaudet, 2014a:5).

The related potential for self-correction in publication whereby science can supposedly correct itself of wrong decisions - and of ignorance production - is not only curtailed by short archival periods, but also by structural secrecy that prevents the gaze from a wider community of readers. Philosophical Transactions, an exception, institutionalized relations of access through user fees for archival use (with limitations for more recent documents under access to information laws). Archival access led to the selfcorrection in the Waterston case (Case 23) rejected at Philosophical Transactions, for example, where it was only some fifty years later that the author's (no longer) new ignorance was finally published. Public space peer review, in contrast with traditional peer review, allows for self-correction with full access to the original manuscript and all editorial documents under the gaze of a wider scientific and non-scientific community. Finally, contingency and secrecy are exclusive to traditional peer review type boundary judgement social forms whereas most contemporary social forms of boundary judgement share the next property, a relation of accountability to empiricism.

3. A relation of accountability to empiricism with scientific explanation imperatives that editorial readers use to evaluate manuscripts

As elaborated in the Methods section, I could not readily account for the structural property of a relation of accountability to empiricism, therefore when I performed inductive analysis looking across cases I investigated how the relation appeared to contribute to ignorance (re)production in the cases. Case data analysis helped me reconceptualize my understanding for this relation - here I use scientific explanation imperatives as an analytical tool.

Cases in this work support that editorial readers' (editors and referees) relation of accountability to empiricism is paramount when dealing with new ignorance in manuscripts. In spite of having had access to only two editorial judgements for one case (Case 23) and two partial editorial decisions (Cases 22 and 25) and no access to all other case editorial judgements and decisions, I advance that in at least thirteen cases ${ }^{20}$ it

${ }^{20}$ Based on interview data and self- and third-party accounts. See cases 2, 3, 4, 6, 8, 9, 10, 11, 13, 14, 15, 23, 25 in Appendix A. Case 1 third-party accounts are not sufficiently explicit to ascertain this relation of accountability, but do suggest it. 
appears that editorial readers used their relation of accountability to empiricism to engage in ignorance reproduction: rejecting manuscripts or delaying paper publication.

Nonetheless, a relation of accountability to empiricism is not exclusive to traditional peer review as the relation is part of lite traditional peer review and of public space peer review, for example. Where this third property contributes to potential for greater ignorance reproduction, however, is when it is combined with contingency and secrecy in traditional peer review. If editorial readers deem that a manuscript's explanations for new ignorance do not meet this relation of accountability, new ignorance can thus remain invisible in a rejected or delayed manuscript. Therefore, engaging in rejection or delay can contribute to reproduction in traditional peer review because contingency and secrecy maintain the original manuscript and editorial judgements and decisions away from public gaze where potential ignorance in these documents thus remains inaccessible and existing ignorance is reproduced.

More specifically, it appears that to justify reproducing ignorance (cf., delaying publication or rejecting a manuscript), editorial readers invoked four scientific explanation imperatives. The imperatives constructed for the cases are: (1) testability (in twelve $\operatorname{cases}^{21}$ ), (2) ties with the past (nine cases ${ }^{22}$ ), (3) ontological economy (two $\operatorname{cases}^{23}$ ), and (4) informativeness (four cases ${ }^{24}$ ). I analyse these more closely with a typical case for each imperative. Although I investigate these individually, in the cases there were more often than not multiple and intersecting scientific explanation imperatives advanced by editorial readers.

\section{Testability}

First, testability refers to a scientific explanation surviving independent tests of its explanatory potential. This rests on notions of empirical intersubjectivity that requires empirical evidence and that it is be possible for other subjects to test and corroborate an explanation (hence, intersubjectivity). The case of Marshall and Warren (Case 15) serves as an example of testability from the twelve cases in which this scientific explanation imperative seemed at play. It would appear that in the process of peer review, editors at the journal The Lancet could find no peers that believed the findings proposed by Marshall and Warren: the presence of bacteria in the human stomach and their role in peptic ulcers (Warren, 2013; Robbins, 2012). According to Warren (2013), the Australiabased researchers had to 'construct' their own peer (2013). Marshall had met a UK-based researcher, Martin Skirrow, who replicated their findings with the help of his registrar Cliodna McNulty (Warren, 2013; Robbins, 2012). The McNulty and Watson (1984) letter published in The Lancet, Warren proposed, was most probably a 'review' for the journal because shortly after, the Marshall and Warren (1984) paper was published (Warren, 2013), and their work eventually led to a Nobel Prize. Subjects in Skirrow's laboratory had thus independently engaged in testing empirical evidence on a relation between bacteria and peptic ulcers. The independent test thus corroborated the scientific validity of Marshall and Warren's work.

${ }^{21}$ Cases 2, 3, 4, 6, 8, 9, 11, 13, 14, 15, 23, and 25.

${ }^{22}$ Cases $3,4,6,9,10,11,15,23$, and 25 .

${ }^{23}$ Cases 3 and 10 . Case 19 suggests such an imperative, but accounts do not substantiate it sufficiently.

${ }^{24}$ Cases 6, 9, 13, and 25. 
Ties with the past

Second, ties with the past means that a scientific explanation holds ties to already established knowledge and ignorance that is independent of the proposed explanation and with related research programs that have demonstrated past success in explanation. Of the nine instances purportedly documented in the cases, the case of Gell-Mann (Case 10) highlights these dynamics with self- and third-party accounts. To start, according to thirdparty Crozon (1987), referees could be described as censors given that their comments had made Gell-Mann “... defend himself vehemently, demonstrating that some of his heresies had already been present in respectable forefathers' work" (my translation, 1987:105). Gell-Mann recounted how in response to referee objections, he finally referred to a paper by Nick Kemmer making an analogous distinction to the one he was proposing in his explanation. With this new reference to the past, editorial readers finally accepted Gell-Mann's explanation (Gell-Mann, 1982:C8-400).

Analyzing from a scientific explanation imperative perspective, not a censorship perspective as proposed by Crozon, it was not sufficient for the manuscript to present new explanations, these had to be tied with established independent explanations. A boundary is created between manuscripts that are not anchored in past and independent explanations - deemed as non-scientific - and those that can anchor themselves in past independent explanations - deemed as scientific. In this case, Gell-Mann proposed an analogy with Kemmer's work - anchoring his work in a successful past explanation.

\section{Ontological economy}

Third, ontological economy means not proposing too many new entities such as supernatural entities, or unobservable entities. Of the two cases in which I observed these dynamics, is once more the case of Gell-Mann (Case 10). His 1953 manuscript on 'strange particles' that faced strong opposition by editorial readers before publication at Physical Review illustrates how this scientific explanation imperative (re)produces ignorance. A 'very sore point' according to Gell-Mann (1982) was that those in the role of editorial readers "... objected to the neutral boson being different from the neutral antiboson" (1982:C8-400). As elaborated above, Gell-Mann finally proposed an analogy with work by Nick Kemmer - after which editorial readers "...finally agreed that it was O.K. to have a neutral boson different from its anti-particle" (1982:C8-400). Furthermore, it was around the same time that accelerators were producing the first results with "...one event $[\ldots]$ compatible with strangeness" (1982:C8-400).

Proposing a new - hitherto unobservable entity - was a matter of negotiating with editorial readers in order to ensure that the manuscript proposed a scientifically acceptable explanation with minimal new entities. An imperative for ontological economy here helped differentiate between what was deemed as a scientific explanation with a well-founded new entity (cf., with reference to Nick Kemmer), or not with what editorial readers first appeared to perceive as an ill-founded new entity.

\section{$\underline{\text { Informativeness }}$}

Finally, a fourth scientific explanation imperative is being informative. 
Informativeness proposes some empirical content that will help decipher the details related with a given postulated effect. This includes specifying "...in some detail just what [a scientific explanation] does and does not predict" (Dawes, 2009:138). Of the four observed instances in the cases, Lauterbur's (2005) (Case 13) Nobel Prize ${ }^{\circledR}$ manuscript on magnetic resonance imaging (or magnetic resonance images - MRI) can serve as an example for these dynamics. Following an initial rejection at the journal Nature, in the revised re-submission the author had added "... references to cancer and other more obviously relevant topics" which he believes finally led to the publication of the paper (2005:1009). References to cancer for Lauterbur appears to have helped construct his work as informative and therefore relevant scientifically.

\section{$\underline{\text { Further theoretical insights }}$}

Theoretically, therefore, a relation of accountability to empiricism is critical because it helps deepen understanding of how and why ignorance is reproduced. Authors have frequently been alone empirically working on new ignorance and outside researchers have not yet, or have only recently, replicated the research. It is also difficult for authors to postulate the informativeness of their research as new ignorance is not yet fully constructed and scant empirical content has been constructed. This means that editorial readers' relation of accountability to empiricism cannot easily be met with limited available empirical evidence. Scientific explanations constructed by authors can therefore appear deficient in imperatives of testability, in ties with the past, in ontological economy, and in informativeness. These scientific explanation imperatives are at the heart of negotiation and compromise in peer review advanced by Jasanoff (1990:62) where "...scientists certify some claims and conventions as valid" (1990:62) or not.

The relation of accountability to empiricism structural property, however, does not contribute to (re)production in itself as I explored here. How traditional peer review reproduces ignorance in these cases is not only by the role of editorial readers holding new ignorance to account to empiricism - determining what is deemed as scientific or not - it is mostly by making the exchange of the new ignorance contingent on traditional peer review and by maintaining the original manuscript and editorial judgements and decisions secret. From a focus on scientific explanation imperatives, a final structural property that appears to contribute to ignorance reproduction focuses specifically on editors' and journal publishers' relation of accountability to readers.

\section{A relation of accountability to readers (by editors and journal publishers) and the criterion of originality}

Editors' and journal publishers' relation of accountability to readers appears to have led to ignorance reproduction in at least five cases ${ }^{25}$. I look at these dynamics in three parts: first in four cases with the editor enacting this relation, second in a case of journal publishers enacting this relation, and third in interviews I performed with individuals in the role of editor.

First, ignorance reproduction in four cases ${ }^{26}$ owed to the manuscript being

${ }_{26}^{25}$ Cases $8,16,17,18$, and 20 .

${ }^{26}$ Cases $8,17,18$, and 20. 
rejected by the role of editor even before being sent to referees. Rejection in these cases meant that the new ignorance proposed in a manuscript remained invisible therefore contributing to reproduction. Furthermore, the relation of accountability to readers appears to have been compounded by a criterion of originality. In the Mullis case of a future Nobel Prize ${ }^{\circledR}$ winning manuscript (Case 17), for example, the journal Science appears to have deemed the manuscript did not meet its criterion of originality - with a meaning of newsworthiness - and suggested the author submit it to a 'secondary journal' (Mullis, 2000:105-106). A relation of accountability to readers combined with a criterion of originality can thus create a boundary between manuscripts considered as newsworthy, or not. The content of exchange therefore holds or does not hold news value.

Second, in the fifth case ${ }^{27}$, what appears to have been (at least partly) a relation of accountability to readers resulted in the journal Medical Hypotheses reverting to journal peer review from its previous editorial-only form of review. The relation in this case was with AIDS scientists and activists who criticized and protested a controversial paper published at Medical Hypotheses. The scientists and activists framed the controversial paper within a wider trend of AIDS denialism (Enserink, 2010; Steinhauser et al., 2012:367). The relation of accountability also appears to have contributed to the dismissal of Bruce Charlton, then in the role of editor at the journal, who refused to change the social form of review from editorial-only to peer review (Enserink, 2010). For Charlton, it appeared imperative to allow for greater ignorance production - as had been advocated by David Horrobin, the journal founder (Horrobin, 2004:4). Journal peer review, Horrobin had argued, led mostly to ignorance reproduction (related in Horrobin, 2004:4). Moreover, the shaping of traditional peer review as paradigmatic in this case and providing a meaning of 'scientific' to the content of review is one that further shapes scientific knowledge as absolute and therefore reliable in comparison with editor-only review.

Finally, five of the seven editors I interviewed specifically brought attention to the accountability relation they hold to readers when they construct editorial decisions. Most of the journals they edited included a print edition with limited space, thus requiring selectivity for papers. At the journal Nature, for example, even if professional editors no longer perform science in practice, they attend conferences, visit laboratories, and engage in conversation with scientists in the field (Kiermer, 2013). Nature editor Véronique Kiermer (2013) advanced that this helps professional editors understand the 'big questions' in areas of research and the types of new ignorance that the journal audience is likely to want to read - that which would capture their interest (2013).

Selectivity further constructs the content of scientific exchange as valuable for readers and authors - where selectivity helps construct news and epistemic value (and related prestige, not discussed in-depth here). In the case of manuscript rejections for future Nobel Prize ${ }^{\circledR}$ winning and for other future valuable new ignorance in Appendix A, however, news value might have conflicted with purported epistemic value - leading to at least temporary ignorance reproduction instead of production.

In contrast, new Web-based social forms such as public space peer review mostly enable short- and long-term epistemic valuation with minimal selectivity and maximal ignorance production. Even rejected manuscript content can eventually be valued, as it

${ }^{27}$ Case 16. 
remains visible and accessible. I conclude with implications from this science in practice research set against Kuhn's theory of paradigms. I also look to implications for authors, policymakers, editors, and journal publishers.

\section{G - Conclusion}

Based on twenty-five cases of purported ignorance (re)production in traditional peer review, in this paper I explored how traditional peer review (re)produces ignorance. Drawing on analysis of case empirical data, first- and third-party accounts, and interview data, I advance that the social form of traditional peer review appears to mostly contribute to ignorance reproduction through four structural properties: (1) contingency traditional peer review places on scientific exchange; (2) secrecy for original manuscripts and editorial judgements and decisions; (3) a relation of accountability to empiricism for editorial readers that helps construct a boundary for manuscripts, deemed as scientific or not; and, (4) a relation of accountability to readers enhanced by a criterion of originality that appears to construct another boundary for manuscripts, deemed as newsworthy or not. These dynamics were set in contrast with public space peer review that, in comparison, appeared more likely to contribute to increased ignorance production.

Furthermore, in the boundary judgement social form of traditional peer review the boundaries of what is deemed as scientific, or not, appear mostly to operate through the relation of accountability to empiricism for editorial readers. The three other properties listed above do not appear to substantively contribute to the determination of the content being deemed 'scientific' or not. Moreover, the relation of accountability to readers working in tandem with a criterion of originality seemingly constructs a second potentially conflicting boundary: the manuscript content as newsworthy, or not.

The type of research approach used here, focused on science in practice, can help nuance theoretical contexts such as Kuhn's (1996) theory of paradigms. In Kuhn's (1996) theory of paradigms, science is classified as 'normal' with puzzle-solving research that is purportedly cumulative (1996:96) or 'revolutionary' with radical changes in worldviews and ways of understanding (1996:111). Paradigms according to Kuhn (1996) are "...universally recognized scientific achievements that for a time provide model problems and solutions to a community of practitioners" (1996:x).

Looking more closely at Kuhn's (1996) theory, it is anchored in knowledge and he refers to the "stubbornness of the anomaly" and "the paradigm that discloses anomaly and the one that later renders the anomaly law-like" (1996:97) where 'unanticipated novelty' and 'discovery' are anomaly. Yet, can 'discovery' be constructed as anomaly in science? Rather, knowledge practices in science as culture promote ignorance economies as I explored in this paper. Ignorance can be understood as dynamically and symbiotically related with knowledge in science in practice.

The research approach in the paper, investigating science in practice, moves the focus to social forms and the relations in which scientists and journal actors engage for knowledge and ignorance production practices. How editorial readers help construct what is deemed scientific, or not, appears to hinge in large part on a relation of accountability to empiricism and four scientific explanation imperatives explored here. These are: (1) testability, (2) ties with the past, (3) ontological economy, and (4) informativeness.

Conceptualizing negotiations between roles in journal peer review - authors and 
editorial readers - holds at least two implications. A first is that although these take place within an overarching knowledge system, science, they are situated practices in roles. Editorial readers' accountability to empiricism and editors' and journal owner/publishers' relation of accountability to readers highlight the situatedness of referee and editor judgements and decisions. In addition, in traditional peer review, secrecy prevents the gaze from a wider scientific readership of science as overarching system. A second implication is that that the investigation of ignorance (re)production in peer review cannot easily be placed within a wider scholarship of 'resistance to new scientific ideas by scientists themselves'. It cannot because as explored in this work, judgements and decisions do not hinge on individual resistance, rather these can be understood to operate through multiple and potentially conflicting relations of accountability in roles.

Moreover, absence of data can serve as data in itself to understand contingency and secrecy of editorial documents, but also tempers the fine-grained theoretical insights that can be drawn from scientific explanation imperatives. That is because self- and thirdparty accounts are themselves constructions permeated with social scientific concepts (i.e., Kuhn's paradigms) and self-analysis. Access to original submitted manuscripts and editorial judgements and decisions could help further nuance understanding into how new ignorance is evaluated and constructed in journal peer review.

Furthermore, for individuals engaged in the role of author, an implication of this work is that it can help authors select social forms in function of potential ignorance (re)production. To engage in the role of author in a social form such as public space peer review can lead to potentially higher ignorance production in the short- and long-term. In contrast, engaging in a social form such as traditional peer review can contribute to potentially higher ignorance reproduction, but potentially higher newsworthiness given selectivity (related with prestige and recursive relations with other types of peer review, not discussed in-depth in this paper).

For policymakers and funding agencies there are at least two implications. First, this work can help maximize return on research investments. By supporting author submissions to journals that maximize ignorance production, policymakers and funding agencies ensure that public funds not only lead to knowledge mobilization but also contribute to continued ignorance mobilization (Gaudet, 2013) at the heart of scientific epistemic practices (see funding bodies Howard Hughes Medical Institute, the Max Planck Society, and the Wellcome Trust that helped launch eLife, a variant of public space peer review, eLife, 2013). Second, this work helps policymakers and funding agencies conceive journal peer review as a scientific object of study - away from its conception as common experience process. This work proposes such a scientific study of journal peer review based on a social form approach.

Finally, for editors and for journal owners/publishers, an implication of this work is in how journal peer review and especially the relation of accountability to empiricism can be investigated. I performed analysis drawing largely on first- and third-party accounts because of structural barriers for original manuscripts and editorial documents. Journal editors and owners/publishers who manage access for these documents could help further empirical research in this area. Anthropological or sociological transdisciplinary collaboration with journals that practice traditional peer review could help reach this goal and contribute to empirical understanding for ignorance (re)production in journal peer review. 
Acknowledgements I thank my doctoral supervisor for comments on previous drafts. I thank interviewees: Nobel Prize ${ }^{\circledR}$ Laureates Thomas Cech, Dan Shechtman, and John Robin Warren, Editor Véronique Kiermer at the New York office of the Nature Publishing Group, Editor William Bains at Hypotheses in the Life Sciences journal, Richard Smith, former editor at the $B M J$, and those who wished to remain anonymous. Finally, I thank the individuals with whom I communicated at journals. Please note that the ideas, arguments, and remaining errors in this work are solely mine however, and do not necessarily reflect the views of individuals and organizations above. Research was supported in part by a Joseph-Armand Bombardier Canada Graduate Scholarship from the Social Sciences and Humanities Research Council of Canada.

\section{References}

Aarssen , L.W. 2012. "Are peer-review filters optimal for the progress of science in ecology and evolution?" Ideas in Ecology and Evolution 5:9-12.

Altman, L.K. 1996. "The Ingelfinger rule, embargoes, and journal peer review-part 1." The Lancet 347:1382-1386.

—. 1999, "Rockefeller U. Biologist Wins Nobel Prize for Protein Cell Research" The New York Times A29. (http://www.nytimes.com/1999/10/12/nyregion/rockefeller-u-biologist-winsnobel-prize-for-protein-cell-research.html?pagewanted=all\&src=pm).

Anderson, D. and P. Walter. 1999. "Blobel's Nobel: A Vision Validated." Cell 99:557558.

Anonymous. 2008a, "National Metrology Institute of Japan Report: Development of International Human Resources (August, 2008)", Retrieved January 4, 2014 (https://www.nmij.jp/ imco/cgi-bin/event en/index.cgi?id=1226647848).

—. 2008b. "Pfizer fails to gain access to peer-review files." Nature 452:677.

—. 2013. "Telephone Interview with Joanne Gaudet June 20, 2013." University of Ottawa.

Anonymous Referee 1. 1846. "Referee Judgement." The Royal Society.

Anonymous Referee 2. 1846. 'Referee Judgement.' The Royal Society.

Aronson, N. 1986. "The Discovery of Resistance Historical Accounts and Scientific Careers." Isis 77:630-646.

Bains, W. 2009. "Leadership and innovation. How consensus management blocks genuine innovation." Bioscience Hypotheses 2:277-281.

—. 2013. "Telephone Interview with Joanne Gaudet June 26, 2013.” University of Ottawa.

Barber, B. 1961. "Resistance by Scientists to Scientific Discovery: This source of resistance has yet to be given the scrutiny accorded religious and ideological sources." Science 134:596-602.

Bardeen, J. 1990. "Theory of size effects in depinning of charge-density waves." Physical Review Letters 64:2297-2299. http://dx.doi.org/10.1103\%2FPhysRevLett.64.2297.

Bass, B.L. and T.R. Cech. 1984. "Specific interaction between the self-splicing RNA of Tetrahymena and its Guanosine substrate-Implications for biological catalysis by RNA." Nature 308:820-826.

Berson, S.A., R.S. Yalow, A. Bauman, M.A. Rothschild, and K. Newerly. 1956. "Insulin- 
I131 metabolism in human subjects: Demonstration of insulin binding globulin in the circulation of insulin treated subjects." Journal of Clinical Investigation 35:170-190.

Biagioli, M. 2002. "From Book Censorship to Academic Peer Review." Emergences: Journal for the Study of Media \& Composite Cultures 12:11-45.

BioMed Central. 2013, "What is 'open peer review', as operated by the medical journals in the BMC series?", Retrieved 2 September, 2013

(http://www.biomedcentral.com/authors/authorfaq/medical).

Blobel, G. 1999. "Nobel Lecture: Protein Targeting.” Pp. 244-287. http://www.nobelprize.org: Nobel Foundation.

Blumberg, B.S. 1977. "Australia Antigen and the Biology of Hepatitis B." Science 197:17-25.

—. 1983. "This Week's Citation Classic." Current Contents 28:159.

- 2003. The hunt for a killer virus: Hepatitis B. Princeton: Princeton University Press.

Bornmann,L., M. Ruediger, and D. Hans-Dieter. 2010. “A Reliability-Generalization Study of Journal Peer Reviews: A Multilevel Meta-Analysis of Interp-Rater Reliability and Its Determinants." PLoS ONE 5:e14331.

Bourdieu, P., J.-C. Passeron, and J.-C. Chamboredon. 1968. Le métier de sociologue: Livre I. Paris: École Pratique des Hautes Études, Mouton and Bordas.

Boyer, P.D. 1997. "Nobel Lecture: Energy, Life, and ATP.” Pp. 120-141. http://www.nobelprize.org: Nobel Foundation.

Brannigan, A. 1981. The social basis of scientific discoveries. Cambridge MA: Cambridge University Press.

Buchanan, M. 1996. "Physics award acclaims superfluid helium." Nature 383.

Campanario, J.M. 1995. "On influential books and journal articles initially rejected because of negative referees' evaluation." Science Communication 16:304-325.

—. 1998. "Peer Review for Journals as It Stands Today-Part 1." Science Communication 19:181-211.

—. 2003. "Working Paper: Rejecting Nobel class articles and resisting Nobel class discoveries.” Pp. 1-16.

—. 2009. "Rejecting and resisting Nobel class discoveries: accounts by Nobel Laureates." Scientometrics 81:549-565.

Campanario, J.M. and E. Acedo. 2007. "Rejecting Highly Cited Papers: The Views of Scientists Who Encounter Resistance to Their Discoveries From Other Scientists." Journal of the American Society for Information Science and Technology 58:734-743.

Cassella, M. and L. Calvi. 2010. "New journal models and publishing perspectives in the evolving digital environment." International Federation of Library Associations and Institutions 36:7-15.

Caulfield, T. and S. DeBow. 2005. "A systematic review of how homeopathy is represented in conventional and CAM peer reviewed journals." $B M C$ Complementary and Alternative Medicine 5. doi:10.1186/1472-6882-5-12.

Cech, T.R. 1989. "Nobel Lecture: Self-splicing and enzymatic activity of an intervening sequence RNA from Tetrahymena.” Pp. 651-674. http://www.nobelprize.org: Nobel Foundation.

—. 2013. "Telephone Interview with Joanne Gaudet June 19, 2013.” University of 
Ottawa.

Charlton, B.G. 2004. "Why Medical Hypotheses does not publish from the field of Alternative healing." Medical Hypotheses 63:557-559.

Chemical Sciences Roundtable National Research Council. 2005. Are Chemical Journals Too Expensive and Inaccessible?: A Workshop Summary to the Chemical Sciences Roundtable, Edited by N. D. Heindel, T. M. Masciangioli, and E. V. Schaper. Washington DC: The National Academies Press.

Compton-Lilly, C. 2013. "Case Studies.” Pp. 54-65 in Reviewing Qualitative Research in the Social Sciences, edited by A. A. Trainor and E. Graue. New York: Routledge.

Couzin-Frankel, J. 2013. "Secretive and Subjective, Peer Review Proves Resistant to Study." Science News 341:1331.

Creager, A.N.H. 2013. Life Atomic: A History of Radioisotopes in Science and Medicine. Chicago: The University of Chicago Press.

Cressey, D. 2010. "Editor says no to peer review for controversial journal." Nature News March 18.

Creswell, John W. 2013. Qualitative Inquiry \& Research Design: Choosing Among Five Approaches. Los Angeles: SAGE.

Crozon, M. 1987. La matière première: la recherche des particules fondamentales et de leurs interactions. Paris: Éditions du Seuil.

Davey Smith, G. 2005. "The biopsychosocial approach: a note of caution." Pp. 77-102 in Biopsychosocial Medicine: an Integrated approach to understanding illness, edited by P. White. Oxford: Oxford University Press.

Dawes, G.W. 2009. Theism and Explanation. New York: Routledge.

Day, N.E. 2011. "The Silent Majority: Manuscript Rejection and Its Impact on Scholars." Academy of Management Learning and Education. 10:704-718.

Dick, J.E. 2003. "Breast cancer stem cells revealed." Proceedings of the National Academy of Sciences 100:3547-3549.

Donati, P. 2011. Relational Sociology: A new paradigm for the social sciences. New York: Routledge.

Dreisbach, C. 2010. "Epistemic Conservatism in Peer Review: A Burkean Defense." presented at 2nd International Symposium on Peer Reviewing: ISPR 2010 in the context of the 4th International Conference on Kowledge Generation, Communication and Management: KGCM 2010. Orlando FL, USA.

Duesberg, P.H., D. Mandrioli, A. McCormack, J.M. Nicholson, D. Rasnick, C. Fiala, C. Koehnlein, H.H. Bauer, and M. Ruggiero. 2011. "AIDS since 1984: No evidence for a new, viral epidemic - not even in Africa." Italian Journal of Anatomy and Embryology 116:73-92.

Editorial Staff. 2007. "Paul Lauterbur: Paul Lauterbur, father of MRI, died on March 27th, aged 77." Accessed November 2, 2013. http://www.economist.com/node/8954439/print.

eLife. 2013, "Review Process eLife", Retrieved 5 August, 2013 (http://www.elifesciences.org/the-journal/review-process/).

Enserink, M. 2010, “Elsevier to Editor: Change Controversial Journal or Resign” Science Insider, Retrieved December 2, 2012 (http://news.sciencemag.org/scienceinsider/2010/03/elsevier-to-editor-changecontro.html). 
Ernst, R.R. 1983. "This Week's Citation Classic.” Current Contents 27:24.

—. 1991. "Biographical." http://www.nobelprize.org: Nobel Foundation.

Ernst, R.R. and W.A. Anderson. 1966. "Application of Fourier transform spectroscopy to magnetic resonance." Review of Scientific Instruments 37:93-102.

Fang, H. 2014. "An Explanation of Resisted Discoveries Based on Construal-Level Theory." Science and Engineering Ethics:1-10. 10.1007/s11948-013-9512-x.

Feigenbaum, M.J. 1995. "Computer-Generated Physics.” Pp. 1823-1854 in Twentieth Century Physics: Volume III, edited by L. M. Brown, A. Pais, N. Bohr, and S. B. Pippard. Bristol, Philadelphia and New York: Institute of Physics Publishing and American Institute of Physics Press.

Firestein, S. 2012. Ignorance: How it Drives Science. New York: Oxford University Press.

Flyvbjerg, B. 2001. Making Social Science Matter: Why social inquiry fails and how it can succeed again. Cambridge: Cambridge University Press.

—. 2006. "Five Misunderstandings About Case-Study Research." Qualitative Inquiry 12:219-245.

Friedman, J.H. 2012. "Rejections." Medicine \& Health Rhode Island 95:134.

Furchgott, R.F. 1993. "The Discovery of Endothelium-Dependent Relaxation." Circulation 87:V3-V8.

Furchgott, R.F. and J.V. Zawadzki. 1980. "The obligatory role of endothelial cells in the relaxation of arterial smooth muscle by acetylcholine." Nature 288:373-376.

Gale, E.A.M. 2001. "The Discovery of Type 1 Diabetes.” Diabetes 50:217-226.

—. 2011. "Viruses and type 1 diabetes: ignorance acquires a better vocabulary." Clinical and Experimental Immunology 168:1-4.

Gallagher, J.S. 2013. "Editorial.” The Astronomical Journal 146:1.

Garland, G.D. 1995. "John Tuzo Wilson. 24 October 1908-15 April 1993.” Biographical Memoirs of Fellows of the Royal Society 41:535-552.

Gaudet, J. 2013. "It takes two to tango: knowledge mobilization and ignorance mobilization in science research." Prometheus: Critical Studies in Innovation 31:1-19.

—. 2014a. "Investigating journal peer review as scientific object of study". uO Research. 1-11. http://hdl.handle.net/10393/31161

- 2014b. "Absence and Presence in Science: Critical Reply to the Special Issue on Absences". Social Epistemology Review and Reply Collective. 3:4. 16-23. http://wp.me/p1Bfg0-1nm

Gell-Mann, M. 1953. 'Isotopic spin and new unstable particles.' Physical Review 92:833834.

—. 1982. "Strangeness." Journal de Physique-Colloque C8-Supplement to \#12 43:c8395-c8-408.

Gleick, J. 1988. Chaos: Making a New Science. New York: Penguin Books.

Godlee, F. 2002. "Making Reviewers Visible: Openness, Accountability, and Credit." Journal of the American Medical Association 287:27-62-2765.

Gross, M. 2007. "The Unknown in Process: Dynamic Connections of Ignorance, NonKnowledge and Related Concepts." Current Sociology 55:742-759.

—. 2010. Ignorance and Surprise: Science, Society and Ecological Design. Cambridge: The MIT Press.

Guédon, J.-C. 2001. "In Oldenburg’s Long Shadow: Librarians, Research Scientists, 
Publishers, and the Control of Scientific Publishing.” Pp. 1-69. Washington, D.C.: Association of Research Libraries.

Hames, I. 2007. Peer Review and Manuscript Management in Scientific Journals:

Guidelines and Good Practice. Malden MA: Blackwell Publishing.

Hess, D. 2010. "Social Movements, Publics, and Scientists." Invited Plenary Lecture, Japanese Society for Science and Technology Studies, Tokyo.

Hettyey, A., M. Griggio, M. Mann, S. Raveh, F.C. Schaedelin, K.E. Thonhauser, M.

Thoß, W.F.D. van Dongen, J. White, S.M. Zala, and D.J. Penn. 2012. "Peerage of

Science: will it work?" Trends in Ecology and Evolution 27:189-190.

Hirschauer, S. 2010. "Editorial Judgments: A Praxeology of 'Voting' in Peer Review." Social Studies of Science 40:71-103.

Hoddeson, L. and V. Daitch. 2002. True Genius: The life and science of John Bardeen. Washington, D.C.: Joseph Henry Press.

Hoffman, P.F. 2014. "Tuzo Wilson and the acceptance of pre-Mesozoic continental drift." Canadian Journal of Earth Science 51:197-207.

Holme, P. 2012, "K. von Klitzing on how his Nobel Prize discovery of Quantum Hall effect was 1st rejected", Retrieved December 3, 2013, 2013 (pic.twitter.com/uC4EBTLS).

-. 1990. 'The Philosophical Basis of Peer Review and the Suppression of Innovation." Journal of the American Medical Association 263:1438-1441.

—. 2004. "Ideas in biomedical science: reasons for the foundation of Medical Hypotheses." Medical Hypotheses 62:3-4.

House of Commons Science and Technology Committee. 2011. "Peer review in scientific publications." vol. I: Ordered by the House of Commons.

Ioannidis, J.P. 2005. "Why Most Published Research Findings Are False." PLoS Medicine. 2:e124.

Ivainer, T. and R. Lenglet. 1996. Les ignorances des savants. Paris: Maisonneuve \& Larose.

Jasanoff, S. 1990. The Fifth Branch: Science Advisers as Policymakers. Cambridge MA: Harvard University Press.

Jha, A. 2013, “Dan Shechtman: 'Linus Pauling said I was talking nonsense': The Israeli Nobel laureate discusses the discovery that caused a furore among fellow scientists" The Guardian. January 6, 2013, Retrieved January 14, 2014 (http://www.theguardian.com/science/2013/jan/06/dan-shechtman-nobel-prizechemistry-interview).

Kiermer, V. 2013. “Telephone Interview with Joanne Gaudet July 25, 2013.” University of Ottawa.

Koonin, E.V., L.F. Landweber, and D.J. Lipman. 2013. "Biology direct: celebrating 7 years of open, published peer review.' Biology Direct 8:1-2.

Kroemer, H. 1963. "A proposed class of heterojunction injection lasers." Proceedings of the IEEE 51:1782-1783.

—. 2000. "Nobel Lecture: Quasi-electric fields and band offsets: Teaching electrons new tricks.” Pp. 244-287. http://www.nobelprize.org: Nobel Foundation.

—. 2013. "The Double-Heterostructure Concept: How It Got Started." Proceedings of the IEEE 101:2183-2187.

Kvale, S. and S. Brinkmann. 2009. InterViews: Learning the Craft of Qualitative 
Research Interviewing. Los Angeles: Sage.

Lapidot, T., C. Sirard, J. Vormoor, B. Murdoch, T. Hoang, J. Caceres-Cortes, M. Minden, B. Paterson, M. Caligiuri, and J.E. Dick. 1994. "A cell initiating human acute leukaemia after transplantation into SCID mice." Nature 367:645-648.

Latour, B. and S. Woolgar. 1986. Laboratory Life: The Construction of Scientific Facts. Princeton: Princeton University Press.

Lauterbur, P.C. 1973. "Image formation by induced local interactions: Examples employing Nuclear Magnetic Resonance." Nature 242:190-191.

—. 2005. "Nobel Lecture: All Science Is Interdisciplinary-From Magnetic Moments to Molecules to Men." Angew. Chem. Int. Ed. (with permission from the Nobel Foundation) 44:1004-1011.

Lee, D.M. 1997. "Nobel Lecture: The extraordinary phases of liquid 3He." Reviews of Modern Physics with permission from the Nobel Foundation 69:645-665.

Levine, D.N. (Ed.). 1971. Georg Simmel: On Individuality and Social Forms, Selected Writings. Chicago: The University of Chicago Press.

Lips, H.M. 1991. Women, Men, and Power. Toronto: Mayfield Publishing Company.

Lipworth, W.L., I.H. Kerridge, S.M. Carter, and M. Little. 2011. "Journal peer review in context: A qualitative study of the social and subjective dimensions of manuscript review in biomedical publishing." Social Science \& Medicine 72:1056-1063.

Mahoney, M.J. 1977. "Publication Prejudices: An Experimental Study of Confirmatory Bias in the Peer Review System." Cognitive Therapy and Research 1:161-175.

Mandavilli, A. 2011. "Trial by Twitter: Blogs and tweets are rupping papers apart within days of publication, leaving researchers unsure how to react." Nature News 469:286-287.

Marshall, B. 1983. "Unidentified Curved Bacilli on Gastric Epithelium in Active Chronic Gastritis." The Lancet June 4:1273-1275.

Marshall, B. and R. Warren. 1984. "Unidentified curved bacilli in the stomach of patients with gastritis and peptic ulceration." The Lancet 16:1311-1315.

Marshall, B.J. 2005. “Autobiography.' http://www.nobelprize.org: The Nobel Foundation.

Maxwell, J.A. 2005. Qualitative Research Design, Vol. 41, Edited by L. Bickman and D. Rog. Thousand Oaks: SAGE Publications.

Mulkay, M. and G.N. Gilbert. 1982. "Accounting for error: How scientists construct their social world when they account for correct and incorrect belief." Sociology $16: 165-183$.

Mullis, K.B. 2000. Dancing Naked in the Mind Field. New York: Vintage Books.

Mullis, K.B. and F.A. Faloona. 1987. "Specific synthesis of DNA in vitro via a polymerase-catalyzed chain reaction." Methods in Enzymology 155:335-350.

Nobelprize.org. 2003, "The Nobel Prize in Physiology or Medicine 2003 - Perspectives". Retrieved 17 November, 2012

(http://www.nobelprize.org/nobel_prizes/medicine/laureates/2003/perspectives.ht ml). http://www.nobelprize.org: The Nobel Foundation.

NSERC. 2005. "Interview with Dr. Polanyi." Ottawa. Accessed December 3, 2013. http://www.nserc-crsng.gc.ca/Prizes-Prix/Polanyi-Polanyi/InterviewInterview eng.asp: National Sciences and Engineering Research Council of Canada (NSERC). 
Olney, W. 2000. "Nobel Men.” Pp. 1-7. http://magazine.ucla.edu/year2000/spring00_02_2.html: UCLA Magazine: The Regents of the University of California.

Osheroff, D.D. 1996. "Nobel Lecture: Superfluidity in 3He: Discovery and Understanding.” Pp. 58-83. http://www.nobelprize.org: Nobel Foundation.

Pascale, C.-M. 2011. Cartographies of Knowledge: Exploring Qualitative Epistemologies. Los Angeles: SAGE.

Peters, E. 1988. Inquisition. New York: The Free Press.

Piché, J. 2012. "The prison idea (un)interrupted: Penal infrastructure expansion, research and action in Canada". Doctoral thesis in Sociology. Carleton University.

Pines, D. 2009. "John Bardeen: Biographical Memoirs." Proceedings of the American Philosophical Society 153:288-321.

PLoS ONE. 2013, “Journals”, Retrieved 25 June, 2013 (http://www.plos.org/publications/journals/).

Polanyi, J.C. 1961. "Proposal for an infrared maser dependent on vibrational excitation." Journal of Chemical Physics 34:347-348.

—. 1990. "John Charles Polanyi: Killam Laureate 1988." in In Celebration of Canadian Scientists: A Decade of Killam Laureates, edited by G. A. Kenney-Wallace, M. G. MacLeod, and R. G. Stanton. Ottawa: The Killam Program of the Canada Council.

—. 2013, "Profile: Killam Biography", Retrieved December 3, 2013 (http://www.utoronto.ca/jpolanyi/profile/profile2.html).

Polich, G., C. Dole, and T.J. Kaptchuk. 2010. "The need to act a little more 'scientific': biomedical researchers investigating complementary and alternative medicine." Sociology of Health \& Illness 32:106-122.

Pöschl, U. 2010. "Interactive open access publishing and public peer review: The effectiveness of transparency and self-regulation in scientific quality assurance." International Federation of Library Associations and Institutions 36:40-46.

—. 2012. "Multi-stage open peer review: scientific evaluation integrating the strengths of traditional peer review with the virtues of transparency and self-regulation."

Frontiers in Computational Neuroscience 6:1-16. 10.3389/fncom.2012.00033.

Pritchard, J.C. 2010. "Animal traction and transport in the 21 st century: Getting the priorities right." The Veterinary Journal 186:271-274.

Prusiner, S.B. 1982. "Novel Proteinaceous Infectious Particles Cause Scrapie." Science, New Series 216:136-144.

—. 1995. "The Prion Diseases." Scientific American 272:30-37.

—. 1998a. "Autobiography." http://www.nobelprize.org: Nobel Foundation.

—. 1998b. "Prions." Proceedings of the National Academy of Sciences 95:13363-13383.

Pulverer, B. 2010. "Transparency showcases strength of peer review." Nature 468:29-31.

Ragin, C.C. 1992. " "Casing" and the process of social inquiry." Pp. 217-226 in What is a case? Exploring the foundations of social inquiry, edited by C. C. Ragin and H. Becker. Cambridge: Cambridge University Press.

Rappert, B. and W.K. Bauchspies. 2014. "Introducing Absence." Social Epistemology: A Journal of Knowledge, Culture and Policy 28:1-3.

Redner, H. 1987. "Pathologies of science." Social Epistemology: A Journal of Knowledge, Culture and Policy 1:215-247. DOI: 10.1080/02691728708578438. 
Robbins, R. 2012. "Profiles of medical courage: the courage to experiment and Barry Marshall." Southwest Journal of Pulmonary and Critical Care 5. Accessed December 21, 2013. http://www.swjpcc.com/general-medicine/tag/robinwarren:12-19.

Roberts, J. and J. Armitage. 2008. "The Ignorance Economy." Prometheus 26:335-354. Sample, I. 2013, "Nobel winner declares boycott of top science journals: Randy Schekman says his lab will no longer send papers to Nature, Cell and Science as they distort scientific process" The Guardian. December 9, 2013.

Seppänen, J.-T., M. Mönkkönen, and J.S. Kotiaho. 2012. "Peer review by the Peers, for the Peers: response to Hettyey et al." Trends in Ecology and Evolution 27:191192.

Shatz, D. 2004. Peer Review: a Critical Inquiry. New York: Rowman \& Littlefield Publishers.

Shechtman, D. 2013. "Telephone Interview with Joanne Gaudet July 15, 2013.” University of Ottawa.

Shechtman, D. and I.A. Blech. 1985. "The Microstructure of Rapidly Solidified AI6Mn." Metallurgical Transactions A 16A:1005-1012.

Shechtman, D., I.A. Blech, D. Gratias, and J.W. Cahn. 1984. "Metallic Phase with LongRange Orientational Order and No Translational Symmetry." Physical Review Letters 53:1951-1954.

Simmel, G. 1906. "The Sociology of Secrecy and of Secret Societies.” American Journal of Sociology 11:441-498.

—. [1971]1907. "Exchange.” Pp. 43-69 in Georg Simmel: On Individuality and Social Forms, edited by D. N. Levine. Chicago: The University of Chicago Press.

Smith, R. 2004. "Milton and Galileo would back BMJ on free speech: Arguments, crazy ideas and open communication are the lifeblood of science." Nature Correspondence 427:287.

-. 2005. "Medical Journals Are an Extension of the Marketing Arm of Pharmaceutical Companies." PloS Medicine 2:e138. DOI:10.1371/journal.pmed.0020138.g001.

- 2006. "Peer review: a flawed process at the heart of science and journals." Journal of the Royal Society of Medicine 99:178-182.

—. 2010. "Classical peer review: an empty gun." Breast Cancer Research 12(Suppl. 4):1-4.

—. 2011. The Trouble with Medical Journals. London: The Royal Society of Medicine Press Limited.

Smithson, M. 1985. "Toward a Social Theory of Ignorance." Journal of The Theory of Social Behaviour 15:151-172.

Stake, R.E. 1995. The Art of Case Study. Thousand Oaks: SAGE Publications.

—. 2006. Multiple Case Study Analysis. New York: Guilford Press.

Steinhauser, G., W. Adlassnig, J.A. Risch, S. Anderlini, P. Arguriou, A.Z. Armendariz, W. Bains, and C. Baker. 2012. "Peer review versus editorial review and their role in innovation science." Theoretical Medical Bioethics 33:359-376.

Stengers, I. 1998. “Qu'est-ce que la science a décidé de ne pas savoir?” Pp. 278-286 in Aux frontières de la science: Dictionnaire de l'ignorance, edited by M. Cazenave. Paris: Hachette Littératures.

Stöhra, J., J.C. Wattsa, Z.L. Mensingera, A. Oehlerc, S.K. Grilloa, S.J. DeArmonda, S.B. 
Prusiner, and K. Giles. 2012. "Purified and synthetic Alzheimer's amyloid beta (A $\beta$ ) prions." Proceedings of the National Academy of Sciences 109:11025-11030.

Strutt, R.J. 1968. Life of John William Strutt, Thurd Baron Rayleigh. Second Edition. Madison: The University of Misconsin Press.

van Rooyen, S., F. Godlee, S. Evans, and R. Smith. 1998. "Effect of Blinding and Unmasking on the Quality of Peer Review: A Randomized Trial." Journal of the American Medical Association 280:234-237.

von Klitzing, K. 1985. "Nobel Lecture: The Quantized Hall Effect.” Pp. 316-346. http://www.nobelprize.org: Nobel Foundation.

von Klitzing, K., G. Dorda, and M. Pepper. 1980. "New Method for High Accuracy Determination of the Fine Structure Constant Based on Quantized Hall Resistance." Physical Review Letters 45:494-497.

Warren, J.R. 1983. "Unidentified Curved Bacilli on Gastric Epithelium in Active Chronic Gastritis." The Lancet June 4:1273.

—. 2013. "Telephone Interview with Joanne Gaudet July 24, 2013.” University of Ottawa.

Waterston, J.J. 1846. "Letter to the Secretary of the Royal Society." Pp. 1-2. London.

Waterston, J.J. and L. Rayleigh. 1892. "On the Physics of Media that are Composed of Free and Perfectly Elastic Molecules in a State of Motion." Philosophical Transactions 183:1-87.

Wehling, P. 2006. "The Situated Materiality of Scientific Practices: Postconstructivism a New Theoretical Perspective in Science Studies?” Science, Technology \& Innovation Studies Special Issue 1:81-100.

Weller, A.C. 2000. "Editorial Peer Review for Electronic Journals: Current Issues and Emerging Models." Journal of the American Society for Information Science 51:328-1333.

Whitfield, J. 2012. "Elsevier boycott gathers pace: Rebel academics ponder how to break free of commercial publishers." Nature News. February 9, 2012. Accessed Oct. 25, 2012. http://www.nature.com/news/elsevier-boycott-gathers-pace-1.10010.

Wilson, J.T. 1963. "A Possible Origin of the Hawaiian Islands.” Canadian Journal of Physics 41:863-870.

—. 1981. "Geophysics." in The Joys of Research, edited by W. J. Shropshire. Washington D.C.: Smithsonian Institution Press.

Yalow, R.S. 1977. "Nobel Lecture: Radioimmunoassay: A Probe for Fine Structure of Biologic Systems." Pp. 244-287. http://www.nobelprize.org: Nobel Foundation.

Yin, R.K. 2009. Case Study Research: Design and Methods, Edited by L. Bickman and D. Rog. Los Angeles: SAGE Publications.

Young, N.S., J.P.A. Ioannidis, and O. Al-Ubaydli. 2008. "Why Current Publication Practices May Distort Science.” PLoS Med 5:e201.

doi:10.1371/journal.pmed.0050201

$<$ http://www.plosmedicine.org/article/info:doi/10.1371/journal.pmed.0050201>.

Zoe, C. 2012, "Paper denying HIV-AIDS link secures publication: Work by infamous AIDS contrarian passes peer review" Nature News \& Comment, Retrieved January 7, 2014 (http://www.nature.com/news/paper-denying-hiv-aids-linksecures-publication-1.9737).

Zuckerman, H. 1972. “Interviewing an Ultra-Elite.” Public Opinion Quarterly 36:159-175. 
Appendix A: Descriptions and Case-Specific Synopsis of Analysis for Twenty-Five Cases of Purported Ignorance (Re)production in Traditional Peer Review

In this Appendix, I construct descriptions for twenty-five cases of purported ignorance (re)production in traditional peer review. For each, I also provide a synopsis of analysis that I analyse at an aggregate level across multiple cases in Phase F, How traditional peer review (re)produces ignorance, in the paper.

References with an asterisk (*) denote primary empirical data constructed or coconstructed (during interviews) over the course of the research. Other references consist of self- and third-party accounts that I deemed valid secondary data sources.

\section{Table of Contents for Appendix A (in alphabetical order)}

Case 1 - Bardeen, John - 1956 and 1972 Nobel Prizes ${ }^{\circledR}$ in Physics ............................ 50

Case 2 - Blobel, Günter - 1999 Nobel Prize ${ }^{\circledR}$ in Physiology or Medicine ..................... 51

Case 3 - Blumberg, Baruch S. - 1976 Nobel Prize ${ }^{\circledR}$ in Physiology or Medicine ........... 51

Case 4 - Boyer, Paul - 1997 Nobel Prize ${ }^{\circledR}$ in Chemistry........................................... 52

Case 5 - Cancer as stem cells, area of study ........................................................ 52

Case 6 - Cech, Thomas - 1989 Nobel Prize ${ }^{\circledR}$ in Chemistry ...................................... 53

Case 7 - Ernst, Richard R. - 1991 Nobel Prize $\AA^{\circledR}$ in Chemistry ..................................... 54

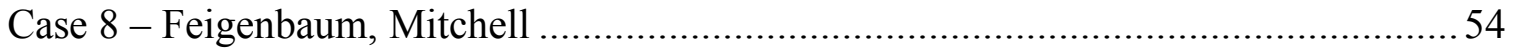

Case 9 - Furchgott, Robert F. - 1998 Nobel Prize $\AA$ in Physiology or Medicine ............ 55

Case 10 - Gell-Mann, Murray - 1969 Nobel Prize ${ }^{\circledR}$ in Physics.................................... 55

Case 11 - Ignarro, Louis J. - 1998 Nobel Prize ${ }^{\circledR}$ in Physiology or Medicine ................ 56

Case 12 - Kroemer, Herbert - 2000 Nobel Prize ${ }^{\circledR}$ in Physics..................................... 57

Case 13 - Lauterbur, Paul C. - 2003 Nobel Prize ${ }^{\circledR}$ in Physiology or Medicine ............. 57

Case 14 - Lee, David M., Douglas D. Osheroff, and Robert C. Richardson - 1996 Nobel

Prize ${ }^{\circledR}$ in Physics .............................................................................. 58

Case 15 - Marshall, Barry J. and J. Robin Warren - 2005 Nobel Prize ${ }^{\circledR}$ in Physiology or

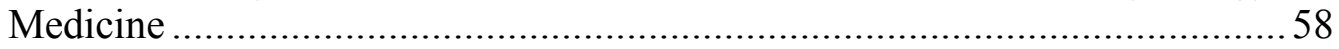

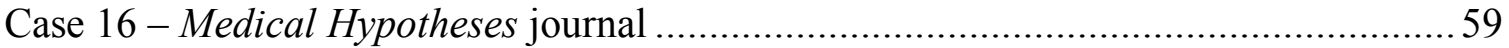

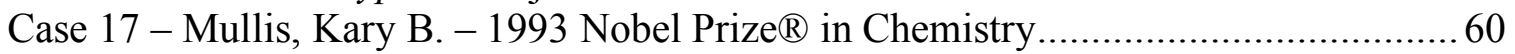

Case 18 - Polanyi, John C. - 1986 Nobel Prize ${ }^{\circledR}$ in Chemistry, 1988 Killam Laureate.. 61

Case 19 - Prusiner, Stanley - 1997 Nobel Prize ${ }^{\circledR}$ in Physiology or Medicine................ 62

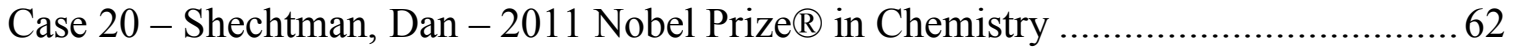

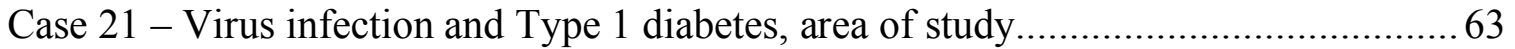

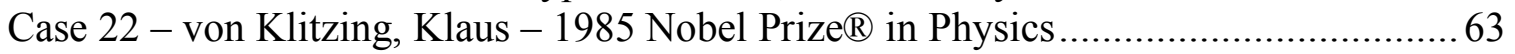

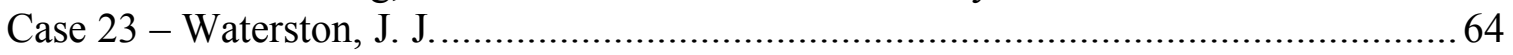

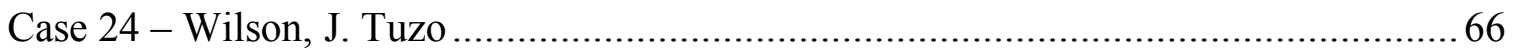

Case 25 - Yalow, Rosalyn S. - 1977 Nobel Prize ${ }^{\circledR}$ in Physiology or Medicine .............. 66 


\section{Case 1 - Bardeen, John - 1956 and 1972 Nobel Prizes ${ }^{\circledR}$ in Physics}

Between 1980 and 1991, then editor in chief David Lazarus at the American Physical Society intervened in order to publish manuscripts submitted by Bardeen that had received bad referee reports (Hoddeson and Daitch, 2002:300; related in Pines, 2009:313). In one of these papers (Bardeen, 1990), Bardeen was proposing new ignorance where "...the depinning of [...] charge-density waves was a macroscopic phenomenon associated with tunneling from one discrete quantum state to another" (Pines, 2009:313). According to Pines (2009) Bardeen did not manage to convince many other researchers to espouse his new ignorance. It would appear that "[a]lthough [Bardeen's] theory accounted in a simple way for the essential experimental facts, John had great difficulty getting his initial paper on the subject published in Physical Review Letters" (2009:313). When the editor in chief investigated the rejections at the journal Physical Review Letters, he noted that “...the referee was totally out of line. I couldn't believe it. I think it was some kid who thought it was sort of a cute thing to cut down an icon" (Hoddeson and Daitch, 2002:300). Lazarus added that Bardeen's last few papers 'were important' and he ensured they did get published (2002:300). Moreover, Pines (2009) remarked that Bardeen's “...oft-expressed fury at the prejudice and ineptitude of [Physical Review Letters] referees was almost unbounded” (2009:313).

Finally, contrary to all other Nobel Prize ${ }^{\circledR}$ laureate cases in this work, the papers in question followed the award of the Prizes. This also means therefore, that contrary to all other Nobel Prize ${ }^{\circledR}$ laureate cases the papers here were not linked directly with the awarding of the Prizes.

Synopsis of analysis: The account of inappropriate judgement by a 'kid' in this case reflects "asymmetrical accounting for error" (Mulkay and Gilbert, 1982). This frames understanding of 'false beliefs' in peer review (cf., rejecting apparently 'valuable' manuscripts) as being distorted by social, or in this case personal elements (cf., referee immaturity) as opposed to 'correct beliefs' (cf., not rejecting 'valuable' manuscripts) as purely cognitive and owing to rational analysis by individual editorial readers (see 1982:181). Rather, I argue that structural secrecy for editorial judgements and anonymity for the role of referee could have shielded potentially unsubstantiated rejection judgements by a supposed 'kid' in the role of referee (see decreased potential for rational decision-making in traditional peer review, Gaudet, 2014:8-9). More specifically, in the absence of wider scientific community scrutiny of editorial judgements, the role of referee did not hold an immediate relation of accountability for the judgement. Later editorial intervention, however, held the judgement to account.

Moreover, structural secrecy and anonymity for the role of referee might have also contributed to Bardeen's apparent disdain for referees at Physical Review Letters. Simmel (1906) proposed that reciprocal knowledge of individuals engaged in relation is a “...positive condition of social relationships" (1906:448). Yet with anonymous peer review, this positive condition of relation cannot be met. For Bardeen, the lack of knowledge about the referee might have contributed to making trust in the referee role and in his/her judgement in that role less likely. 


\section{Case 2 - Blobel, Günter - 1999 Nobel Prize ${ }^{\circledR}$ in Physiology or Medicine}

In 1971, Günter Blobel and a colleague proposed what was constructed as an 'astonishingly bold' "Signal Hypothesis" (new ignorance) in Experimental Biology (Anderson and Walter, 1999:557). Blobel apparently endured endless rejections of his grants and papers (1999:557). Anderson and Walter (1999) remarked "[t]hat in the end [Blobel] proved to be right, in such an astounding degree of detail, was all the more galling and stupefying to his incredulous detractors" (1999:557). During a news conference following the award of his Nobel Prize ${ }^{\circledR}$, Blobel recounted that in over thirty years of research he had endured several disappointments, “...such as when your grants and papers are rejected because some stupid reviewer rejected them for dogmatic adherence to old ideas" (Altman, 1999:A29).

According to Anderson and Walter (1999), one of the problems that might have elicited rejection of the author's new ignorance "Signal Hypothesis" was that when it was originally proposed, it was speculative and not founded on empirical evidence (Anderson and Walter, 1999:557). Moreover, Blobel acknowledged that his and his colleague's “... proposals at this point were pure speculation without any supporting evidence" (Blobel, 1999:247), which they nevertheless managed to publish at an early stage (1999:247).

Synopsis of analysis: The case draws attention to potential tension in relations of accountability to empiricism and more precisely the scientific explanation imperative of testability (requiring empirical evidence and that an explanation in a manuscript can be tested and corroborated by other subjects, hence 'intersubjectivity') for those in the role of editorial readers given the speculative nature of the proposals by the authors. Furthermore, as with Bardeen in Case 1, a lack of knowledge about the referee might have contributed to diminishing Blobel's trust in the referee role and editorial judgements that apparently held onto 'old ideas'.

\section{Case 3 - Blumberg, Baruch S. - 1976 Nobel Prize ${ }^{\circledR}$ in Physiology or Medicine}

The case of Baruch S. Blumberg centres on relations with a paper that was originally rejected at the Annals of Internal Medicine journal in 1967, but eventually published at the same journal (London et al., 1969) in 1969 (Blumberg, 1977:19). In the paper (London et al., 1969), the researchers had extended initial observations that they had made on ignorance for an association between 'Australia Antigen' and the hepatitis B virus (1977:19; Blumberg, 2003:2, 99-100) that eventually led to the creation of a diagnostic method and a vaccine against the hepatitis B virus (Blumberg, 2003:2). Blumberg (1983) advanced that "[ $\mathrm{t}]$ he editors were reluctant to publish a paper asserting that the hepatitis virus had been found, and required additional studies and publications to have this concept accepted" (my emphasis, Blumberg, 1983:159).

Moreover, then editor at the journal, Ed Huth, told Blumberg that "...the rejection of [the 1967] paper was one of the big errors of judgement the journal had made" (Blumberg, 2003:100). The reviewer who rejected the 1967 paper, Gerald Klatskin, for his part "...confessed that he had deemed [the 1967 paper] to be just one more in a series of reports claiming that the hepatitis virus had been found" (2003:100). It had been the reviewer's experience that researchers with similar claims had eventually been refuted 
when others had attempted to replicate the findings (2003:100).

Synopsis of analysis: In this case, it appears that the relation of accountability to empiricism in the roles of editorial readers and scientific explanation imperatives (cf., testability, ties with the past, and ontological economy) were primary elements in the original rejection in 1967. Finally, in contrast to cases 1 and 2, Blumberg's (eventual ${ }^{28}$ ) knowledge of the name of the individual who served in the role of referee appears to reflect trust in the role of referee, in spite of disappointment at the initial rejection (2003:100, 102).

\section{Case 4 - Boyer, Paul - 1997 Nobel Prize ${ }^{\circledR}$ in Chemistry}

By the time Boyer received his Nobel Prize $\AA$, he had already been working for twenty years on new ignorance (cf., a hypothesis): “...the process by which molecules produce ATP (adenosine triphosphate), thereby transmuting light, air, water and food into the energy required for both plant and animal life" (Olney, 2000:2). Although his new ignorance was eventually valued with the Nobel Prize ${ }^{\circledR}$, it encountered resistance, including rejection from what the author deemed as a 'leading journal' in his area of study, The Journal of Biological Chemistry (Olney, 2000:2; Boyer, 1997:125). Consequently, the author made use of his new membership in the National Academy of Sciences to publish in the Proceedings of the National Academy of Sciences (PNAS) (Boyer, 1997:125).

Since he first proposed his new ignorance, methodological advances have allowed researchers to photograph the process in action. This is in contrast to the original context where "... at the time he proposed it, Boyer's hypothesis was so original that a methodology to either confirm or disprove it had not been invented" (Olney, 2000:2).

Synopsis of analysis: The case features potential tension in relations of accountability to empiricism for the role of editorial readers and the scientific explanation imperatives of testability and ties with the past at The Journal of Biological Chemistry.

\section{Case 5 - Cancer as stem cells, area of study}

This meta level case centres on cancer stem cell publications (i.e., Bains, 2009; Lapidot et al., 1994; Dick, 2003). According to Bains (2009) before the scientific community constructed ignorance on cancer stem cells, "[ $\mathrm{t}]$ he standard view of cancer was one of a bulk of mutating cells, not a source and a sink" (2009:280). Bains (2009) bemoaned the purported 'high wall of peer consensus', including journal editorial peer review, in delaying cancer stem cell research. This was in spite of new empirical tools and underlying concepts purportedly being available in the mid 1990s (2009:280). Some of the research in the slow rise of stem cell research in the 1990s included Lapidot et al. (1994) and a review paper by Dick (2003). Bains concluded that the lag in constructing ignorance on cancer stem cells "... was because cancer stem cell biology was not accepted by the process that deemed what biology was practical, fundable, useful and

\footnotetext{
${ }^{28}$ It is not possible to ascertain why the author is aware of the referee's identity. It is unlikely, however, that this knowledge was acquired at initial traditional peer review.
} 
publishable" (2009:280).

Synopsis of analysis: I analyse three elements in the case. First, the "high wall of peer consensus' to which Bains refers was no doubt fuelled, I argue, by the contingency that traditional peer review exercises on scientific exchange. Second, compounding contingency, structural secrecy probably further prevented new ignorance on cancer stem cells from entering into scientific exchange and potential new theorizing and research. Finally, in Bain's last comment the recursive nature of peer review is paramount. Publications help construct careers, which help construct funding applications, which in turn help construct further publications - all mobilizing respective forms of peer review.

\section{Case 6 - Cech, Thomas - 1989 Nobel Prize ${ }^{\circledR}$ in Chemistry}

The case focuses on relations with the Bass and Cech (1984) paper that encountered resistance from referees but was eventually published at the journal where it was originally submitted, Nature. The paper was the first to explore new ignorance on how RNA molecules can bind small molecules (cf., metabolites) in the same manner as protein enzymes (Cech, 2013)*. Empirically, it was a first example of such binding (today there are thousands of examples) and the researchers' proposed ignorance went counter to established ignorance in biology that did not liken RNA molecule behaviour with that of protein enzyme binding (2013)*.

Enzymologist referees were unanimously negative according to Cech about the use of the concepts "catalysis" and "enzyme-like" (Cech, 1989:666-668; 2013*). In addition, Cech (2013)* indicated that the referees did not highlight problems with data or with the manner in which the experiments had been conducted. Those engaged in the role of referee were rather overwhelmingly not in agreement with new ignorance proposed: the theoretical framework of 'enzyme-like' binding. In addition, although the reviews were generally thoughtful (Cech, 1989:668) some comments in the referees' judgements were extremely, or perhaps even personally critical (Cech, 2013)*.

In an attempt to deal with the editorial judgements he had received and to negotiate publication, Cech communicated with an editor at Nature by telephone and learned that the journal was willing to publish the paper, but was asking the authors to respond to referee criticism (2013)*. Finally, it was some fifteen years later that new technology allowed for the absolute determination of the structure showing the mode of binding for the RNA molecule, and vindicating the work in the paper (2013)*.

Synopsis of analysis: It would appear that in this case the referees' disciplinarybased relation of accountability to empiricism and scientific explanation imperatives (testability, ties with the past, and informativeness) prevailed. Without confirmation from technology that was only available some fifteen years later, the referees appeared loath to accept that 'enzyme-like' binding could be at play. Furthermore, structural secrecy shielding editorial judgements and decisions from a wider community of scholars in other disciplines prohibited scientific exchange and potential 'self-correction' for editorial judgements. In addition, structural secrecy away from the gaze of a wider community and anonymity in the role of referee might have fostered what Cech (2013)* deemed as personally critical comments in editorial judgements. 


\section{Case 7 - Ernst, Richard R. - 1991 Nobel Prize ${ }^{\circledR}$ in Chemistry}

The case centres on relations with a paper (Ernst and Anderson, 1966) presenting new ignorance on the potential to "...enhance the sensitivity of high resolution proton magnetic resonance" (1966). Essentially, the authors' work formed the basis for Fourier transform magnetic resonance spectroscopy (Ernst, 1983:24). In the mid-1960s however, the authors could not foresee that their proposed concept would later transform nuclear magnetic resonance (NMR) (Ernst, 1983:24).

The paper was twice rejected by the Journal of Chemical Physics and finally published at Review of Scientific Instruments (Ernst, 1991). Campanario (2009:555) constructed the latter as a 'less known' journal. According to Campanario (2009), the editors at Journal of Chemical Physics based their rejection on lack of originality in the manuscript (2009).

Synopsis of analysis: There are two relevant elements for analysis in the case. Firstly, the author twice attempted to publish at what was deemed a high prestige journal, and eventually published at what was deemed a lower prestige journal. Such 'prestige' espouses a meaning of news for the content of scientific exchange with high prestige journals having higher newsworthy publications. Secondly, it would appear that the criterion of originality at Journal of Chemical Physics led to (at least temporary) ignorance reproduction, until the author published elsewhere. As with other cases, dynamics of attempts at publication remain 'invisible' without author self-accounts.

\section{Case 8 - Feigenbaum, Mitchell}

I start by contextualizing the case. Feigenbaum's proposed new ignorance on dynamical systems (cf., chaos theory) was featured in a book entitled 'Twentieth Century Physics' that described the century's achievements in the area of Physics. Although he did not win a Nobel Prize ${ }^{\circledR}$ for his innovative work, he won numerous awards and prizes that constructed his prestige and helped him secure research funding (Gleick, 1988:180).

Two of his early papers on the topic in 1976 and 1977 were rejected at peer review with the first being retained six months in review (Feigenbaum, 1995:1850; Redner, 1987:224). Such rejections contributed to his assertion that "[p]apers on established subjects are immediately accepted. Every novel paper of mine, without exception, has been rejected by the refereeing process" (Feigenbaum, 1995:1850). In spite of a lack of publications, by 1977 the author's work had garnered much attention (and some detractors) in mathematics and physics epistemic communities (Gleick, 1988:181). He engaged in direct scientific exchange of pre-print papers, including one to more than one thousand readers (Feigenbaum, 1995:1849, 1850; Gleick, 1988:181). Finally, "[o]ne editor who sent back a Feigenbaum manuscript recognized years later that he had rejected a paper that was a turning point for the field; yet he still argued that the paper had been unsuited to his journal's audience of applied mathematics " (Gleick, 1988:180-181)

Moreover, in 1978 a colleague had advised Feigenbaum that "...until some connection with any physical thing could be shown no one would take it as other than a great curiosity" (1995:1850). In 1979 such a connection with a 'physical thing' was 
measured, which led to dynamical systems becoming 'science' according to Feigenbaum (1995:1850).

Synopsis of analysis: First, it appears that a relation of accountability to empiricism and to scientific explanation imperatives (testability) might have contributed to Feigenbaum's two early rejections. Pre-print papers in scientific exchange, however, revealed the potential value for the new proposed ignorance in the physics and mathematics epistemic communities even before peer-reviewed publications. Second, the applied mathematics editor who rejected one of his early manuscripts appears to have done so based on a relation of accountability to his journal's readers.

\section{Case 9 - Furchgott, Robert F. - 1998 Nobel Prize ${ }^{\circledR}$ in Physiology or Medicine}

The manuscript Robert F. Furchgott and a co-author submitted to the journal Nature featured new ignorance on endothelium-dependent relaxation (Furchgott and Zawadzki, 1980). Furchgott recounted how "[o]ne of the two reviewers of the paper expressed considerable doubt about the validity of our experimental procedures and conclusions" (Furchgott, 1993:V3). Following lengthy rebuttals and changes to the manuscript, an editor at Nature indicated that the paper could be published, but it would first have to be shortened and expunged of a "discursive and anecdotal style" to resemble Nature's shorter letter format (1993:V3). The author complied with the request and recognized that the editor "...was right in so advising me" (1993:V3) to shorten the manuscript, which led to publication in late 1980.

Synopsis of analysis: In spite of limited case details, the main element of ignorance reproduction tension appears tied with one of the referee's relation of accountability to empiricism and scientific explanation imperatives. These include testability (doubt about validity of procedures), ties with the past (not using purportedly 'valid' procedures anchored in the past), and informativeness (doubt about conclusions).

\section{Case 10 - Gell-Mann, Murray - 1969 Nobel Prize® in Physics}

The 1953 strong opposition by editors and referees and eventual publication of Murray Gell-Mann's manuscript (Gell-Mann, 1953) at the journal Physical Review is the focus of the case. In the original manuscript that had been entitled "Isotopic Spin and Curious Particles", Gell-Mann advanced new ignorance on 'strange particles' or more commonly known as a theory of elementary particles.

To contextualize, Gell-Mann (1982) recounted that at the time in the early 1950s, “...speculation by theorists in the physics journals was not considered particularly respectable" (1982:C8-395). He encountered opposition to his new concept of strangeness (1982:C8-395, C8-397; Crozon, 1987:105), yet also met interest in the new ignorance as he distributed pre-prints of articles (including Gell-Mann, 1953) to laboratories worldwide (Gell-Mann, 1982:C8-399). In contrast, several research groups were working on the topic in Japan and K. Nishijima independently produced and published a model quite similar to Gell-Mann's around the same time (Crozon, 1987:105). 
More specifically with Gell-Mann's 1953 manuscript under review at Physical Review, the author described how editors rejected the concepts of 'Curious Particles' and of 'Strange Particles' and made him change his paper for a phrase he constructed as 'sufficiently pompous' - New Unstable Particles (Gell-Mann, 1982:C8-400). A 'very sore point' according to Gell-Mann was those in the role of editorial readers "...objected to the neutral boson being different from the neutral anti-boson" (1982:C8-400). Editorial readers rejected his first explanation, which then made him refer to a paper by Nick Kemmer making an analogous distinction after which "...they finally agreed that it was O.K. to have a neutral boson different from its anti-particle" (1982:C8-400). In describing the sore point episode, Crozon (1987) proposed that the referees might best be described as censors and that Gell-Mann had had to "...se défendre pied à pied, montrant que certaines de ses hérésies étaient déjà présentes chez des anciens plus respectables" (1987:105). The author also had to add explanations and clarifications with respect to misconceptions regarding the generalized Pauli principle (Gell-Mann, 1982:C8-400). Furthermore, it was around the same time that accelerators were producing the first results with "...one event [...] compatible with strangeness" (1982:C8-400) to which the author reacted with much enthusiasm.

Finally, a subsequent classroom encounter with a colleague who objected to the same 'very sore point' in exchanges with Physical Review made Gell-Mann think, "[h]ere we go again, just like the Physical Review. I only hope he isn't the referee with whom I had all the trouble" (1982:C8-402).

Synopsis of analysis: I propose four elements for analysis. First, the editormandated change to 'New Unstable Particles", constructed as 'sufficiently pompous' by Gell-Mann, is an example of a change for the construction of new ignorance that does not reflect the author's voice but that must be made in order to publish in traditional peer review. The original author's voice is typically lost, though in this case the author tried to reclaim his voice by constructing his narrative of the events. Second, the use of an analogous distinction and the additional explanations and clarifications requested, point to scientific explanation imperatives (ontological economy for the neutral boson and neutral anti-boson and ties with the past for the Kemmer addition and clarifications for the Pauli principle). Third, the importance of the accelerator results for the author corroborates a relation of accountability to empiricism for Gell-Mann. Finally, the classroom encounter underlines two issues. Firstly, a lack of trust in the author-referee relation that stems from anonymity in the role of referee. Secondly, continued powerimbalance between the roles of author and referee where an anonymous referee can continue interacting with an author from a position of power after publication.

\section{Case 11 - Ignarro, Louis J. - 1998 Nobel Prize ${ }^{\circledR}$ in Physiology or Medicine}

Louis J. Ignarro's proposed new ignorance as theories on nitric oxide met 'professional skepticism' according to Olney (2000:4). Editorial readers at major journals rejected early manuscripts in which he constructed "...his contention that a substance that is basic to nitroglycerin and part of the chemistry of smog is also crucial to the life process" (2000:4). With time however, other researchers replicated his work therefore mobilizing Ignarro's ignorance on nitric oxide as a neurotransmitter (2000:4). A recent 
therapeutic mobilization of the author's work is the anti-impotency drug Viagra and in 2000 the author foresaw applications in preventing "...vascular complications of diabetes" (2000:5).

Synopsis of analysis: A potential element in the rejection of Ignarro's new ignorance in early manuscripts might have been the relation of accountability to empiricism for editorial readers and at least two scientific explanation imperatives, testability and ties with the past.

\section{Case 12 - Kroemer, Herbert - 2000 Nobel Prize ${ }^{\circledR}$ in Physics}

In 1963, Herbert Kroemer submitted a paper in which he had mobilized new ignorance to propose a pair of heterojunction injectors (as wide gap emitters) - instead of using only one (Kroemer, 1963:1783) - to the journal Applied Physics Letters; it was rejected (Kroemer, 2013:2185). As Kroemer put it, "[u]nfortunately, I let myself be talked out of fighting the rejection, and was persuaded to submit it instead as a letter to the Proceedings of the IEEE, where I was assured it would be published" (2013:2185). The published letter (Kroemer, 1963), however, was 'largely ignored' according to the author (Kroemer, 2000:458).

To further contextualize the case, Kroemer was in a commercial setting at the time, not in a University, and held a relation of accountability to his employer. His employer, Varian Associates, however did not seem to be overly enthusiastic about his new ignorance and filed and obtained a patent, but refused to provide Kroemer with further resources to develop the new laser (2013:2186). For the commercial entity, the preoccupation seemed to be immediate competition with existing lasers - an economic relation with short-term profit goals. In contrast, Kroemer's new ignorance of the doubleheterostructure concept was to eventually lead to new types of lasers and light-emitting diodes (LED) following his move to a university institutional setting (Kroemer, 2013; Kroemer, 2000).

Synopsis of analysis: The case highlights how a need to publish appears to have veered the author to a publication that might not have been ideally suited to the audience the author wished to reach, potentially leading to decreased mobilization of his proposed ignorance. The reasons not to appeal rejection in this case are not clear, but do point to ignorance reproduction for closed processes with dichotomous outcomes (in this case rejection at Applied Physics Letters).

\section{Case 13 - Lauterbur, Paul C. - 2003 Nobel Prize® in Physiology or Medicine}

The manuscript in which Paul Lauterbur proposed new ignorance on magnetic resonance imaging (or magnetic resonance images - MRI) was originally rejected at the journal Nature in 1971 (Editorial Staff, 2007). One of the reasons for rejection, it appears, was the 'fuzziness' of the images provided in the manuscript (Nobelprize.org, 2003). An appeal by the author with Nature editors, however, eventually led to publication in 1973 (Lauterbur, 1973; Lauterbur, 2005:1009). In reconstructing his manuscript during the appeal, the author "...was [...] trying to think of another example that would work in 
practice, but it was to be over a quarter of a century later that an example, involving the differential shift of the spectra of two closely spaced atoms in an inhomogeneous electric field, was published" (2005:1009). Finally, in his revised submission, the author added "... references to cancer and other more obviously relevant topics" which he believes finally led to the publication of the paper (2005:1009).

Synopsis of analysis: The Lauterbur rejection and publication case appears to bring attention to accountability to empiricism for editorial readers and scientific explanation imperatives of testability and informativeness.

\section{Case 14 - Lee, David M., Douglas D. Osheroff, and Robert C. Richardson - 1996 Nobel Prize ${ }^{\circledR}$ in Physics}

The authors in this case proposed new ignorance on new phases of liquid Helium3 (3H3). The manuscript they submitted to Physical Review Letters was a correction to a previous letter that they had successfully and easily published at Physical Review Letters (Osheroff, 1996:72-73). The new manuscript was rejected (Lee, 1997:655), however, with a referee indicating that the differences between the original letter and the new letter were not sufficient; a decision upheld by two editors at Physical Review Letters (1996:73). Furthermore, according to Buchanan (1996), "[o]ne referee argued that the system "cannot do what the authors are suggesting it does" "(1996:562). The lengthy appeal process (Lee, 1997:655) the authors engaged in included enlisting collaboration from an associate editor, Jim Krumhans, to help overturn the reject decision which finally led to publication in 1972 (Osheroff, 1996:73). Contextualizing the case, other researchers were verifying the authors' results and John Wheatley, for example, presented evidence at the 1972 International Conference on Low Temperature Physics supporting that produced by the authors (1996:73).

Synopsis of analysis: Underlying the ignorance dynamics in this case, it appears that accountability to empiricism for editorial readers, the scientific explanation imperative of testability, and a variation on of the Ingelfinger's rule of non-duplicate publication might have all contributed to the initial decision to reject publication. As the publication of similar letters was at the same journal, I do not include this case as one of compliance with Ingelfinger's rule in the cross-case analysis.

\section{Case 15 - Marshall, Barry J. and J. Robin Warren - 2005 Nobel Prize® in Physiology or Medicine}

Barry Marshall and Robin Warren constructed new ignorance ${ }^{29}$ on two topics. First, proposing that bacterium H. Pylori caused peptic ulcers. Second, advancing the presence of bacteria in the human stomach (Warren, 2013)*. To contextualize, before the authors' work, the stress model (a biopsychosocial model) to explain the cause of peptic ulcers prevailed (Davey Smith, 2005:84-85) and it was generally accepted that bacteria

${ }^{29}$ The proposed ignorance was not new as it had already been advanced as early as 1875 (Davey Smith, 2005:84), but the stress model (biopsychosocial) to explain the cause of peptic ulcers prevailed (2005:84$85)$. 
could not survive in the highly acidic human stomach (Warren, 2013*; Robbins, 2012).

The case centres on the authors' efforts to publish a peer-reviewed paper at The Lancet. It appears that the journal could find no referees that 'believed' in the results being presented (Warren, 2013; Robbins, 2012). According to Warren (2013)*, the researchers had to 'construct' their own peer (2013)*. Marshall had met a UK-based researcher, Martin Skirrow, who replicated their findings with the help of his registrar Cliodna McNulty (Warren, 2013*; Robbins, 2012). The McNulty and Watson (1984) letter published in The Lancet, Warren proposed, was probably a 'review' for Lancet editors because shortly after the Marshall and Warren (1984) paper was published (Warren, 2013)*. Interestingly, Robbins (2012) advanced that the replication in Skirrow's laboratory showed "...that the spiral organism was not merely an Australian phenomenon but was present in ulcer patients in the UK as well" (2012).

In spite of the publication, however, the researchers still met with high levels of skepticism that led Marshall to infect himself in order to self-experiment (2012). Marshall advanced that he met "... with constant criticism that [his] conclusions were premature and not well supported. When the work was presented, [...] results were disputed and disbelieved, not on the basis of science but because they simply could not be true" (Marshall, 2005). The researchers' results slowly gained acceptance in the early 1990s (Robbins, 2012). Finally, two letters the authors published at The Lancet in 1983 (Warren, 1983; Marshall, 1983), which did not undergo peer review, were later recognized as the original publications on the topic by the Nobel Foundation.

Synopsis of analysis: At least three elements warrant analysis in the case. First, dominating elements are the accountability to empiricism for editorial readers and the scientific explanation imperatives of testability and ties with the past. Second and related with accountability to empiricism, reference to "Australian phenomenon" advances a meaning of localized knowledge production. That no referees could be 'found' who believed the research results also points to referees as localized knowers. Finally, the controversy surrounding the peer-reviewed paper highlights valuation for the content of scientific exchange that has undergone peer review. This contrasts with the initial nonvaluation of the two 1983 non-peer reviewed letters that only gained attention and value following award of the prize.

\section{Case 16 - Medical Hypotheses journal}

The case focuses on relations of boundary judgement at a journal, Medical Hypotheses, and more specifically its transition from being an editorial-only review journal to a peer reviewed journal. To contextualize, entrepreneur David Horrobin had launched Medical Hypotheses in 1975 as editorial-only review. He proposed that " $[\mathrm{t}] \mathrm{he}$ history of science has repeatedly shown that when hypotheses are proposed it is impossible to predict which will turn out to be revolutionary and which ridiculous. The only safe approach is to let all see the light and to let all be discussed, experimented upon, vindicated or destroyed" (Horrobin, 2004:4). His vision for the journal would radically change in 2010, however, following the publication of papers with controversial ignorance on the link between AIDS and human immunideficiency virus (HIV).

The controversy centered mostly on Peter Duesberg's controversial paper in 
which he proposed new ignorance challenging existing ignorance that AIDS is caused by the HIV (Cressey, 2010; Enserink, 2010). Criticism and protest from AIDS scientists and activists framed the article within a wider trend of AIDS denialism (Enserink, 2010; Steinhauser et al., 2012:367). In response to criticism, the publisher retracted Duesberg's and a second paper on the same topic from the journal and expurged these from medical literature (Enserink, 2010). In early May 2010, commercial publisher Elsevier also fired then editor Bruce Charlton at Medical Hypotheses for refusing to change the social form of review from editorial-only review to peer review (Enserink, 2010). In spite of the controversy, however, Duesberg's paper was eventually published (Duesberg et al., 2011) in a peer-reviewed journal in 2011 (Steinhauser et al., 2012:368; Zoe, 2012).

To further contextualize, in 2003-2004 then editor at BMJ Richard Smith was criticized by the journal Nature for having posted Web-based rapid responses (non peerreviewed) supporting the same contrasting view on the link between AIDS and HIV (Smith, 2011:60). Smith defended the journal's position on the controversial rapid responses by arguing that science was based on free speech and a need for transparency in scientific exchange (Smith, 2004). In clarifying his journal's position, Smith added: "I'm not arguing that those who doubt the link between HIV and AIDS are right, but I want to keep our threshold for posting rapid responses as low as possible" (2004:287).

Synopsis of analysis: I analyse two elements. First, the commercial publisher's economic relations and relation accountability to readers (more specifically to AIDS scientists and activists) appear to have motivated the change from editorial-only review to peer review. The latter is constructed as more 'conservative' and would presumably therefore reduce potential for controversy and impact on profit. The shaping of traditional peer review as paradigmatic and providing a meaning of 'scientific' to the content reviewed is one that further shapes scientific knowledge as absolute and reliable. In spite of that, the eventual publication of Duesberg's paper at a peer-reviewed journal highlights how the structural secrecy of traditional peer review tends to render invisible controversy and therefore allows for repeated submission that hold no relation with previous submissions. This further reproduces science as absolute knowledge. Second, Horrobin's opening quote for Medical Hypotheses and Smith's defence of the BMJ's controversial rapid responses underline an apparent need for scientific exchange without the contingency of traditional peer review. Such transparency, however, runs counter to scientific knowledge as news and as absolute. The 'messiness' of scientific knowledge and ignorance dynamics becomes visible with transparency making for unpalatable news.

\section{Case 17 - Mullis, Kary B. - 1993 Nobel Prize® in Chemistry}

In his to be Nobel Prize ${ }^{\circledR}$ winning co-authored paper (Mullis and Faloona, 1987), Kary Mullis constructed new ignorance on how a chemical procedure (polymerase chain reaction (PCR)) enhanced how scientists could render DNA fragments visible. The new ignorance on DNA analysis would become valuable for several applications including genetic disease diagnostics and molecular paleobiology (Mullis, 2000:104-105). The manuscript was rejected, however, at the journal Nature and then at the journal Science. Science indicated that the paper was not suitable for its readers and suggested that Mullis submit it to a 'secondary journal'. Following a period of time during which the author's 
"...disgust with the journals mellowed" (2000:105-106), he published in Methods in Enzymology at the request of Ray Wu who 'understood' PCR and was preparing a volume in the journal.

To contextualize, in 1968 Mullis had successfully published a highly speculative paper in Nature. The paper "...was a description-from [his] own experience and imagination-of the entire universe from the beginning to the end" (2000:103). He had been a second year graduate student at the time of publication and was unprepared for the reaction it received. He was dismayed when the "...Nature Times News Service circulated an article beginning, "It sounds like the wildest science fiction. But an American scientist seriously suggests that half the matter in the universe is going backwards in time" (2000:104). This earlier publication he later came to reason, should never have been accepted for publication in such a 'prestigious' journal (2000:104).

Synopsis of analysis: It would appear that for the editors at Science, a relation of accountability to their readers (rejecting papers that are not deemed newsworthy enough for a 'primary' journal) led to ignorance reproduction. Furthermore, the contextual narrative of publication for a highly speculative paper at Nature appears to hold a meaning of 'news' and 'newsworthiness' for the content of scientific exchange.

\section{Case 18 - Polanyi, John C. - 1986 Nobel Prize ${ }^{\circledR}$ in Chemistry, 1988 Killam Laureate}

In a manuscript rejected at Physical Review Letters and then published in 1961 at Methods in Enzymology (Polanyi, 2013), Polanyi proposed new ignorance as a type of chemical laser using "....inversion between vibrational states" instead of “...population inversion with respect to electronic states" in previous proposals for lasers (Polanyi, 1961:347). The journal Physical Review Letters “.... rejected the paper as lacking scientific interest" (Polanyi, 1990:243). Responding to an interview question about how he reacted to the rejection of his first theoretical description of chemical lasers at Physical Review Letters, the author recounted that as an inexperienced researcher he had originally thought that the rejection meant that his manuscript was boring and must be wrong. After reading a newspaper story recounting the same type of rejection at the same journal for the inventor of lasers, Theodore Maiman, however, he revised his evaluation for his manuscript as maybe not being "so bad" (NSERC, 2005). Following his reading of the newspaper story, the author "... submitted the identical manuscript to the Journal of Chemical Physics, where it was promptly published" (Polanyi, 1990:243-244).

Synopsis of analysis: I analyse two elements. First, rejection based on 'lack of scientific interest' reflects a need to publish content of scientific exchange as news and newsworthy and reflects a relation of accountability to readers. It therefore suggests an originality criterion. Second, had it not been for a newspaper story that rendered 'visible' a rejection for Maiman's paper that would otherwise have remained structurally secret and invisible, it is unclear if Polanyi would have considered resubmission at another journal. Individualization of the rejection reflects the onus placed on individual authors instead of bringing attention to structural properties in traditional peer review that lead to dichotomous outcomes not necessarily reflecting the scientific epistemic value of a manuscript. 


\section{Case 19 - Prusiner, Stanley - 1997 Nobel Prize ${ }^{\circledR}$ in Physiology or Medicine}

Prusiner $(1995 ; 1998 b)$ purportedly encountered resistance at peer review after having constructed the role of proteins as infectious agents and having coined the concept 'prions ${ }^{, 30}$ (Friedman, 2012:134; Prusiner, 1998a). Virologists, according to Prusiner, were especially skeptical of the new protein-only infectious entity proposed (Prusiner, 1998a; related in Kim, 2007 and Reeves, 2002). Friedman advanced that Prusiner “...was not above denouncing the people who had rejected his theories and his papers" (Friedman, 2012:134). In addition, early on Prusiner remarked that his proposal was deemed 'heretical' (Prusiner, 1995:30). More recently, Prusiner purportedly encountered resistance for new ignorance on prions and Alzheimer's disease (Stöhra et al., 2012). The case involves Prusiner as author and traditional peer review for his prion-related manuscripts from 1982 to 2012. In 1982, Prusiner published his first controversial article on prions (1982), and in 2012 his more recent controversial research was published (Stöhra et al., 2012). Finally, contextually the case is significant given the prevalence of neurodegenerative disease (i.e., BSE, Alzheimer's, Cruzfeld Jacob's disease) and other potential applications for prion research.

Synopsis of analysis: One potentially relevant element for analysis in the case is the scientific explanation imperative of ontological economy - where the 'prion' as a new biological entity was controversial. This supports a potential relation of accountability to empiricism for editorial readers, although I do not have access to specific empirical evidence in journal peer review dynamics for this claim (therefore I do not include it in the cross-case analysis). Absence of publication-related data in this case prevents me from advancing further case-specific analysis. As is evident for all cases, however, the case is relevant theoretically for contingency, and in that structural secrecy prevented access to editorial judgements and decisions, and original manuscripts.

\section{Case 20 - Shechtman, Dan - 2011 Nobel Prize ${ }^{\circledR}$ in Chemistry}

Dan Shechtman's first (co-authored) manuscript constructing new ignorance "[a] new structural concept [...] to account for the observed electron diffraction patterns" (Shechtman and Blech, 1985:1005) - was rejected at the Journal of Applied Physics. The editors had not sent out the manuscript to reviewers stating that the community of physicists would not have any interest in its content and proposed that the authors submit the manuscript to a metallurgical journal instead (Shechtman, 2013)*. Shechtman then submitted the manuscript at Metallurgical Transactions $A$ where it was accepted for publication (Shechtman and Blech, 1985). Publication was slow according to the author, with a delay of some eight months (Shechtman, 2013)*. During the slow publication period, the author collaborated with other researchers and published a second paper that was quickly accepted and published at Physical Review Letters (Shechtman et al., 1984; Shechtman, 2013*). The author recounted that the second publication 'made a splash' before the official 'first' publication and attracted attention from several disciplines including mathematics, physics, chemistry, and material science, in addition to launching

30 Prions stand for 'proteinaceous infectious particles' (Prusiner, 1995:30). 
a new area of research (Shechtman, 2013)*. Even though Shechtman managed to (eventually) publish papers on 'quasi-period materials' and there was extensive interest in quasi-periodicity, he faced considerable skepticism from researchers including from double Nobel Prize ${ }^{\circledR}$ winner Linus Pauling who rejected the existence of quasi-period materials to his death (Jha, 2013).

Synopsis of analysis: Citing lack of interest for potential readers is another example of constructing the content of scientific exchange as 'newsworthy' or not, moving attention away from the epistemic value of the content. Such a reason for rejection also highlights a relation of accountability to readers. Resistance from fellow chemists to Shechtman's new ignorance, however, such as from the likes of double Nobel Prize ${ }^{\circledR}$ winner Linus Pauling, might have contributed to the original rejection.

\section{Case 21 - Virus infection and Type 1 diabetes, area of study}

This case focuses on an area of study: type 1 diabetes. More precisely, the hypothesis (ignorance) that a virus might be a causal agent in type 1 diabetes (Gale, 2011:1) for manuscripts submitted to The Lancet journal from 1974 to 2011. This case is potentially significant in that over 40 years (since the 1960s), in spite of over 15,000 papers (estimated in 2001, all journals not only The Lancet (Gale, 2001:224)) on the topic, the same hegemonic ignorance claim prevailed in 2011 (Gale, 2011).

I chose the journal The Lancet given that Gale (2001) identified the key role this journal played in promoting one of the clearest constructions of the hypothesis in 1974 (2001:223). The role of The Lancet in the publication of the clear hypothesis in 1974, though apparently only after nine months, and following negotiations with the editor (Gale, 2001:223), establishes then editorial readers' initial reluctance and then willingness to publish new ignorance. I covered the temporal span of 1974 to 2011 to capture the start of the construction up to Gale's latest review of the topic in 2011 (Gale's review includes reference to several other researchers who concur with Gale).

Furthermore, given the prevalence of type 1 diabetes worldwide, this is a significant case study with respect to ignorance (re)production -researchers supposedly pressed to solve such a large-scale problem might be inclined to construct new ignorance.

Synopsis of analysis: Absence of publication-related details in the case prevents me from constructing a case-specific analysis of purported ignorance reproduction in the area of study. As with Case 19, however, the case is relevant theoretically for contingency, and in that structural secrecy prevented access to editorial judgements and decisions, and the original manuscripts.

\section{Case 22 - von Klitzing, Klaus - 1985 Nobel Prize ${ }^{\circledR}$ in Physics}

The manuscript Klaus von Klitzing submitted to Physical Review Letters containing his new ignorance on the 'Quantized Hall Effect' was originally rejected (Anonymous, 2008). The manuscript was returned in June 1980 with an editorial judgement of revise and resubmit to new referees. The editorial judgement included the following: "[o]n the basis of the resulting [referee(s)] report(s), we judge that the paper is 
not suitable for publication in Physical Review Letters in its present form but might be made so by appropriate revision" (made visible in a partial reproduction of editorial decision, Holme, 2012). The author resubmitted a revised manuscript that was published at Physical Review Letters (von Klitzing et al., 1980). Furthermore, the author described that until 1980 data from the experimental Hall effect had been subjected to analysis using an "incorrect model" (von Klitzing, 1985:325). Finally, then Associate Editor George Basbas purportedly advanced that peer review had contributed to constructing 'prize winning work' (Campanario, 2003).

Synopsis of analysis: One element that stands out in the case is that if von Klitzing had not resubmitted his manuscript, ignorance reproduction of the "incorrect model" would have persisted with no visible trace of von Klitzing's Quantized Hall Effect. In the absence of editorial judgements, I cannot further explore Basbas' comment on the role of review in constructing 'prize winning work'. Absence of fine-grained publication-related details therefore prevents me from constructing detailed case-specific analysis of ignorance (re)production. As with Cases 19 and 21 above, however, the case is relevant theoretically for contingency, and in that structural secrecy prevented access to editorial judgements and editorial decisions, and the original manuscript.

\section{Case 23 - Waterston, J. J.}

In 1892, then Royal Society President Lord Rayleigh published a paper close to fifty years after referees had rejected its new ignorance on the theory of gases (in 1845). In it, Rayleigh included an introduction to explain the lengthy delay in publication. Priority had thereafter been (wrongly) attributed to three other scientists from mid- to late nineteenth century for different elements in the rejected manuscript (Waterston and Rayleigh, 1892:3).

Moreover, Rayleigh advanced that one of the reasons why the paper might not have been well received by referees is because Waterston "...mentions no predecessors" (1892:3) though he acknowledges that the author might not have been aware of work by predecessors. Neither referee alludes to this absence.

The first referee offered a short editorial judgement stating that "[i]n my opinion the paper is nothing but nonsense, unfit even for reading before the Society" (Anonymous Referee 1, 1846:1-2)*. A second referee constructed some of the proposed new ignorance on elastic media as being "...founded on a principle entirely hypothetical" (Anonymous Referee $\left.2,1846: 1^{*}\right)$ and "[t]he original principle itself involves an assumption which seems to me very difficult to admit, and by no means a satisfactory basis for a mathematical theory" (1846:3)*. This referee, however, added a disclaimer in his judgement and indicated that he could not be "...satisfied without obtaining the opinion of mathematicians" (1846:4)*. I obtained no additional referee judgement, and Rayleigh does not give details on a third referee. Furthermore, in a letter, Waterston requested that the Society consider making an exception in his case to return his original manuscript so that he "...might be enabled to submit it to the few who take an interest in such subjects" (Waterston, 1846)*. As I did not obtain a copy of a response letter or any other document related with this case, it is difficult to ascertain if Waterston was granted an exception and received his manuscript before it was deposited in the Royal Society's archives. 
In addition, Rayleigh characterized the second referee as "... one of the best qualified authorities of the day, and evidently devoted to a most difficult task his careful attention" (Waterston and Rayleigh, 1892:3). In defence of the individual referees and their rejection of the paper, it was later remarked that "[r]eferees are naturally liable to make mistakes like other men, and Rayleigh was instrumental in remedying a longstanding injustice in a case of this kind" (Strutt, 1968:169).

Furthermore, after his paper was rejected by the journal, Waterston never published again and was purported to have been "...contemptuous of scientific men with but few exceptions" and characterized The Royal Society in 'strong terms' (Strutt, 1968:170). Rayleigh remarked on the absence of a resubmission that "[i]t is singular that Waterston appears to have advanced no claim for subsequent publication, whether in the Transactions of the Society, or through some other channel" (Waterston and Rayleigh, 1892:2).

Finally, Rayleigh suggested that it was unwise of a young unknown author to attempt to publish 'highly speculative investigations' at a society that would hesitate to print knowledge (and ignorance) of 'unknown value'. He added that "[ $\mathrm{t}] \mathrm{o}$ say that he was not always successful [in tackling difficult questions in his manuscript] is only to deny his claim to rank among the very foremost theorists of all ages" (1892:3).

Synopsis of analysis: I analyze six elements in the case. First, the case offers a glimpse into an early purported 'self-correction' in science that remedied a seeming 'injustice'. That self-correction could occur, however, hinged on the existence of archives that at least created conditions of possibility to self-correct. As discussed in the Methods section, journals that responded to my request for editorial judgements and decisions and original manuscripts indicated that their archives only covered short temporal spans (1015 years). Lack of access to these short span archives thus precludes self-correction. Correspondingly, actors in science promote author 'self-correction' through multiple submissions - as is evident in Rayleigh's comment of lack of resubmission. Had Waterston resubmitted, according to this logic, he would have been vindicated and published. Moving the focus to individual author responsibility, however, detracts from structural properties that contribute to rejection.

Second, as I advanced for other cases, structural secrecy away from the gaze of a wider community and anonymity in the role of referee might have fostered the first referee's unsubstantiated editorial judgement.

Third, as with Case 1, Rayleigh in the role of editor constructs the author as young and unknown, which reflects "asymmetrical accounting for error" (Mulkay and Gilbert, 1982). This frames understanding of 'false beliefs' in peer review (cf., rejecting apparently 'valuable' manuscripts) as being distorted here by personal elements (cf., perceived youth and lack of reputation of the author) as opposed to 'correct beliefs' (cf., not rejecting 'valuable' manuscripts) as purely cognitive and owing to rational analysis by individual editorial readers (see 1982:181). Simultaneously, this constructs the author as a situated knower - where being a young scientist should preclude "embarking upon higher flights" without first having contributed "...work whose scope is limited, and whose value is easily judged" (1892:3). The assumption here being that referees - as situated knowers themselves - could not easily judge the knowledge and ignorance constructed in Waterston's manuscript. Had he submitted easier to judge knowledge first, 
the logic follows, referees could take the first submission as an indication of validity of knowledge from this young author, then applicable to subsequent 'flightier' submissions.

Fourth, in the absence of wider scientific community scrutiny of editorial judgements, the role of referee did not hold an immediate relation of accountability to its judgements. Later editorial intervention by Rayleigh, however, held the judgement to account.

Fifth, the disclaimer by the second referee that a mathematician should be consulted constructs the referee as a situated knower who acknowledges the borders of his scientific knowledge.

Finally, reference to 'highly speculative investigations' and lack of reference to predecessors highlights a relation of accountability to empiricism and to the scientific explanation imperatives of testability and ties with the past.

\section{Case 24 - Wilson, J. Tuzo}

J. Tuzo Wilson was one of the first to propose new ignorance on the formation of Hawaiian type chains of islands that differed from then accepted ignorance of the 'rigid Earth-model' (Wilson, 1963:864). His manuscript on the topic was rejected by a leading discipline-specific journal, Journal of Geophysical Research, after which he submitted the manuscript to a new learned society Physics journal, the Canadian Journal of Physics, where it was published (Wilson, 1981:130; Garland, 1995:545). The author's selection of the second journal was based on his nationality (Canadian) and his sense that a Canadian-based journal would publish his work, although he acknowledged that the selection was not “...a very obvious place to send it" (Wilson, 1981:130).

Following the first publication and the uptake of his new ignorance (Garland, 1995:545; Hoffman, 2014) by his epistemic community, however, he published in Nature, in Science, and in 1990 in the Journal of Geophysical Research (bibliography in Hoffman, 2014:207).

Synopsis of analysis: Analogous with von Klitzing (Case 22), had Wilson not submitted his manuscript at a second journal, the 'rigid earth model' ignorance reproduction would have continued with no visible trace of Wilson's potential new ignorance. In this case, the onus on the individual author to try to find an alternative journal to publish his work led him to submit at a journal with readers that did not appear to be ideally suited to his work. Furthermore, absence of publication-related details in the case prevents me from constructing a case-specific analysis of ignorance (re)production. As with Cases 19, 21, and 22 above, the case is nevertheless relevant theoretically for contingency, and in that structural secrecy prevented access to editorial judgements and decisions, and the original manuscript.

\section{Case 25 - Yalow, Rosalyn S. - 1977 Nobel Prize ${ }^{\circledR}$ in Physiology or Medicine}

The manuscript in which Rosalyn S. Yalow (and her co-authors) constructed new ignorance on how "...patients treated with animal-derived insulin developed antibodies against it" (Creager, 2013:301) was originally rejected at the journal Science (Yalow, 1977:448). The authors then submitted it to the Journal of Clinical Investigation where it 
was peer reviewed, revised and rejected in September 1955 (partial letter reprinted in 1977:449). Following negotiations, the paper was eventually published in the Journal of Clinical Investigation in 1956 (Berson et al., 1956).

The (partial) 1955 rejection letter contains some details on one of the major criticisms brought forth by referees: that the researchers' data does not warrant the 'dogmatic conclusions' proposed (Yalow, 1977:449). The editorial decision includes references to the use of 'inadequate criteria' and 'insufficient proof'. Furthermore, the editorial compromise led to a change in the title with the removal of "insulin antibody" (1977:449).

To contextualize, the epistemic community of immunologists was not open to such new ignorance in the 1950s according to Yalow (1977:448). Finally, it would only be in 1959 that some of the theoretical concepts proposed in the paper could finally be explored experimentally (1977:450).

Synopsis of analysis: I analyse two elements in the case. First, the dominating analytic elements in this case are the accountability to empiricism for editorial readers and the scientific explanation imperatives of testability, ties with the past, and informativeness. Second, similar to Gell-Mann (Case 10), the removal of 'insulin antibody' in the construction of new ignorance does not reflect the author's voice but the removal had to occur in order to publish in traditional peer review. The original author's voice is typically lost, although in this case the author reclaimed her voice by constructing her narrative of the events and publishing part of the rejection letter. 